University of Louisville

ThinkIR: The University of Louisville's Institutional Repository

8-2017

\title{
Traces of the (un)familiar : family, identity, and the return of the repressed in the photographs of Ralph Eugene Meatyard.
}

\author{
Hunter Martin Kissel \\ University of Louisville
}

Follow this and additional works at: https://ir.library.louisville.edu/etd

Part of the Modern Art and Architecture Commons, and the Photography Commons

\section{Recommended Citation}

Kissel, Hunter Martin, "Traces of the (un)familiar : family, identity, and the return of the repressed in the photographs of Ralph Eugene Meatyard." (2017). Electronic Theses and Dissertations. Paper 2807. https://doi.org/10.18297/etd/2807

This Master's Thesis is brought to you for free and open access by ThinkIR: The University of Louisville's Institutional Repository. It has been accepted for inclusion in Electronic Theses and Dissertations by an authorized administrator of ThinkIR: The University of Louisville's Institutional Repository. This title appears here courtesy of the author, who has retained all other copyrights. For more information, please contact thinkir@louisville.edu. 


\title{
TRACES OF THE (UN)FAMILIAR: FAMILY, IDENTITY, AND THE RETURN OF THE REPRESSED IN THE PHOTOGRAPHS OF RALPH EUGENE MEATYARD
}

\author{
By \\ Hunter Martin Kissel \\ B.A, Transylvania University, 2014 \\ A Thesis \\ Submitted to the Faculty of the \\ College of Arts and Sciences of the University of Louisville \\ in Partial Fulfillment of the Requirements \\ for the Degree of \\ Master of Arts \\ in $\operatorname{Art}(\mathrm{C})$ and Art History, Critical and Curatorial Studies \\ Department of Fine Arts \\ University of Louisville \\ Louisville, Kentucky
}

August 2017 
Copyright 2017 by Hunter Martin Kissel

All rights reserved 

TRACES OF THE (UN)FAMILIAR: FAMILY, IDENTITY, AND THE RETURN OF THE REPRESSED IN THE PHOTOGRAPHS OF RALPH EUGENE MEATYARD

$$
\text { By }
$$

Hunter Martin Kissel

B.A., Transylvania University, 2017

A Thesis Approved on

July 27,2017

By the following Thesis Committee

\begin{tabular}{c}
\hline Dr. Chris Reitz \\
Thesis Director \\
\hline Dr. Jongwoo Jeremy Kim \\
Second Committee Member \\
\hline Brian Sholis \\
Third Committee Member
\end{tabular}




\section{DEDICATION}

To Dorothy May Kissel

and

Betty Ann Corrigan 


\section{ACKNOWLEDGMENTS}

This project would be substantially lacking if not for the guidance of Dr. Jongwoo Jeremy Kim and Dr. Chris Reitz. I am immeasurably grateful for their encouragement and criticism offered throughout the duration of this project. They have both heavily shaped my abilities as a writer, critical thinker, and individual. I would also like to extend thanks to Brian Sholis for his contributions as committee member and for our relevant conversations, for sharing research materials with me, and for demonstrating curatorial and scholarly expertise.

My educational pursuits would not have been possible without the support from the Hite Art Institute at the University of Louisville and the Elizabeth P. and Fredrick K. Cressman Scholarship award. The Hite has provided me with invaluable learning resources, a solid professional network, and opportunities to contribute to the vibrant arts community in Louisville that I would not have had otherwise.

I am also indebted to multiple individuals who, through interviews and archival inquires, expanded my knowledge of Meatyard and photography. Christopher Meatyard has been extremely generous during each stage of this project. He expanded my familiarity with the more nuanced qualities of Meatyard's life and practice as well as certain unpublished photographs by his father. I would also like to thank Elizabeth Reilly at the University of Louisville Photographic Archives, Bebe Lovejoy at the Art Museum at the University of Kentucky, Cynthia Young at the International Center of Photography, 
Dr. Susan Jarosi at the University of Louisville, as well as C.J. Pressma and Peter Morrin for their insight about Meatyard.

Lastly, I thank my parents, Joni and Bernie, and Colin for their unwavering love, encouragement, and continuous belief in me, and Dani for being a pillar of support and an extra set of eyes whenever I needed them. Without them, this endeavor would not have been possible. 


\begin{abstract}
TRACES OF THE (UN)FAMILIAR: FAMILY, IDENTITY, AND THE RETURN OF THE REPRESSED IN THE PHOTOGRAPHS OF RALPH EUGENE MEATYARD

\author{
Hunter Martin Kissel
}

July 27,2017

This thesis explores the ways in which photographs by Ralph Eugene Meatyard provoke the uncanny_ or Das unheimlich as Freud originally wrote in 1919-by breaking from conventions of mid-twentieth century family photography often utilized to establish and maintain genealogical unity. Meatyard's photographs of his family and friends are accentuated by blurring techniques, prolonged exposures, and the incorporation of dimestore masks, and as a result depict moments when reality is disrupted by the return of repressed material from childhood. For a multitude of reasons, Meatyard's photographs elicit comparisons to Surrealist photography as well as certain American modernists who also explored the notion of identity, such as Duane Michals, Van Deren Coke, and Minor White. Although he rarely left his home of Lexington, Kentucky, Meatyard was aware of the camera's widespread use to produce and retain social myths. His photographs unveil these myths by incorporating elements that align with psychoanalytic theory.
\end{abstract}


TABLE OF CONTENTS

PAGE

ACKNOWLEDGMENTS.............................................................

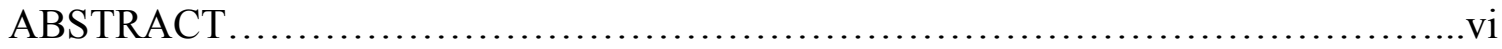

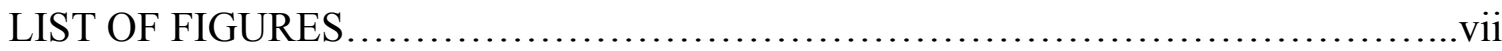

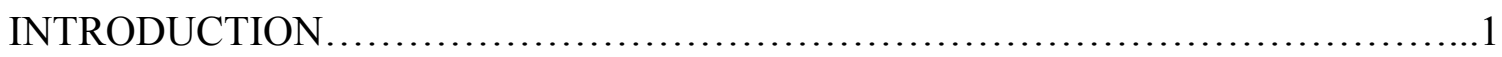

BREAKING FAMILY PHOTOGRAPHY ..........................................

PURSUING THE UNCANNY ................................................... 33

REFLECTIVE AND FRAGMENTED: MEATYARD AND THE INSTABILITY OF

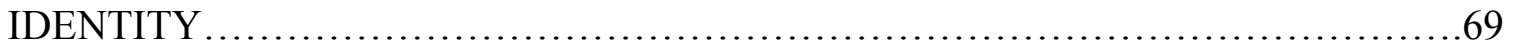

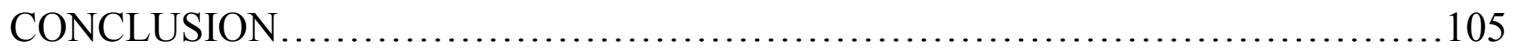

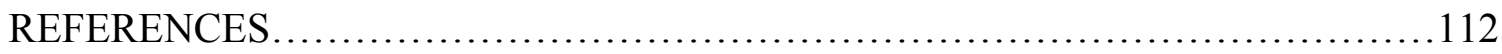

CURRICULUM VITAE ........................................................ 118 


\section{LIST OF FIGURES}

FIGURE

PAGE

1. Bingham (Paris), Portrait of a standing man, c. 1865, Collection of Geoffrey

Batchen.

2. Wallace Studio (Louisville, KY), Photograph of seven siblings, 1964, Collection of the author.

3. Ralph Eugene Meatyard, Untitled (Woman and child framing parallelogram window), c. 1970-2, gelatin silver print, $63 / 4 \times 67 / 8$ ". Copyright Estate of Ralph Eugene Meatyard.

4. Ralph Eugene Meatyard, Lucybelle Crater and Her 40 Yr Old Husband Lucybelle Crater, c. 1969-71, gelatin silver print, $7^{7} / 16$ x 7 1/2”. Copyright Estate of Ralph Eugene Meatyard.

5. Ralph Eugene Meatyard, Lucybelle Crater \& 20 Yr Old Son's Legless Wife Lucybelle Crater, c. 1969-72, gelatin silver print, $7^{7} / 16$ x 7 1/2”. Copyright Estate of Ralph Eugene Meatyard.

6. Ralph Eugene Meatyard, Lucybelle Crater \& 15 Yr Old Son Lucybelle Crater, c. 1970, gelatin silver print, $7 \frac{3}{8} \times 7 \% \frac{5}{8}$. Copyright Estate of Ralph Eugene Meatyard.

7. Ralph Eugene Meatyard, Chapter Pain \#6, c. 1960, gelatin silver print, $7 \frac{3}{8} \mathrm{x}$ $7 \frac{5}{8}$ ". Courtesy University of Louisville Photographic Archives. Copyright Estate of Ralph Eugene Meatyard.

8. Ralph Eugene Meatyard, Occasion for Diriment (Young girl and masked boy beating his breast), 1962, gelatin silver print, 7 x 7 1/2”. Copyright Estate of Ralph Eugene Meatyard.

9. Ralph Eugene Meatyard, Untitled (Group of children with dolls and masks), 1963, gelatin silver print, $7 \% 16$ × 8 1/4". Collection of Jonathan Greene. Copyright Estate of Ralph Eugene Meatyard.

10. Hans Bellmer, L'Idole, 1937. Bihl Bellmer Collection. Courtesy Editions FilipacchiSonodip. 
11. Ralph Eugene Meatyard, Untitled (Boy below white mask and broken mirror), 1962, gelatin silver print, $77 / 16$ × $7 \frac{5}{8}$ ". Copyright Estate of Ralph Eugene Meatyard.

12. Ralph Eugene Meatyard, Untitled (Boy wearing white mask below broken mirror), 1962, gelatin silver print, $7 \frac{7}{16} \times 7^{3} / 8$ ". Copyright Estate of Ralph Eugene Meatyard...51

13. Ralph Eugene Meatyard, Untitled (Archway with ghost), 1966, gelatin silver print, 7 $3 / 8$ x $71 \frac{1}{4}$ ". Copyright Estate of Ralph Eugene Meatyard.................................54

14. Man Ray, Explosante-fixe, 1934. Private Collection, Paris........................58

15. Ralph Eugene Meatyard, Untitled (Two ghosts with fireplace), 1969, gelatin silver print, $6^{1 / 4}$ x 6 1/4.". Copyright Estate of Ralph Eugene Meatyard..........................60

16. Ralph Eugene Meatyard, Untitled (Boy holding mannequin hand), 1961, gelatin silver print, $7 \frac{1 / 2}{2} 7 \frac{1 / 2}{2}$. Copyright Estate of Ralph Eugene Meatyard. 61

17. Maurice Tabard, Hand and Woman (Main et femme), 1929. Collection of Robert Shapazian, Fresno, California.

18. Ralph Eugene Meatyard, Untitled (Male nude in bathroom), 1970, gelatin silver print, $11 \frac{1}{16}$ x $9 \frac{1}{1} 16^{\prime}$. Copyright Estate of Ralph Eugene Meatyard............................66

19. Hans Bellmer, Doll (La Popuée), 1936/1949. Musée National d'Art Moderne, Paris .71

20. Ralph Eugene Meatyard, Romance (N.) from Ambrose Bierce \#3 (Masked children on numbered steps), 1962, gelatin silver print, $7 \frac{1}{1} 16 \times$ x $7 / 3$ ”. Copyright Estate of Ralph

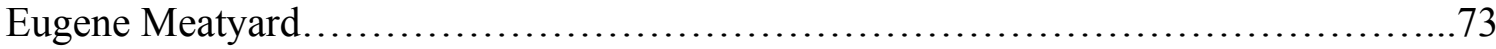

21. Ralph Eugene Meatyard, (title unknown), c. 1960, gelatin silver print. Copyright Estate of Ralph Eugene Meatyard.................................................... 75

22. Duane Michals, Now Becoming Then, gelatin silver print, 8 x 10". Courtesy Sidney Janis Gallery, New York....................................................... 77

23. Duane Michals, A Story About a Story, 1989, gelatin silver print. Copyright Duane

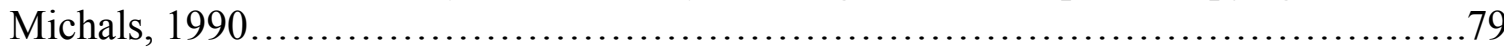

24. Ralph Eugene Meatyard, Untitled (Still life: doll atop photo), 1961, gelatin silver print, $71 / 4 \times$ x $7 \frac{1}{8} 8^{\prime}$. Copyright Estate of Ralph Eugene Meatyard.........................84

25. Van Deren Coke, The Witnesses, 1959/1966. Courtesy Arizona State University Art

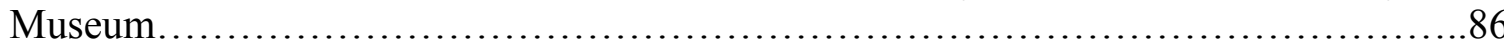

26. Van Deren Coke, Recollections of Malvern Hill, 1970.............................88 
27. Minor White, Movement Studies 56, 1946. Courtesy The Minor White Archive, Princeton University Art Museum. Copyright Trustees of Princeton University..........92

28. Minor White, Tom Murphy, San Francisco, from The Temptation of St. Anthony is Mirrors, 1948, gelatin silver print, $3 \frac{1}{2} 2$ x $4 \frac{5}{16}$ ". Courtesy the Minor White Archive, Princeton University Art Museum. Copyright Trustees of Princeton University...........95

29. Minor White, Tom Murphy, San Francisco, from The Temptations of St. Anthony is Mirrors, 1947, gelatin silver print, $2 \frac{1}{16}$ x $4 \% \frac{5}{8}$ ". Courtesy the Minor White Archive, Princeton University Art Museum. Copyright Trustees of Princeton University..........96

30. Minor White, Tom Murphy, San Francisco, from The Temptations of St. Anthony is Mirrors, 1947, gelatin silver print, $4 \% 16$ x 35/16". Courtesy the Minor White Archive, Princeton University Art Museum. Copyright Trustees of Princeton University....

31. Ralph Eugene Meatyard, LBC and Eastern Man's Friend LBC, 1969-72, gelatin silver print, $7 \frac{3}{8} \times 77 / 16$ ". Copyright Estate of Ralph Eugene Meatyard. ...

32. Minor White, Tom Murphy, San Francisco, from The Temptation of St. Anthony is Mirrors, 1947, gelatin silver print, $4 \frac{1}{2} \times 2$ x $1 \frac{1}{8}$ ". Courtesy the Minor White Archive, Princeton University Art Museum. Copyright Trustees of Princeton University........101

33. Minor White, Tom Murphy, San Francisco, from The Temptation of St. Anthony is Mirrors, 1948, gelatin silver print, $3 \% 16$ x 4 $7 / 16$ ". Courtesy the Minor White Archive, Princeton University Art Museum. Copyright Trustees of Princeton University........102

34. Ralph Eugene Meatyard, Untitled (Series of three self-portraits with artist walking over hill) (image one), 1972, $63 / 4$ × 6 $7 / 8$ ". Copyright Estate of Ralph Eugene Meatyard.

35. Ralph Eugene Meatyard, Untitled (Series of three self-portraits with artist walking over hill) (image two), 1972, 6 3/4 x 6 \% 8 \%". Copyright Estate of Ralph Eugene Meatyard.

36. Ralph Eugene Meatyard, Untitled (Series of three self-portraits with artist walking over hill) (image three), 1972, $63 / 4 \times 67 / 8$ ". Copyright Estate of Ralph Eugene Meatyard. 


\section{INTRODUCTION}

Ralph Eugene Meatyard moved to Lexington, Kentucky in 1950 to take a position with a local optical firm called Tinder-Krauss-Tinder that, in addition to eyewear, sold camera equipment. ${ }^{1}$ Within a year of living in his new home, Meatyard's son Michael was born, which spurred the optician to purchase a second-hand Leica in order to photograph Michael during the child's developmental stages. ${ }^{2}$ By the mid-twentieth century, photography was employed globally as a means for documenting family, especially for parents who wished to take an active role in their children's lives. ${ }^{3}$ It could have been that Meatyard embraced the camera because he was fearful of a childhood gone unrecorded, or maybe he was simply interested in making photographs of his son. In any case, the affiliation between photography and family was strong enough by 1950 to win Meatyard over to its appeal.

\footnotetext{
${ }^{1}$ Brian Sholis, "Assembly Required," in Kentucky Renaissance: The Lexington Camera Club and Its Community, 1954-1974, exh. cat. (New Haven: Yale University Press in association with the Cincinnati Art Museum, 2016), 5.

${ }^{2}$ Meatyard used a Leica for five years. In 1955, he acquired a Rolliflex that he used until his death. Robert C. May, "The Lexington Camera Club: 1936-1972," The Kentucky Review 9, no. 2 (Summer 1989), 15-16.

${ }^{3}$ In the first chapter of On Photography, Susan Sontag references a study conducted in France concluding that a household with children is twice as likely to own a camera than a household without children. These findings affirm her contention that "cameras go with family life." Susan Sontag, "In Plato's Cave," in On Photography (New York: Picador, 1977), 8.
} 
Meatyard began shooting Michael—and later his other children Christopher and Melissa - regularly on weekends and continued to do so throughout each of their adolescent phases. ${ }^{4} \mathrm{He}$ inserted adults, such as his wife Madelyn, into his images, too. Meatyard was, technically speaking, engaging in the practice of family photography. Yet the photographs he created possess deliberate breaks from what may be considered standard images of family: Meatyard's models are frequently blurred, wear ghoulish masks, and are located in abandon buildings. Additionally, his subjects are often depicted in motion, causing their bodies to be distorted and obscured due to the camera's inability to capture their excessive movement. How are these images to be categorized, since they contain elements of family photography, yet stray from convention? More importantly, what do Meatyard's photographs of children and adults indicate about his own assessments of photography, family, and identity? These questions are the impetus for the following analysis.

Meatyard joined the Lexington Camera Club in 1954. From its outset, the club strived to work against dominant modes of photography being practiced elsewhere in the United States. As many camera clubs in the US — as well as Meatyard himself, brieflyaffiliated with the Photographic Society of America (PSA) during the twentieth century, the Lexington Camera Club remained an independent entity whose members were distinguished by individual experimentation rather than by the ways in which their photographs aligned with the narrative-driven techniques regularly employed by the

\footnotetext{
${ }^{4}$ Cynthia Young, "Introduction," in Ralph Eugene Meatyard, exh. cat. (Göttingen, Germany and New York: Copublished by Steidl Publishers and the International Center of Photography, 2004) 11.
} 
PSA. ${ }^{5}$ Van Deren Coke, who was the club's mentor when Meatyard joined in 1954, iterated that exceptional photographs could be made anywhere, including Lexington. ${ }^{6}$ With Coke's guidance, Meatyard found inspiration in Lexington and the surrounding areas, utilizing the aesthetics of local architecture and terrains as backdrops in his images.

By 1959 Meatyard identified no more than twelve photographic subjects he was exploring. One, which he called "uncanny pictures," is described simply as "not surreal, but which give the feeling of being not quite of this world." ${ }^{, 7}$ None of the series refer to the inclusion of people, although many mention elements of nature in their titles: "rock photographs," "ice pictures," "light photographs," among others. If Meatyard's photographs of family were to align with any of his series, "the uncanny" seems most appropriate. This text takes Meatyard's claim as legitimate and articulates a reading of his figurative works by referring specifically to Sigmund Freud's "The Uncanny" (1919) as well as twentieth century theorists and artists who explore the interconnectedness of childhood, identity, and photography. Freud's essay concentrates on a specific type of anxiety experienced by adults who encounter repressed material from childhood, especially as it pertains to the disruption of reality and the possibility for the inanimate to

\footnotetext{
${ }^{5}$ Although Meatyard was a member of the PSA, he was outwardly disapproving of the organization as a whole. In an interview conducted in 1970, he described the PSA as "the old hat folks" and "gimmickers." Meatyard, Ralph Eugene, interview by Nathalie Andrews, February 25, 1970, transcript, Oral History Center, University of Louisville Archives \& Records Center, Louisville, KY.

${ }^{6}$ Barbara Tannenbaum, "Fiction as a Higher Truth: The Photography of Ralph Eugene Meatyard," in Ralph Eugene Meatyard: An American Visionary, ed. by Barbara Tannenbaum, exh. cat. (New York: Rizzoli International Publications in conjunction with the Akron Art Museum, 1991), 16.

${ }^{7}$ Ralph Eugene Meatyard, "My Aims," unpublished draft of lecture delivered to the Louisville Photographic Society, 1959, Meatyard Archive.
} 
become animate. By incorporating blurring techniques, prolonged exposures, and props such as dolls in masks, Meatyard produced images that provoke the uncanny as Freud outlines it. The first chapter of this essay lays the groundwork for an analysis connecting Meatyard to Freud by examining the components and history of mid-twentieth century family photography and determining the ways in which Meatyard breaks from the genre. In addition to framing Meatyard's figurative photographs as evocations of the uncanny, the second chapter links Meatyard's representational strategies to those of certain Bretonian Surrealists whose photographs were influenced by Freudian psychoanalysis. ${ }^{8}$ The final chapter builds upon the previous ones by juxtaposing Meatyard's photographic methods of exploring identity with those of other twentieth century photographers: Duane Michals, Coke, and Minor White.

\footnotetext{
${ }^{8}$ There is an implicit divergence in my text from Meatyard's characterization of his "uncanny pictures." He states these photographs are not surreal, but I argue that by provoking the uncanny, he inescapably draws comparisons to Surrealist photography. According to his middle-child, Christopher, Meatyard was interested in psychoanalysis and the unconscious, albeit on a general level. Here, I seek to establish a definite connection between Meatyard and Surrealism.
} 


\section{BREAKING FAMILY PHOTOGRAPHY}

Although many of Meatyard's figurative photographs contain any combination of his wife Madelyn and/or any number of their three children, the images hardly subscribe to dominant conventions of the genre of family photography. Indeed, Meatyard deliberately positions his family members within living rooms, backyards, and nearby vicinities to artificially stage private moments shared between them, but these moments contain visual disruptions in the form of blurring techniques, positioning of figures, photographic cropping, the attire worn by Meatyard's models, and more. In other words, Meatyard's photographs of family possess some necessary elements of family portraiture while simultaneously breaking from established visual codes that produce familiar meaning. As a result, his images at once align with and resist categorization. Meatyard's compositions are not accidental nor are they reflective of the relationships forged between him and his children. It would be truer to state that Meatyard, until his death in 1972, worked with his own family and carefully chosen backdrops to pursue a photographic language independent of the conventions and rules of mid-twentieth century family photography. Instead, he sought to develop a style characterized by his thorough manipulation of the camera and the properties of the photographic process. The images he made reflect a gray area between strict conformity to and complete divergence from dominant traditions of using the camera as a device for constructing the concept of family. 
Pierre Bourdieu argues that all social units are defined by their relation to the preeminent familial social body. Family, as Bourdieu claims, is a "classificatory scheme and a principle of the construction of the social world" built upon traditions, customs, and activities that instigate a sense of unity in individuals. ${ }^{9}$ Photography, it would seem, is capable of manufacturing images of family because any photograph is contingent on actions that took place before the camera, including family gatherings, events, and ceremonies. Early versions of the camera required specialists to operate, but by the midtwentieth century some cameras were small, cheap, and easy-to-use, effectively democratizing photography and the production of photographs. Families in America during this period realized the potential for photography to play an important role in the documentation of significant family events and "climatic moments of social life" imperative to maintaining family togetherness. ${ }^{10}$ Photography's link to elitist culture had partly diminished by the time Meatyard purchased his first camera and was more commonly employed by hobbyists and families to generate permanent records of lived experience. A new kind of photography connected to family and the quotidian blossomed in the mid-twentieth century, and it brought with it a new set of standards and rules by which meaning could be rendered and interpreted.

In Family Photographs: Content, Meaning, and Effect (1981), Julia Hirsch provides readers with dissections of twentieth century family photographic portraiture and, in doing so, offers what can be thought of as how-to guides for constructing the most

\footnotetext{
${ }^{9}$ Pierre Bourdieu, "On the Family as a Realized Category," Theory Culture Society 13:3 (1996): 21-22.

${ }^{10}$ Pierre Bourdieu, "The Cult of Unity and Cultivated Differences" in Pierre Bourdieu et al., Photography: A Middle-brow Art, trans. Shaun Whiteside (Stanford, CA: Stanford University Press, 1990): 19-21.
} 
potent images of familial unity concurrent with period trends. Hirsch describes how certain historical precedents for family photography inform the ways in which families use the camera to render themselves as intrinsically unified. She argues that popular conceptions of family—not unlike the theories posited by Bourdieu—influence poses, settings, and interpretations of family portraits.

Hirsch identifies two categories of family photography that permeated the midtwentieth century: formal and candid. In formal photographs families attempt to represent their (real or imagined) unity and solidarity, whereas candid photographs spur from accidents or the personality of the photographer. Individuals fully face the camera in formal photographs in order to sufficiently display any family resemblance they bear; here, viewers "look at, not into family." ${ }^{.11}$ Candid photographs, on the other hand, can include any combination of pose, composition, or setting, and are concerned with feeling instead of the representation of family attributes. ${ }^{12}$ Hirsch notes that neither category is more able than the other to render a complete characterization of its subjects, since a photograph is merely a slice of the physical world, a limited view of a broader occurrence. ${ }^{13}$

A family photograph can contain any number of people, but is distinguished from other types of portraiture by perceivable genetic similarities shared between those depicted and the poses they adopt. Facial features like noses, eyes, chins, and foreheads are visual clues for determining familial ties. Relationships between sitters are further

\footnotetext{
${ }^{11}$ Hirsch, Family Photographs: Content, Meaning, and Effect (New York: Oxford University Press, 1981): 95.

${ }^{12}$ Hirsch, Family Photographs, 101-109.

${ }^{13}$ Hirsch, Family Photographs, 101.
} 
enhanced by certain gestures, such as when they look at or angle their heads towards each other. ${ }^{14}$ These, Hirsch contends, illustrate family bonds, but are ultimately "no more than a set of poses, of textures, to go on, and we recognize...that the picture tells only the barest of narratives. ${ }^{15}$ Both amateur and professionally made family photographs are thus driven by dominant indications of social roles - a father displays his power, a mother her tenderness, and children demonstrate their reverence for their parents. ${ }^{16}$ Blood ties in family photographs are represented by poses suggestive of ideals of family and the overt presentation of physical resemblance.

Places, in addition to bodily similarities and placement, are important features of family portraiture, for they assert a family's conquest of land or connection to specific settings. For example, a house in a family portrait provokes stability and an automobile may suggest adventure or flexibility. ${ }^{17}$ Hirsch states that outdoor settings are used for photographing large groups to demonstrate a family's hold over their environment, and photographs taken indoors not only imply that private experience is vital to moral development, but also reveal, through the presence of household decorations and keepsakes, class and social interests. ${ }^{18}$ Twentieth century family photographs that serve to establish and maintain a sense of unity for a group of people thrive from their adherence to one of two possible stylistic categories, the display of physical likeness and

\footnotetext{
${ }^{14}$ Hirsch, Family Photographs, 5.

${ }^{15}$ Hirsch, Family Photographs, 7-9.

${ }^{16}$ Hirsch, Family Photographs, 12-13.

${ }^{17}$ Hirsch, Family Photographs, 51-52.

${ }^{18}$ Hirsch, Family Photographs, 51-56.
} 
appropriate domestic roles, and certain backdrops that elevate the perception of communal achievement and experience.

Some aspects of formal family photography derive from trends in portraiture popular during the turn of the twentieth century often adopted to portray individuals or groups as distinguished members of society. When photography was invented in the midnineteenth century, those with the necessary equipment to make photographs - and more specifically photographs of people — turned to the tradition of oil paining in depicting their subjects. ${ }^{19}$ In this vein, a subject's pose and attire, as well as the overall composition of a photograph, could indicate a person's social status or power.

In an example of photographic portraiture from 1865 (Figure 1), a Parisian man stands in front of a rather neutral background, save for the lavish curtains. His body appears in three-quarter turn and he rests his left hand on the back of a chair. A top hat is held in his left hand by his side, and his eyes concentrate on something in the distance. The clothes he wears - a bowtie, sport jacket with tails, and polished shoes—suggest he belongs to the upper class. His right leg is straight and his left leg is slightly bent.

Some of the elements in this photograph are borrowed from the tradition of oil painting that, as Hirsch argues, informs family photography of the twentieth century. For instance, the Parisian man stands in the center of the photograph so that his head is located at the midpoint between the middle and top of the frame; his left leg is

\footnotetext{
${ }^{19}$ Oil painting was a primary reference point for early photographers, but it was not the only one. Early portraitists borrowed tricks from the theatre and sculpture as well in order to transfer meaning into the minds of viewers. Eugenia Parris Janis, "Review Essay: Portraiture," in Reading into Photography: Selected Essays, 1959-1980, Thomas F. Barrow, Shelley Armitage, and William E. Tydeman, eds. (Albuquerque: University of New Mexico Press, 1982), 180.
} 


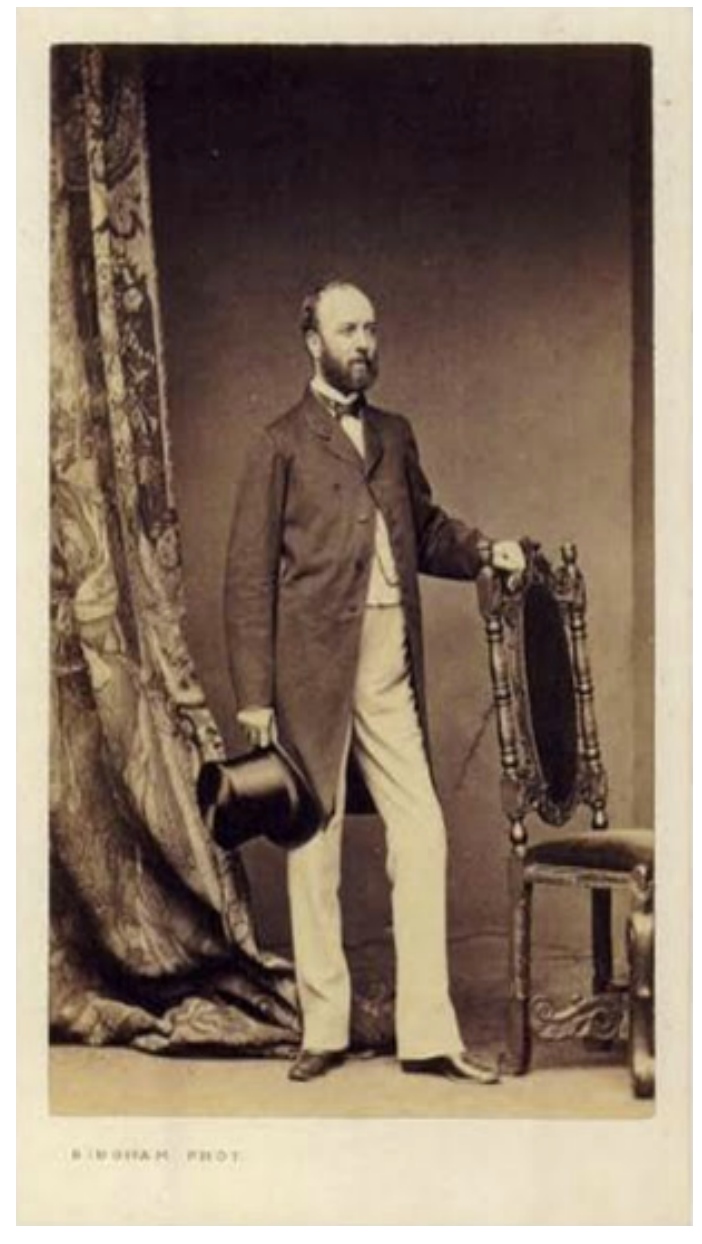

Figure 1. Bingham (Paris), Portrait of a standing man, c. 1865. Collection of Geoffrey Batchen. 
hinged so as not seem awkward or stiff; his body is complimented by the background and lighting (his head is haloed by the photograph's middle tones); and certain props-the hat, the chair, and curtains - assist in promoting his status as an elite. Especially in group portraits, props can aid in generating a desired meaning. ${ }^{20}$ Such compositional techniques had not entirely dissipated by time Meatyard was making work. Rather, they had been modified and adjusted to comply with the evolution of family photography.

A photograph of seven children made in 1964 (Figure 2), for example, exemplifies some of the mid-twentieth century norms. The four youngest sit in a row squeezed together and two more stand above them. One, who appears to be almost fifteen, serves as the peak. They are nicely dressed, formed in front of a slated wooden wall in vogue during the decade when the image was printed. None of those seated look at the camera, the three others do confidently — there must be something happening off to the side, signaled most by the youngest one's dropped jaw. Their arms are to their sides and their backs are straight. The wall is banal, although it does provide a sense of structure for the pyramid of adolescents.

${ }^{20}$ These features of the Parisian man reflect the analysis of early twentieth century photography as described in Sidney Allan, Composition in Portraiture (New York: Edward L. Wilson, 1909). Allan was a notable German-Japanese poet and photography critic of the early- and mid-twentieth century. Composition in Portraiture is an instructional publication on how to make photographic portraits. Throughout the book, Allan cites conventions used in Renaissance and Dutch portraiture as well as photography of the early twentieth century to establish dominant norms of portraiture. It should be understood that by the time Meatyard was making photographers these conventions were becoming out-of-date. Nevertheless, the techniques Allan describes would persist throughout the century and into today: Hirsch refers to such conventions in her own discussion. 


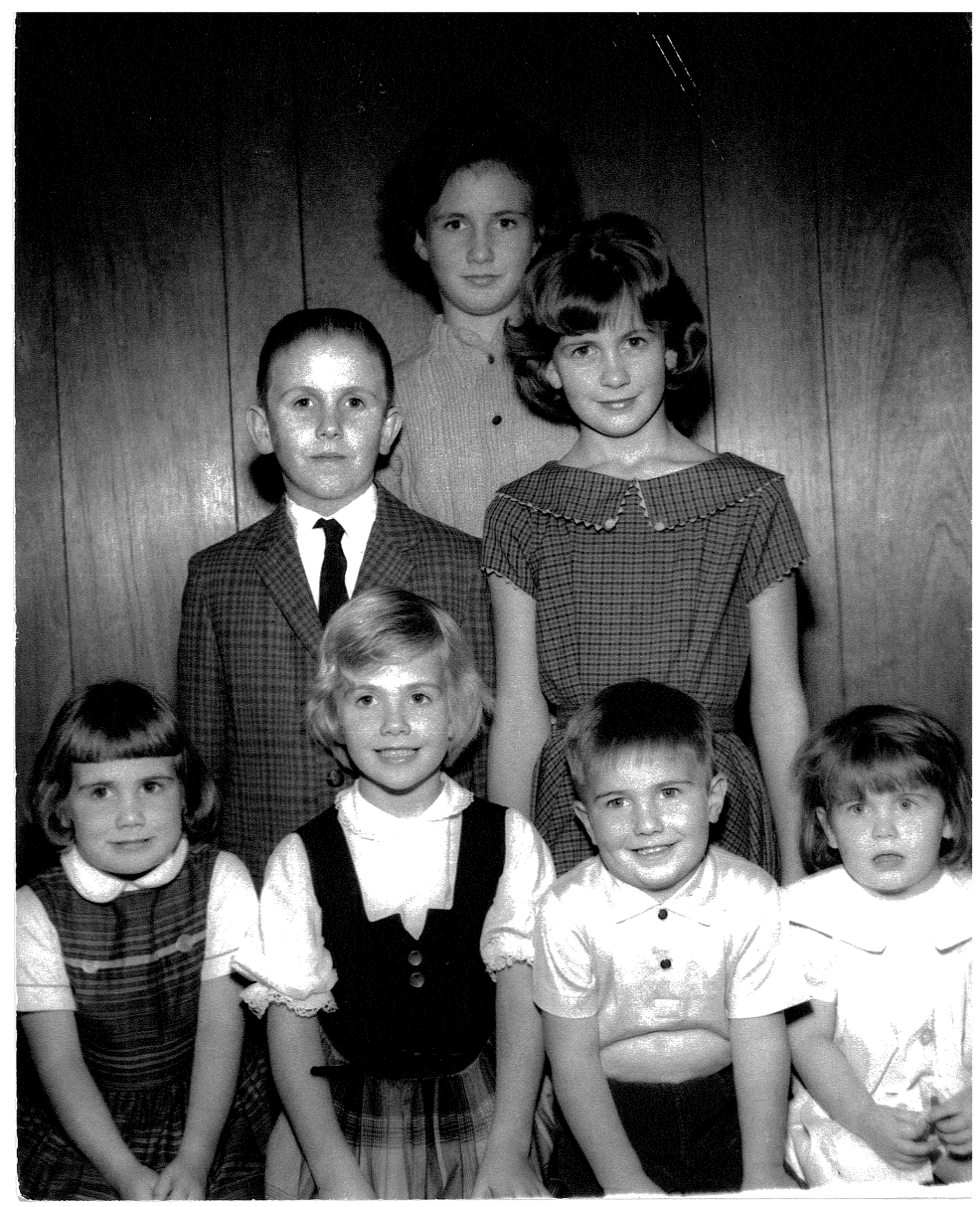

Figure 2. Wallace Studio (Louisville, KY), Photograph of seven siblings, 1964. Collection of the author. 
The triangular shape the bodies construct is unmistakable, and for viewers it may provoke spiritual ties between the members of the group. ${ }^{21}$ Similarities of eyes, noses, and foreheads can be noticed quite easily, and some of the children's heads tilt inward toward the group. These are relatives, and their respective positions in the photograph represent their family roles: the three standing are older and more experienced in life, they may even help adults care for the four near the bottom of the frame. The wall suggests they are in a comfortable space meant for large groups - maybe a house or a photography studio. Each child, with their expression and clothing, offers some personality, but they ultimately succumb to the conventions set upon them. Their kinship is on display.

The group's position in the frame, their frontal poses and similar clothing, the background, and even the lighting and rich tonalities work together in relationship to exhibit the concept of family. Bourdieu might say a photograph such as this generates a "family feeling" since the components of the image — which are rather unremarkable by themselves - coalesce to manufacture "the integration of the assembled family." 22 The elements of a family photograph do not transmit meaning on their own. Instead, the reading of a portrait of relatives as a necessarily unified group depends on the relationship between the sitters, setting, and props (clothes, lighting, etc.), as well as a conditioned audience: “does what I'm looking at adhere to other family photographs I've seen?" Meatyard, in pursuit of new kind of family photography that resisted

\footnotetext{
${ }^{21}$ Hirsch, Family Photographs, 28.

${ }^{22}$ Bourdieu, "On the Family as a Realized Category," 22.
} 
categorization, sought ways to render (his) family in fleeting states that break from fixed conventions.

Meatyard began placing figures in his photographs as soon as he began using a camera and before he joined the Lexington Camera Club in $1954 .{ }^{23}$ But it was the club's mentor, Van Deren Coke, that encouraged Meatyard and other club members to use their surroundings as source material for their photographs - Coke believed great photographs could be made anywhere, not just in larger cities like New York and San Francisco. ${ }^{24}$ Meatyard took Coke's advice and began shooting at various locations in and around Lexington.

Of the many sites near Lexington that Meatyard would venture to throughout the course of his career, he was particularly drawn to the vacant ruins of a wooden shed that, after photographing his son Michael in it in 1954-5, served as a prime setting to make Untitled (Woman and child framing parallelogram window) (1970-1972) (Figure 3) almost twenty years later. ${ }^{25}$ In the image, we see two females - one grown and the other an adolescent—-standing indoors with their backs turned against each other. Their postures are straight and both are near opposite sides of the frame; we as viewers are presented with full-length profiles. The younger of the two, who is positioned on the left, disrupts the symmetry of the composition by turning her head towards the camera: her face is slightly blurred and she wears a mask. Upon closer inspection, so does her

\footnotetext{
${ }^{23}$ Personal communication with Christopher Meatyard, February 23, 2017.

24 Tannenbaum, "Fiction as a Higher Truth," 16.

${ }^{25}$ Tannenbaum, "Fiction as a Higher Truth," 18.
} 


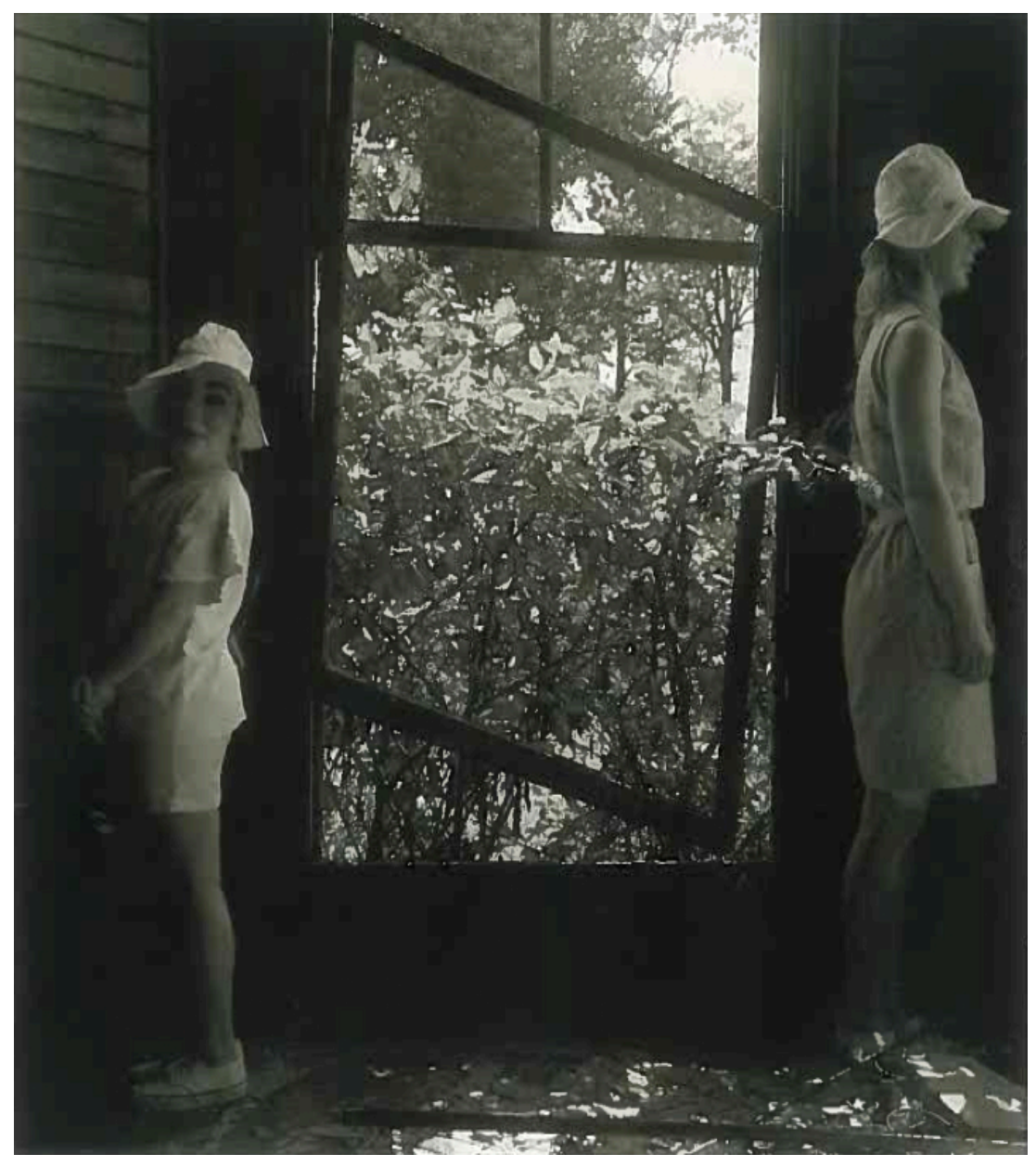

Figure 3. Ralph Eugene Meatyard, Untitled (Woman and child framing parallelogram window), c. $1970-2$, gelatin silver print, $63 / 4 \times 6 \%$ " Copyright Estate of Ralph Eugene Meatyard. 
counterpart. The entire scene is illuminated by stark sunlight entering the room through a collapsing window centered within the photograph, dividing the two figures.

Untitled (Woman and child framing parallelogram window) seemingly includes obvious cornerstones for family photography: two figures that, because of their placement in a domestic setting as well as certain physical resemblances they share, can be interpreted as a mother and child in their home. They both wear brimmed sunhats, white clothes and shoes, and their legs are exposed just above their knees - indeed, their clothing is similar, but not entirely the same. The youngest dons a short-sleeved t-shirt and shorts while the figure on the right wears a sleeveless top and skirt.

Although it is likely such features allude to a familial relationship, kinship is not certain among these sitters; rather, it is contingent on viewers' familiarity with photography's widespread social application. Bourdieu asserts “photographic practice only exists and subsists for most of the time by virtue of its family function or rather the function conferred upon it by the high points of family life."26 Drawing on Bourdieu's conception of family can generate a formulation of the ways in which images like Untitled (Woman and child framing parallelogram window) enters into and breaks from the genre of family photography. That is, this image by Meatyard unveils how family is a construct, functioning antithetically to the camera's presumed neutrality.

When making photographs, Coke encouraged Meatyard to begin by selecting a background. Doing so, Meatyard declared in 1970, "eliminates a lot of errors." ${ }^{27}$ Clearly Meatyard believed that the background initializes the meaning of a photograph, and the

\footnotetext{
${ }^{26}$ Bourdieu, "The Cult of Unity and Cultivated Differences," 19.

${ }^{27}$ Meatyard, interview by Natalie Andrews, 1970.
} 
site in Untitled (Woman and child framing parallelogram window) is no exception. By the combination of their presences alone, a wooden interior, window, and nearby shrubbery often designate a livable space, yet the quality of each within this photograph suggests otherwise: the window's frame is inoperable and has decayed so that one side hangs lower than the other while overgrown foliage penetrates the interior space. What seem to be the remains of a mattress are scattered on the floor near the figure on the right; a mattress would fall under the category of "consumer durables" that Bourdieu states help to establish the "family unit," but here the discarded springs and frame elude more to destruction. ${ }^{28}$ Hirsch furthers the claim set out by Bourdieu, recognizing the possibility for interior objects to represent family stability, heritage, and lived experiences. ${ }^{29}$ In this example, the window is the central point of the image, dividing the figures and leaving them as compliments, rather than focal points, to the overall composition. If anything, the background weakens any insinuation of a unified family that the presentation of the figures and their resemblance may otherwise attempt to represent.

The impulse to designate the two figures in Untitled (Woman and child framing parallelogram window) as members of the same clan derives from the serviceability of photography as a tool for family integration. If, as Bourdieu claims, over two-thirds of photographers use the camera to document family functions, gatherings, or events, then we can assume that the majority of people who engage in the production of photographs (whether as subjects or picture-takers) are doing so in the name of family

\footnotetext{
${ }^{28}$ Bourdieu, "The Cult of Unity and Cultivated Differences," 29.

${ }^{29}$ Hirsch, Family Photographs, 52.
} 
documentation. ${ }^{30}$ These events — these high points of family interaction —are frequently attended by individuals from successive generations of the same bloodline and make for optimal photo-taking moments: nearly three-fourths of figurative images are of groups and, moreover, ones depicting adults with children "capture and symbolize the image of the family line. ${ }^{\prime 31}$ Bourdieu's statistics illustrate that the pairing of female figures in Meatyard's photograph is, in all likelihood, one of mother and daughter. While it is common for groups consisting of adults and children to appear in family photographs, it is not enough to simply capture them within the edges of a single photograph if one wishes to produce the effect of family. As described above, family photography adheres to stricter stereotypes, from which Meatyard consciously strays.

Not only does Meatyard's photograph defy certain norms of family photography, it just as well resists the standards of general portraiture. The figures' heads are not the central focus of the image, nor do they hover just above the center of the composition. Both figures are standing, however their legs are straight and unbent. As for the background, Meatyard works against tradition when he chooses to place faces against either some of the lightest (the brim of the left figure's hat) or darkest tones (the wooden wall) found within the entire photograph. The natural light in Meatyard's image not only starkly contrasts the interior in which the figures are placed, it violently intrudes the frame altogether.

Frontal poses offer the best viewing angles for identifying physical resemblance, and thereby evidence of familial relationships. In Untitled (Woman and child framing

\footnotetext{
${ }^{30}$ Ibid.

${ }^{31}$ Bourdieu, "The Cult of Unity and Cultivated Differences," 26.
} 
parallelogram window), the bodies of both figures are presented in profile view. To further break from convention, Meatyard places his models near the edge of the frame, facing away from each other. Bourdieu observes that in the majority of group photographs subjects are often seen with their arms around others' shoulders andespecially in photographs of couples — with arms around others' waists, which signal their being-of-the-moment. ${ }^{32}$ The window in Untitled (Woman and child framing parallelogram window) disrupts the otherwise smoothness of the interior and separates Meatyard's subjects, denying the opportunity for this commonly employed device to manifest. ${ }^{33}$ Profiled subjects and physical separation make familial bonds nearly undetectable.

Perhaps the most direct way to identify these two figures as a parent and child is through the physical likeness they share - their similar facial features, for instance. The adult figure in the photograph maintains a full-length profile and we are able to see only the right side of her face. The seemingly younger figure turns her head toward us in full frontality; we are afforded the chance to look upon her entire face. But she and the adult figure wear masks that hide their identities. Masks are prevalent in Meatyard's photographs and are worn by his models primarily to depersonalize them. Through this

\footnotetext{
${ }^{32}$ Bourdieu, "The Social Definition of Photography," in Photography: A Middle-brow Art, 81 .

${ }^{33}$ Frontality and the placement of arms around others strengthen not only the image a group wishes to provide itself, but also assists in prescribing roles within said group that align with traditional parts of family: the mother, father, sibling, etc. Bourdieu, "The Cult of Unity and Cultivated Differences," 24.
} 
depersonalization, masks become vehicles for open-ended interpretation. ${ }^{34}$ With masks on, the two figures in Untitled (Woman and child framing parallelogram window) are anyone; the identities of Meatyard's subjects, whose faces are at once unique and universal, are ambivalent and unstable.

By giving his models masks to wear, Meatyard makes clear his awareness of the archetypes of family photography that rely on the specificity of faces, ages, and genders to make sense of who is featured in an image. In this sense, the construction of family unity partially relies on recognizable individuals interacting together as well as the outward display of certain (and generally shared) emotions. With their eyes and mouths covered, we cannot be sure who either figure is. ${ }^{35}$ The masks are yet another break from these conventions that would have us believe in the social inherency of the family category.

Yet Untitled (Woman and child framing parallelogram window) does in fact contain standards elements of family photography. This photograph is clearly staged—it would fall under Hirsch's concept of formal family photography. The composition is far too rigid and deliberate to be classified as a candid photograph. Likewise, it was taken in (the remnants of) a domestic space where a family privately develops its moral

\footnotetext{
${ }^{34}$ In a conversation with Meatyard's son Christopher, I was informed that Meatyard was invested in exploring how a subject's psychological state is determined by more than just their facial expressions. Masks offer a means for reading a personality based on an individual's body language and placement within a scene. Personal communication with Christopher Meatyard, November 15, 2016.

${ }^{35}$ See Elizabeth Siegel, "The Universalizing Mask," in Ralph Eugene Meatyard: Dolls and Masks, exh. cat. (Santa Fe, NM: Radius Books, Inc., 2011), 126-127.
} 
conditions. ${ }^{36}$ These elements of Untitled (Woman and child framing parallelogram window), in addition to two outfits that possess similarities while ultimately being different, may trigger unease in viewers because of the ways in which they resist categorization. Is Meatyard's example a family photograph? Surely it contains too many divergences from conventional standards to be so. But it is not a complete break from the genre either. This image embodies the photographic language Meatyard was after: one that conforms to qualities of family photography while possessing some elements that transcend convention.

Meatyard's photographic exploration into the concept of family culminates with The Family Album of Lucybelle Crater, a series of photographs that documents the fictional Lucybelle Crater alongside her family and friends, many of whom are also given the name Lucybelle Crater. ${ }^{37}$ In each photograph, Meatyard's wife, Madelyn, dons the same mask - a grotesque façade of a woman with bulging eyes, a contorted nose, and a tongue hanging from an open mouth, revealing only two teeth separated by a large gap. The expression of the mask is eternally dumbfounded. ${ }^{38}$ Madelyn is always accompanied by another individual — usually one of the Meatyard children or family friends—who could be wearing any one of the masks from Meatyard's stockpile of rubber faces. The

\footnotetext{
${ }^{36}$ Hirsch, Family Photographs, 52.

${ }^{37}$ Meatyard worked on The Family Album of Lucybelle Crater from 1969 until his death in 1972. The name Lucybelle Crater derives from a Flannery O'Connor short story entitled "The Life You Save May Be Your Own," in which a woman and her daughter are both named Lucynelle Crater. Tannenbaum, "Fiction as a Higher Truth," 49.

${ }^{38}$ When asked why he chose a grotesque mask for Lucybelle Crater, Meatyard replied he intended to "make [her] a somewhat grotesque person, really." Ralph Eugene Meatyard, lecture to the Midwest Society of Photographic Education (SPE), Louisville Conference, March 1972. Unpublished talk devoted to the Lucybelle Crater project. Transcript in Meatyard archive.
} 
figures are typically placed next to each other within the confines of a home, either in a living room, on a porch, or on a suburban lawn. The breaks from portraiture that Meatyard applies in this body of work are different and fewer than those from his previous figurative photographs like Untitled (Woman and child framing parallelogram window): The Family Album of Lucybelle Crater in many ways corresponds with the conventions set by Bourdieu, Hirsch, and others.

What makes The Family Album of Lucybelle Crater different from other figurative photographs by Meatyard is that it is comprised of snapshots (these are close to what Hirsch calls candid photographs). Snapshots fulfill their duty by acting strictly as analogues: they are valued for being "emotionally significant" and are most effective when they are compositionally mundane, positioning subjects frontally and in the center of a frame. ${ }^{39}$ But the extent to which snapshots are made, used, and distributed varies from group to group. The Family Album of Lucybelle Crater, therefore, is a series of mostly predictable compositions.

In one photograph, titled Lucybelle Crater and Her 40 Yr Old Husband Lucybelle Crater (c. 1969-1971) (Figure 4), Meatyard poses with his wife in the center of the frame - she dons the Lucybelle Crater mask and he wears a transparent mask of an elderly man. The entirety of Madelyn, who is positioned on the right, faces the camera; she keeps her arms crossed over her torso. Meatyard's body aims at his wife but his head is turned to face the viewer. Only his left hand is visible, which remains at his side. They

${ }^{39}$ Catherine Zuromskis, "On Snapshot Photography," in Photography: Theoretical Snapshots, ed. by J.J. Long, Andrea Noble, and Edward Welch (New York: Routledge, 2009), 53. 


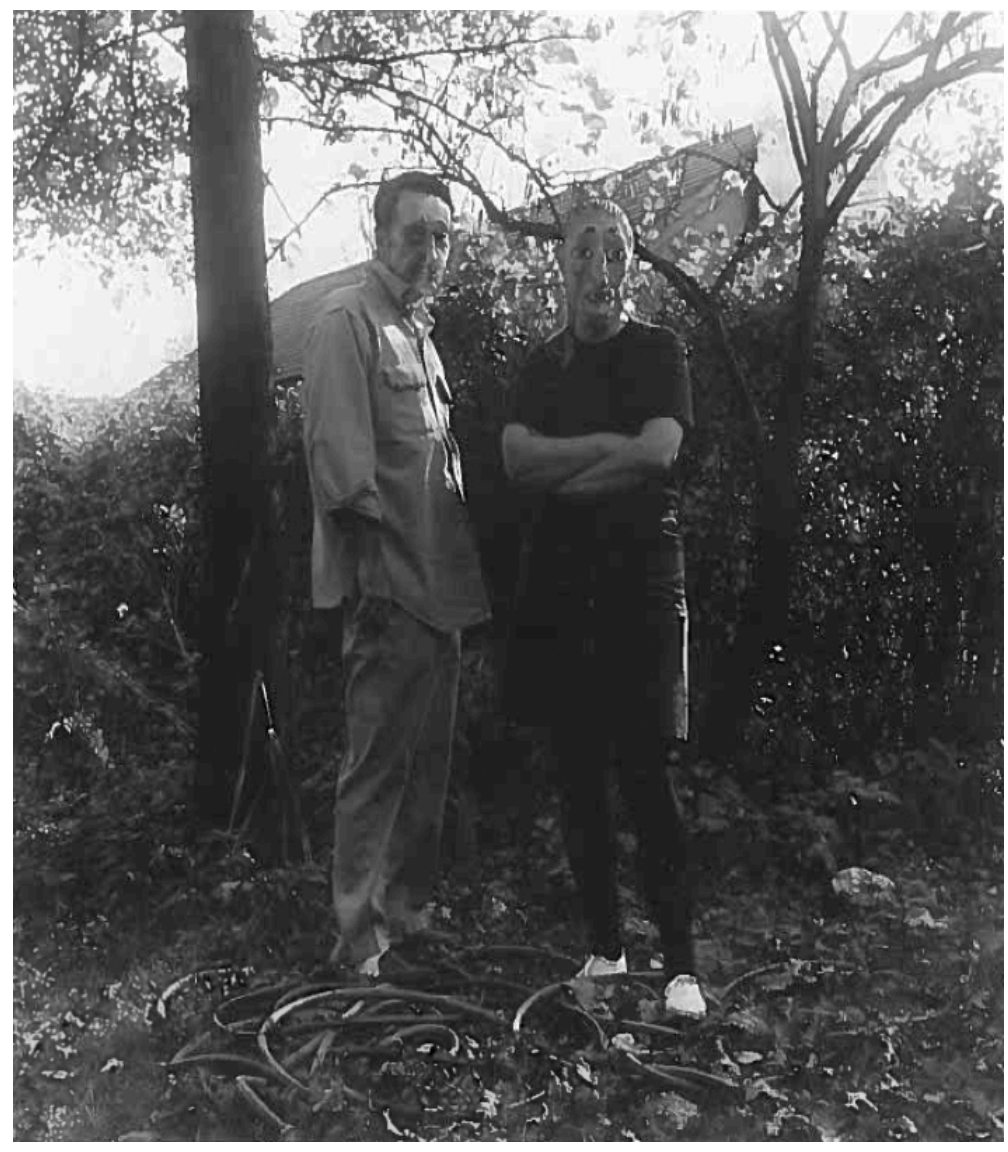

Figure 4. Ralph Eugene Meatyard, Lucybelle Crater and Her 40 Yr Old Husband Lucybelle Crater, c. 1969-71, gelatin silver print, $7 \% 1{ }_{16}$ x 7 1/2”. Copyright Estate of Ralph Eugene Meatyard. 
appear in what looks to be a backyard where the roof of the neighboring house can be seen over the hedges that the couple stands in front of. Leaves are scattered on the grass, some covering parts of a looping garden hose. There are certain biblical themes at play here: Meatyard and his wife can be identified as surrogates of Adam and Eve: the location in which we find them is the Garden of Eden and the garden hose is a stand-in for the cunning serpent. ${ }^{40}$ This reference stems from photography's capability of birthing the social myth of the family category. Myths aid humanity's grasp on worldly order. Claude Levi-Strauss argues as much when stating that myths perpetuate the "illusion that [man] can understand the universe and that he does understand the universe." ${ }^{41}$ Indeed, the myth of Adam and Eve — the first nuclear family—resonates in the minds of families who create their own image for themselves. Lucybelle Crater, her friends, and the settings they occupy emulate historicized modes of meaning that, like this particular body of work, rely upon the relationships of a photograph's parts - the people, the background, the props, and so forth. History, and presumably the history of family photography, is constructed by the many ways components of an image - or what Levi-Strauss would call cells — can "be arranged and rearranged." ${ }^{\text {42 }}$ This photograph by Meatyard depicts Lucybelle Crater and her husband, Adam and Eve, as well as all families who employ similar photographic conventions. The Family Album of Lucybelle Crater is "any family, anywhere." 43 This includes — and perhaps originates with — the telling of Adam and Eve.

\footnotetext{
${ }^{40}$ Tannenbaum, "Fiction as a Higher Truth," 50.

${ }^{41}$ Claude Levi-Strauss, Myth and Meaning (New York: Schocken Books, 1979), 17.

${ }^{42}$ Levi-Strauss, Myth and Meaning, 40.

${ }^{43}$ Meatyard, lecture to the Midwest SPE.
} 
Perhaps this is why Meatyard utilized dominant visual codes in the Lucybelle Crater project in ways that he did not in his other figurative photographs. Both Meatyard and his wife in Lucybelle Crater and Her $40 \mathrm{Yr}$ Old Husband Lucybelle Crater position their heads towards the camera, which are appropriately nearer the top edge of the frame than the composition's centerline. Madelyn's hands are hidden and her left leg is bent; Meatyard's only visible hand is at rest. The peaking roof in the background provides a middle tone to surround their faces. The natural light is neither intrusive nor visually overwhelming. Instead, the light establishes a sense of depth within the frame.

Madelyn's frontality exemplifies the kind of pose that, by the late twentiethcentury, was often adopted by individuals in family photographs. The character of her crossed arms and contrapposto make it seem as if she reluctantly succumbs to the function of the camera as a recorder of family — she presents herself straightforwardly and without filter. In doing so, she converts "[herself] in advance into an image," as Roland Barthes would argue, ensuring that the way in which she is captured on film aligns with previous photographs of her. ${ }^{44}$ By posing in a similar fashion each time she is photographed, Meatyard's wife invariably mimics her past self — she refers to the image of her in order to produce a likeness. Barthes claims that this continuation of selfreferential behavior leads to a "sensation of inauthenticity." ${ }^{45}$ In other words, the poses Madelyn adopts are not responsive to a given moment; rather they attempt to emulate previous versions of herself. Bourdieu also considers frontality: he argues that an individual's frontal pose projects self respect as well as respect for whomever they are

\footnotetext{
${ }^{44}$ Roland Barthes, Camera Lucida (New York: Farrar, Straus, and Giroux, 1981), 10.

${ }^{45}$ Barthes, Camera Lucida, 13.
} 
facing — in this case, the viewer. ${ }^{46}$ Lucybelle Crater's pose may seem somewhat abrasive, but it holds the norms of modern family photography. This is especially apparent when we consider other examples from the series, such as Lucybelle Crater \& 20 Yr Old Son's Legless Wife Lucybelle Crater (c. 1969-1972) (Figure 5) and Lucybelle Crater \& $15 \mathrm{Yr}$ Old Son Lucybelle Crater (c. 1970) (Figure 6). In both cases, Madelyn's frontality is an unnatural one. In the former, her hands anxiously hold the bottom of her sweater. In the latter, her legs are spread and her neck sinks into her chest. In both images, her posture indicates that while she may be indifferent to being photographed, she nonetheless demonstrates her reverence for the camera as well as every potential viewer.

Meatyard's Lucybelle Crater project omits some of the breaks featured in examples like Untitled (Woman and child framing parallelogram window) in an effort to substitute itself for every family album. Yet in all images Meatyard incorporates masks. Whereas masks in the first Meatyard photograph deny indications of family resemblance, they are the vehicles for collectivism in The Family Album of Lucybelle Crater. Indeed, masks here affirm "the [similarities] of people when their differences are gently erased. ${ }^{.47}$ In this project, difference is left to pose, composition, and background. By following conventions, Meatyard insists that every family portrait—and everyone - is

\footnotetext{
${ }^{46}$ Frontality is associated with the cultural values of honor, dignity, and reverence and is assumed by individuals wishing to "control the objectification of one's own image." Bourdieu, "The Social Definition of Photography,"82-3.

${ }^{47}$ Young, "Introduction," 12.
} 


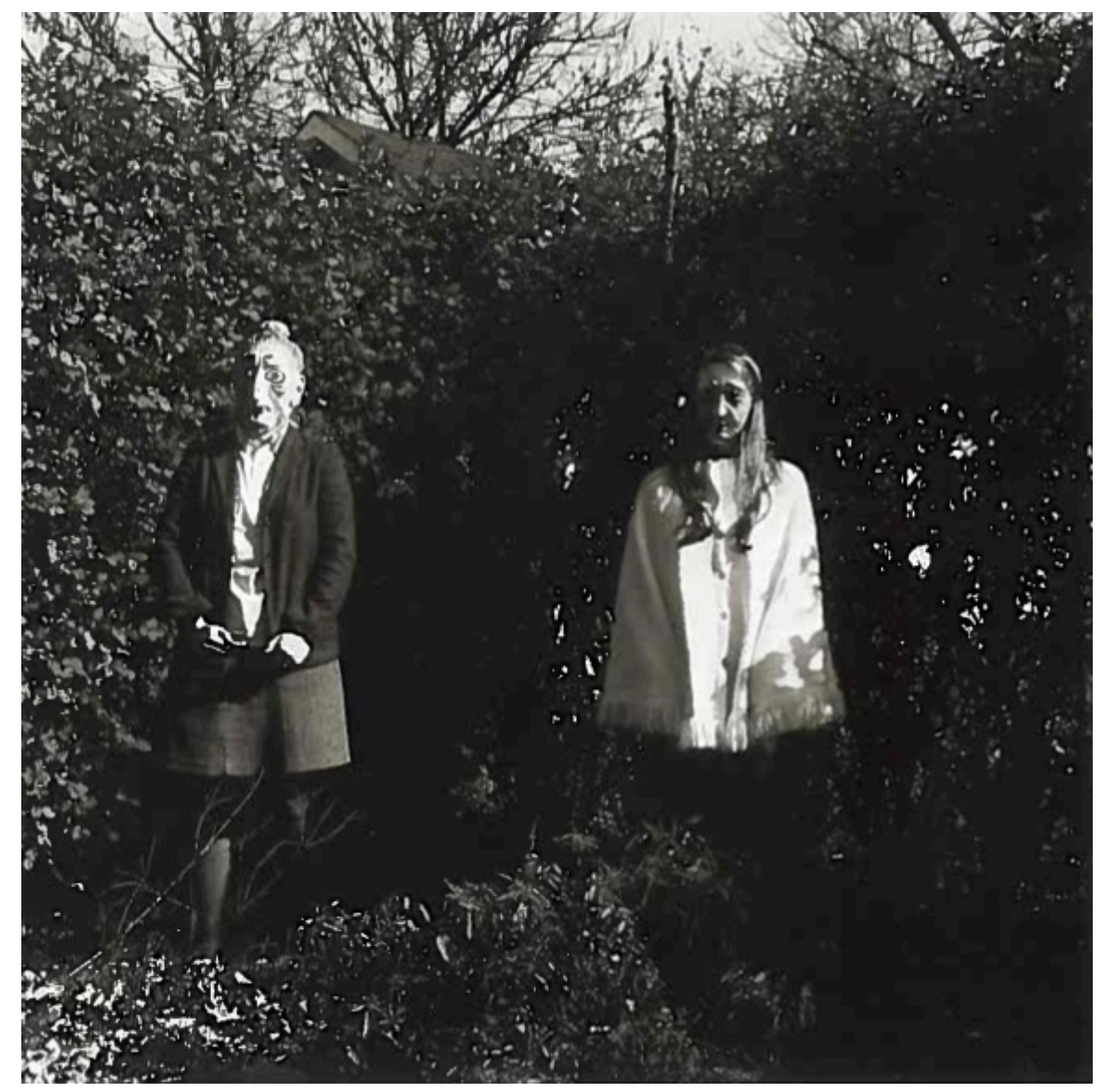

Figure 5. Ralph Eugene Meatyard, Lucybelle Crater \& 20 Yr Old Son's Legless Wife Lucybelle Crater, c. 1969-72, gelatin silver print, $7 \frac{7}{16}$ x 7 1/2”. Copyright Estate of Ralph Eugene Meatyard. 


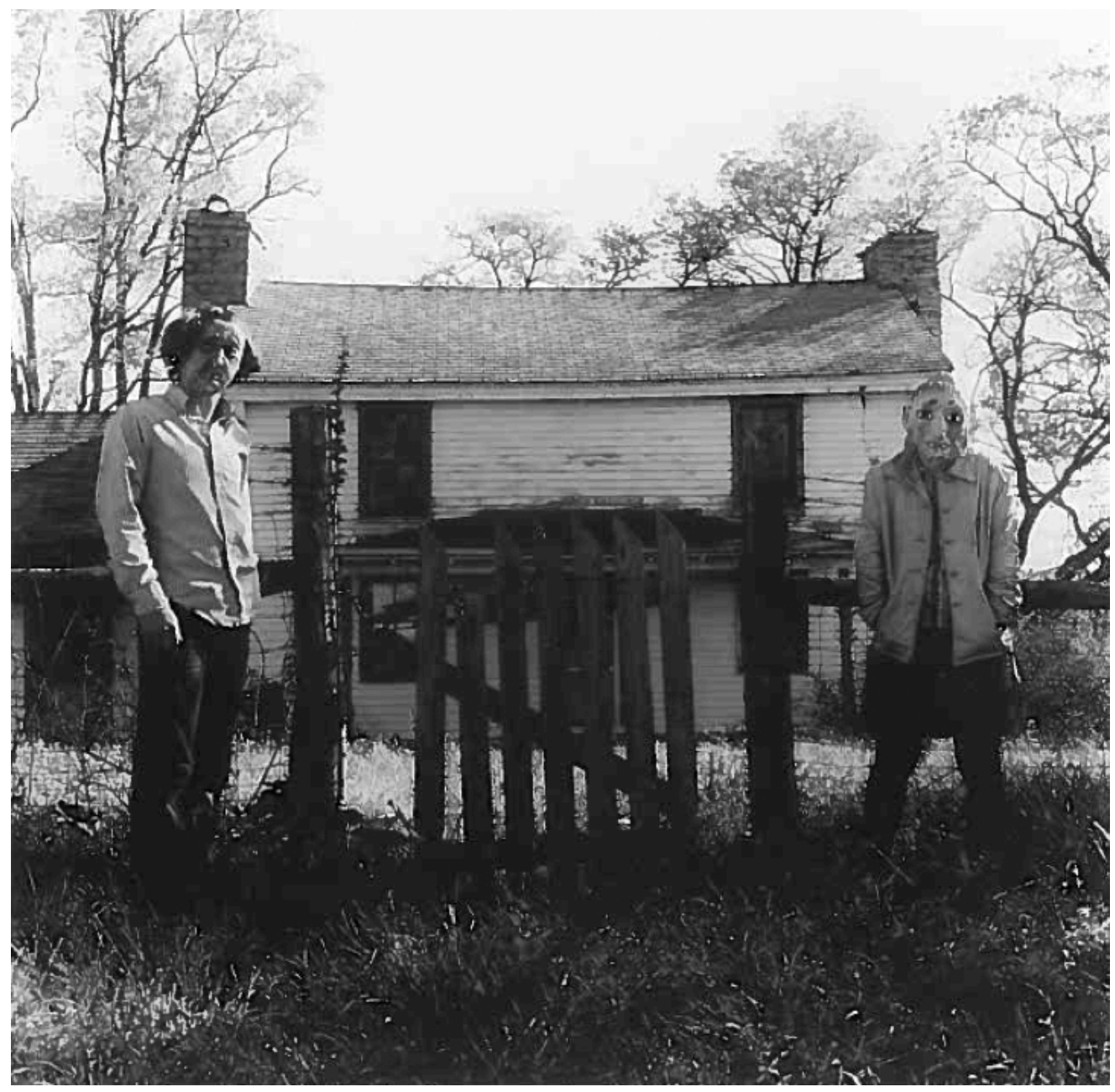

Figure 6. Ralph Eugene Meatyard, Lucybelle Crater \& 15 Yr Old Son Lucybelle

Crater, c. 1970, silver gelatin print, $7 \frac{3}{8} \times 7 \frac{5}{8}$ ". Copyright Estate of Ralph Eugene Meatyard. 
essentially the same when photographed. This sentiment aligns with Bourdieu's theory that family is an internalized social construct:

Every time we use a classificatory concept like "family", we are making both a description and a prescription, which is not perceived as such because it is (more or less) universally accepted and goes without saying. We tacitly admit that the reality to which we give the name "family", and which we place in the category of "real" families, is a family in reality. ${ }^{48}$

Put another way, one who chooses the term "family" to describe a photograph they encounter is, in actuality, assigning meaning to it — that of "family." Meatyard was surely aware of the ways in which photographs aided this kind of categorization, as The Family Album of Lucybelle Crater reflects. This series affirms that "family" is a label whose distribution is contingent on a photograph's sum of its parts, not actually the photograph itself. Bourdieu would agree, stating that family is a concept predicated "on a constellation of words." ${ }^{49}$ It does not matter if individuals wearing masks in any of Meatyard's images are in fact members of the same family, rather what is crucial is that they, in addition to their surroundings, adhere to proper markers for the family category: "Lucybelle is everybody," Meatyard said, "This may be taken as an ordinary family album, but it does bring in the idea that a Paul is a Paul., ${ }^{, 50}$

\footnotetext{
${ }^{48}$ Bourdieu, "On the Family as a Realized Category," 20.

${ }^{49}$ Bourdieu, "On the Family as a Realized Category," 19.

${ }^{50}$ See "3 Cogitations: directed to Lucybelle Crater or somebody else with the same name," in The Family Album of Lucybelle Crater: Ralph Eugene Meatyard (New York: The Jargon Society and Madelyn Meatyard: 1974), 73-6.
} 
By structuring Lucybelle Crater and her companions as images of family, Meatyard assigns meaning to his subjects that are not necessarily inherent to them or their relationships. At the same time, he creates his images in accordance with a preexisting category. This is what Roland Barthes describes as a "message without a code": because we are unable to describe a photograph by using a similar visual code, we change descriptive structures in turning to language. Here, our use of photographic languagewhat Barthes calls the connoted message — depends on preexisting categories and stereotypes. ${ }^{51}$ The photograph itself, on the other hand, he terms the denoted message. It is that piece of visual information in the world that is only ever explained utilizing the tools afforded to it by the language system. Photographs are absorbed visually, but the feelings they invoke are articulated with a different code entirely—language. The photograph thus behaves linguistically, or at least we interpret it to behave as such. ${ }^{52}$ Here, Barthes builds on semiotic theory established by Ferdinand de Saussure. Saussure argues that two elements constitute all of language. The first, langue, refers to the overarching disposition, makeup, and regulations of language that allow for language's exertion. Parole, the second element of Saussure's, is each instance of language that occurs in the physical world, the "individual utterances made by speakers of the language in concrete everyday situations. ${ }^{.53}$ In family photography, a broad, intangible set of

${ }^{51}$ See Roland Barthes, "The Photographic Message," in Image-Music-Text (New York: Hill and Wang, 1977), 15-31.

${ }^{52}$ Barthes, “The Photographic Message,” 16-20.

${ }^{53}$ For a fuller account of Saussure's contributions to Semotics, see Terence Hawkes, "Linguistics and Anthropology," in Structuralism and Semiotics (Berkeley: University of California Press, 1977), 19-28. Saussure famously used the game of chess as an analogy for the relationship between langue and parole: The rules of chess transcend any 
conventions and standards - the langue of the genre - manifests itself in the qualities and characteristics of each family portrait - the parole. The Family Album of Lucybelle Crater can be read like a language of stock poses, props, and locations. Meatyard's photographs of his own family are therefore marked by their breaks from tradition. Namely, through the incorporation of masks.

In The Family Album of Lucybelle Crater, the mask is a simple gesture, yet one that carries heavy implications. For one, it removes specificity and individuality. As a kind of pastiche of family photography typical of the twentieth century, the Lucybelle Crater project denies sitters, models, and subjects an opportunity to engage with one of the most alluring qualities of portrait photography: the ability to "control the circulation of our faces." ${ }^{, 54}$ Aside from the mask, others components of family photography are frequent. We see Meatyard's wife and her companions outside of their homes, fully facing the camera, and angling their bodies toward each other. If viewers have ever participated in the process of family photography, it is likely they have relied on some of the conventions found in Meatyard's images. But the mask covers Madelyn's face. It could be anyone underneath that piece of rubber, including those who look upon Lucybelle Crater and even you reading this right now. Lucybelle Crater is, in a sense, every viewer who fixates on her likeness. Meatyard's pursuit of developing a photographic language that rests between tradition and divergence results in images that, even when they align with many conventions, are never completely classifiable. This

individual game, yet they only ever actualize within the sequences of moves made during a game. Although langue determines parole, it "has no concrete existence of its own" ( $\mathrm{p}$. 21).

${ }^{54}$ Hirsch, Family Photographs, 10. 
quality of being in-between, of being recognizable but with obvious visual ruptures, is what Meatyard was after - the simultaneity of that which is familiar and unfamiliar. 


\section{PURSUING THE UNCANNY}

Meatyard's breaks from traditional portraiture and family photography — whether through pose, background, composition, or the incorporation of masks - provoke a sense of disease in their viewers. Indeed, Meatyard's practice was marked by various "disruptions of "correct' photographic seeing." 55 Through them, his images pervert photographic techniques taken on by hobbyists and amateurs - here photography's social function is turned on its head. I submit that many of Meatyard's photographs of family and childhood allude to aspects of the psychic phenomenon that Freud described in 1919 as "the uncanny" or Das unheimlich ${ }^{56}$ In its most basic sense, the uncanny is a certain feeling that overwhelms an individual upon his/her encounter with an aesthetic experience that "belongs to the realm of the frightening." 57 This experience, as Freud suggests, is fueled by the return of repressed material from childhood or other primordial states. As children, our purest ways of thinking allow us to believe in, and even befriend, mystical forces that defy the laws of reality we later live by as adults: children confide in shadows and the surrounding world to assist in developing a sense of self. As we grow

older, we realize inanimate objects possess no internal souls — especially not ours — and

\footnotetext{
${ }^{55}$ A.D. Coleman, "Mysteries of the Verge of Vernacular," Portfolio Magazine no. 17 (Summer 1993): 19.

${ }^{56}$ There are multiple translations and republications of Freud's "The Uncanny." The version I refer to in this essay can be found in: Sigmund Freud, The Uncanny, trans. David McLintock (London: Penguin Books, 2003).

${ }^{57}$ Sigmund Freud, “The Uncanny," 123.
} 
our dependency on mystical forces vanishes, allowing shadows and the like to become vehicles for prompting the uncanny. ${ }^{58}$ At the same time, the fear derived from childhood complexes can provoke the uncanny. Freud insinuates that as adults we are at times faced with the primordial fear of death and castration, symbolic or otherwise. The kind of anxiety experienced from the fear of castration is comparable to that experienced from the fear of death. To Freud, the fears of castration and death are variants of each other. Whether magical forces or childhood complexes, we overcome-or surmount, to use Freud's term - certain beliefs we once held as children in order to develop into adults. ${ }^{59}$ In both cases, we eventually realize that such modes of thinking are based on fiction. Before describing how Meatyard evokes the uncanny, the fullness of Freud's concept must be laid out. There are sections of the psychoanalysist's essay that are particularly important for generating a reading of Meatyard's photograph as instances of the uncanny. Namely, Freud's dialogue about the ways in which children engage in the process of self-projection, those moments when fantasy and reality merge, and castration anxiety help frame certain images by Meatyard. Freud's text has also been used as a tool for unpacking Surrealist photographs of the early twentieth century-Meatyard's techniques and subject matter are indicative of the efficacious legacy of Surrealist photographic methods.

During the early twentieth century, when a small amount of literature existed connecting aestheticism to themes of dejection, sorrow, and death, Freud turned to the writings of the German psychologist Ernst Jentsch to build parts of his psychoanalytic

\footnotetext{
${ }^{58}$ Freud, "The Uncanny," 142.

${ }^{59}$ Freud, “The Uncanny," 154.
} 
framework. ${ }^{60}$ Jentsch investigates the relationship between aesthetic experience and the unfamiliar with specific reference to the uncanny. Elsewhere, and more prominently, Freud finds assistance in E.T.A Hoffmann's short story entitled "The Sandman" (1817), which tells of a man named Nathanial whose repressed childhood memories of his father's death leave him in a state of disarray when, as an adult, he is confronted by his father's killer, Coppelius. It is unclear to readers whether Nathanial's experience as a child is real or not: Nathanial remembers Coppelius threatening to remove the child's eyes before killing his father, but we cannot be sure of the accuracy of their encounter. Nevertheless, the horror Nathanial experiences, which is grounded in castration anxiety, is so traumatic that it can never be completely repressed and thus occasionally seeps into Nathanial's later life. As a young adult, Nathanial falls in love with a lifelike automaton, Olympia, created by Coppelius, who poses as a lawyer throughout the latter sections of the story. Upon realizing Olympia is merely a doll, Nathanial becomes grief-stricken. Years removed from his encounter with Olympia, Nathanial stands on a hill, looking through an eyeglass given to him earlier in the story by Coppelius, who he believes he sees in the town square below. His memories of Olympia, Coppelius, and his father's death return to Nathanial at once, sending him into a manic state in which he plunges to his death. ${ }^{61}$ To Freud, "The Sandman" embodies significant features of the uncanny: the

${ }^{60}$ Freud notes that Jenstch was instrumental in connection the uncanny and the inability to differentiate the animate and inanimate. See Freud, "The Uncanny," 125.

${ }^{61}$ To avoid redundancy and to maintain brevity, I am unable to provide a detailed recount of "The Sandman" here. It is crucial to understand, however, that Nathanial's fear of the Sandman is formed before he even meets Coppelius by myths told to him by his mother and the housemaid. As a result, Coppelius's villainy is filtered through fictive descriptions of a nonexistent figure. No matter how evil Coppelius may have truly been, Nathanial's fear stems from imagination—animism is a key term Freud uses in "The 
fear of castration, the animation of the inanimate, and the return of repressed material from childhood.

Freud acknowledges the uncanny's colloquial forms, which carry meanings of "death, dead bodies, revenants, spirits, and ghosts" and include all that can be found within "a haunted house." ${ }^{, 62}$ In order to provide a stricter framework for the uncanny, he refers to the term's etymology. "The uncanny" is an English translation from Freud's native German: Das unheimlich (the uncanny), the binary opposite of Das heimlich (the canny), which means "belonging to the house," "familiar," or "homely." Unheimlich, then, translates most generally to "unhomely." Yet heimlich, as it alludes to privacy (especially in the vein of the home), can also mean, among other things, "concealed, kept hidden, so that others do not get to know it." ${ }^{, 3}$ In this sense, Freud notes heimlich can mean both what is familiar (that of the home) and what is unfamiliar (the concealed). Freud stipulates that unheimlich is only the opposite of heimlich as it applies to the first definition - the familiar — and therefore unheimlich can only be understood as that which is not familiar, or that which is "hidden away." But Freud contends that heimlich, which can denote "the concealed", and unheimlich, when used as the opposite of another meaning of heimlich, are two terms able to describe the other: unheimlich and heimlich

Uncanny." What are imperative to take from Hoffmann's story are the components that fringe on real or unreal: the initial encounter with Coppelius, the automaton, and whether Coppelius is the lawyer Nathanial meets in adulthood. E.T.A. Hoffmann, "The Sandman," in Selected Writings of E.T.A. Hoffmann: The Tales Volume 1, trans. and ed. Leonard J. Kent \& Elizabeth C. Knight (Chicago: The University of Chicago Press, 1969), 137-167.

${ }^{62}$ Freud, "The Uncanny," 148.

${ }^{63}$ Freud, "The Uncanny," 126-9. 
thus become paradoxically one in the same. ${ }^{64}$ The co-meaning of heimlich and unheimlich becomes a tool for Freud to explore how the familiar can be repressed to become unfamiliar, which returns later in life to become familiar again. This return of the (un)familiar is most commonly experienced through the reemergence of what Freud calls "the omnipotence of thoughts," indicated by a magical kind of thinking belonging to a child, mostly as a result of narcissism and a denial of mortality. This "animistic view of the universe" is repressed during an individual's developmental stages on the way to adulthood when it becomes clear that such magical forces do not exist. ${ }^{65}$ Animism is playfully depicted in Chapter Pain \#6 (c. 1960s) (Figure 7), which contains a figure cloaked in a bed sheet, waving their arms, standing near a barrier of shrubs and bushes. The figure appears to be a child dressed as if for Halloween, and they do not necessarily startle adult viewers - the ghost in this photograph may even arouse a sense of amusement. But to a child, the bed sheet may contain no one at all underneath. To an undeveloped consciousness, this could truly be a spirit emerging from or vanishing into the mysterious wooded area. Although Freud believes this sort of mentality is ultimately repressed by adults, it "leaves residual traces that can still make themselves felt." ${ }^{, 06}$ These traces, which were once familiar, belong to the uncanny and appear in many of Meatyard's photographs.

The "omnipotence of thoughts," the belief that inanimate objects possess animate qualities, is further emphasized in Freud's text with reference to the concept of

\footnotetext{
${ }^{64}$ Freud, "The Uncanny," 129-134.

${ }^{65}$ Freud, "The Uncanny," 147.

${ }^{66}$ Ibid.
} 


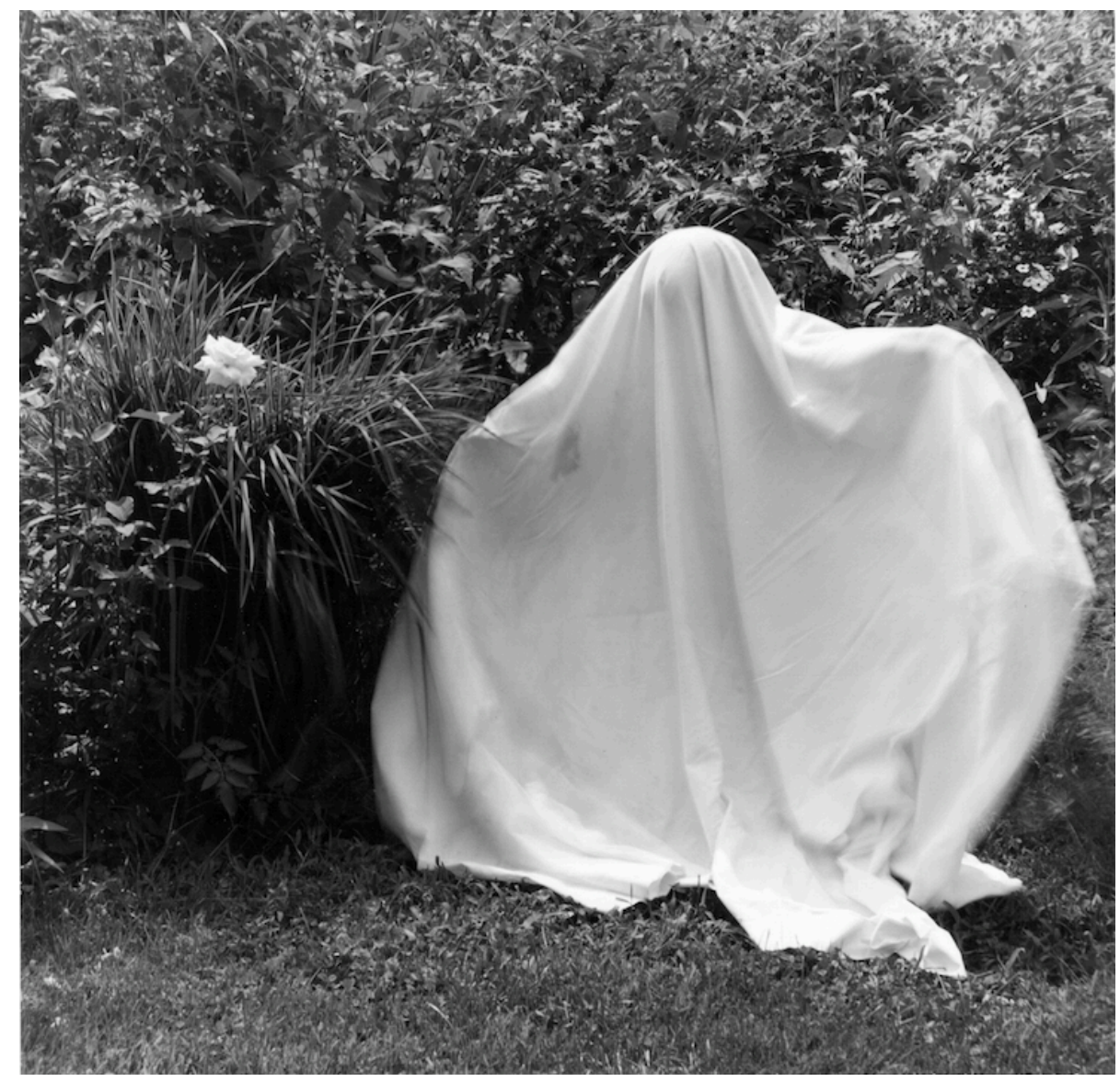

Figure 7. Ralph Eugene Meatyard, Chapter Pain \#6, c. 1960, gelatin silver print, 7 3/8 X $7 \%$ ". Courtesy University of Louisville Photographic Archives. Copyright Estate of Ralph Eugene Meatyard. 
“doubling." As a child, when self-identity is in its most fundamental state, doubling can be used as a defense mechanism to deal with troubling experiences threatening one's sense of self. ${ }^{67}$ Children turn to inanimate objects for self-projection, but as the conscience evolves the need for a double, like the belief in magical forces, dissipates and is repressed in our adult states.

The third and final section of "The Uncanny" specifies the difference between the uncanny of the real, which is encountered through life experience, and the uncanny of fiction, encountered in literature and writing. ${ }^{68}$ A photograph, as an impression of the physical world, belongs to the uncanny of the real, which Freud states is stimulated by the omnipotence of thoughts or childhood complexes. However, it is entirely possible that both versions of the uncanny of the real - those from both the omnipotence of thoughts and from repressed childhood complexes_coincide. After all, Freud says, many beliefs in the omnipotence of thoughts were held during childhood. ${ }^{69}$ Meatyard's unorthodox photographs of family and children provoke the uncanny by incorporating visual references to the omnipotence of thoughts, or animism, thereby blurring the line between reality and fiction.

Meatyard's photographs enter the arena between reality and imagination most decisively through the use of blurring techniques. In one case, two figures occupy an unspecified wooden interior, their bodies and faces are not entirely in focus (Figure 8). The face and arms of one figure, a young girl, are so heavily blurred that her features are

${ }^{67}$ Doubling "was originally an insurance against the extinction of the self." Freud, "The Uncanny," 142.

${ }^{68}$ Freud, "The Uncanny," 154.

${ }^{69}$ Freud, "The Uncanny," 154-5. 


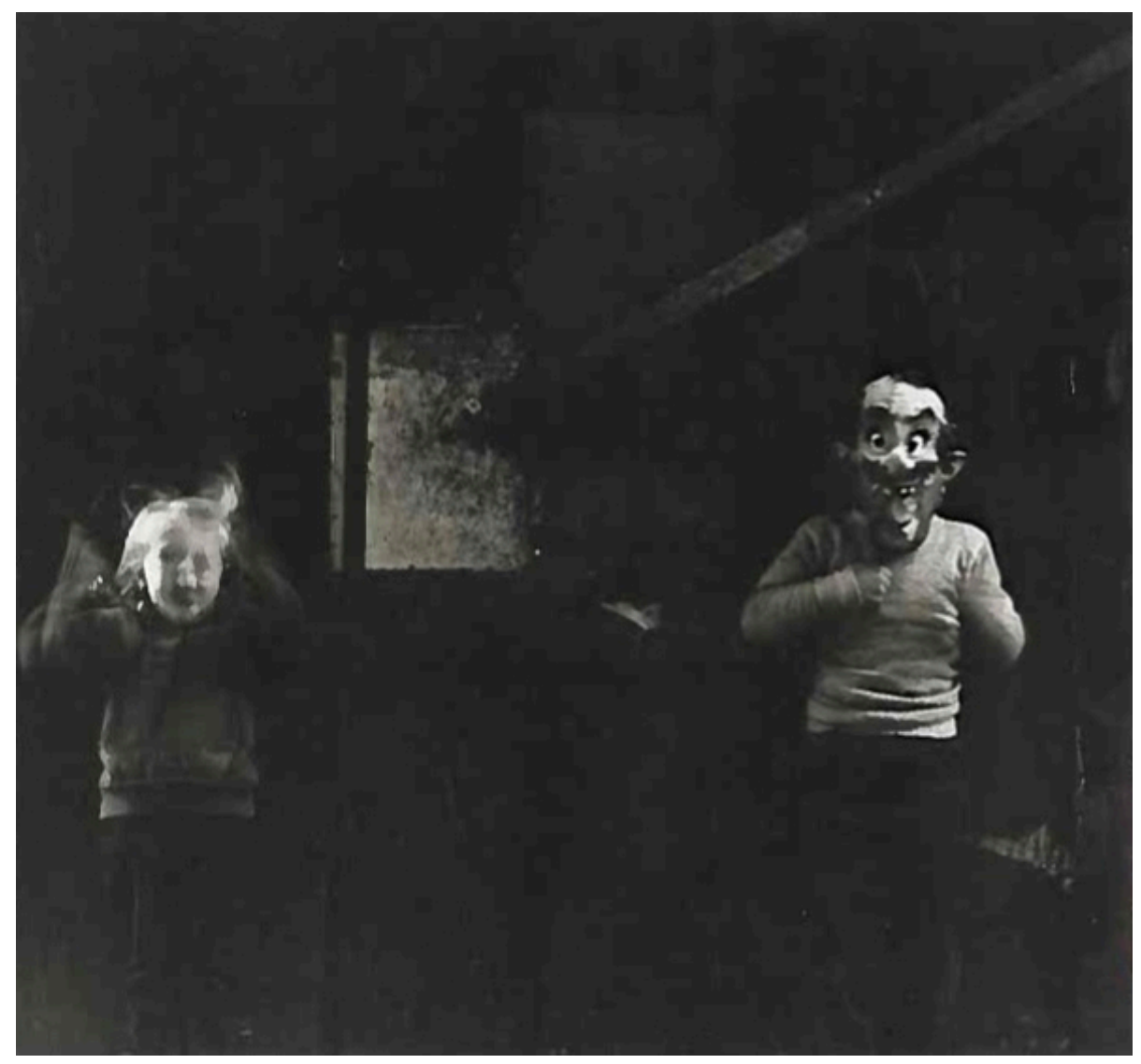

Figure 8. Ralph Eugene Meatyard, Occasion for Diriment (Young girl and masked boy beating his breast), 1962, gelatin silver print, 7 x 7 1/2”. Copyright Estate of Ralph Eugene Meatyard. 
distorted and somewhat missing altogether; we cannot determine which direction her limbs are moving. The other figure appears to be of similar size but the ghoulish mask he or she wears prevents us from knowing his or her true identity. This figure is also partially blurred — his/her arms more so than other body parts. Both figures' feet are cropped out of the frame: they could be grounded or, as far as we know, they could be floating midair. The setting itself, although deeply shadowed, contains notable characteristics of a barn or warehouse: a wooden beam extends from a steel frame positioned between the two figures and the interior appears highly industrial.

What can we assume of the relationship between the two figures and of the state in which they exist? The distance between them, as well as the mask that one figure wears, defy the standards of family photography. Can we rightly assume these are siblings? Certainly not. It is more constructive to think of the masked figure as a product of the young girl's imagination that enters the scene via the girl's projection of herself onto nearby shadows. In this case, the ghoul is the inanimate come to life. Freud notes that shadows can assist in the development of the conscience, a contention echoed by Rosalind Krauss: "The shadow is the earliest form through which the soul is imagined. Projecting the persistence of the bodiless self after death in the form of a 'Shade,' the shadow is also for many cultures the form in which the souls of the dead return to haunt or take possession of the living." ${ }^{.70}$ As a blurred figure the young girl is neither fully in our world nor completely vanished from it. Her transparent state is indicative of an existential incompleteness that the accompanying figure, as the personification of her

\footnotetext{
${ }^{70}$ Rosalind E. Krauss, "Corpus Delicti," in L'amour Fou: Photography and Surrealism, Rosalind E. Krauss and Jane Livingston, exh. cat. (New York: Abbeville Press, in conjunction with the Corcoran Gallery of Art, 1985), 82.
} 
projected characteristics, helps to fulfill. For an adult viewer with a more developed consciousness than the depicted girl, Meatyard's photograph is a momentary return to a mentality propelled by the emergence, as well as the necessity, of ghouls and spirits that act as personifications of childlike beliefs. The need for this type of self-projection becomes repressed in order for many of us to enter adulthood. This image aligns with Freud's notion that the uncanny is a return of that which was once familiar made unfamiliar, now materializing as the familiar again.

Blurring and masks are employed again in Untitled (Group of children with dolls and masks) (1963) (Figure 9). This time, however, dolls, instead of shadows, are sources for imaginary companions to emerge. Seven figures are seated side-by-side on a grassy area, forming a line that runs horizontally across the photograph. Six of their faces are distorted or hidden either by blurring techniques, masks, or turning their heads from the camera; only a young girl (possibly the same from our previous example) who sits furthest left shows her face in full- - her attention is fixated not on the others around her, but on something she holds - a doll. Nine other dolls, some of which have missing limbs, are scattered in the foreground and two unworn masks can be found near the far right edge of the frame and hung on a bush behind the group, respectively.

Of the tangible objects that provoke the uncanny, Freud maintains a significant connection between children and dolls in asserting that children "make no sharp distinction between the animate and inanimate, and that they are especially fond of treating their dolls as if they were alive." ${ }^{, 71}$ This observation is illustrative of the function

\footnotetext{
${ }^{71}$ Remember that Hoffmann's plot is partially driven by Nathanial's inability to distinguish between a living woman and an automaton. Freud would likely characterize
} 


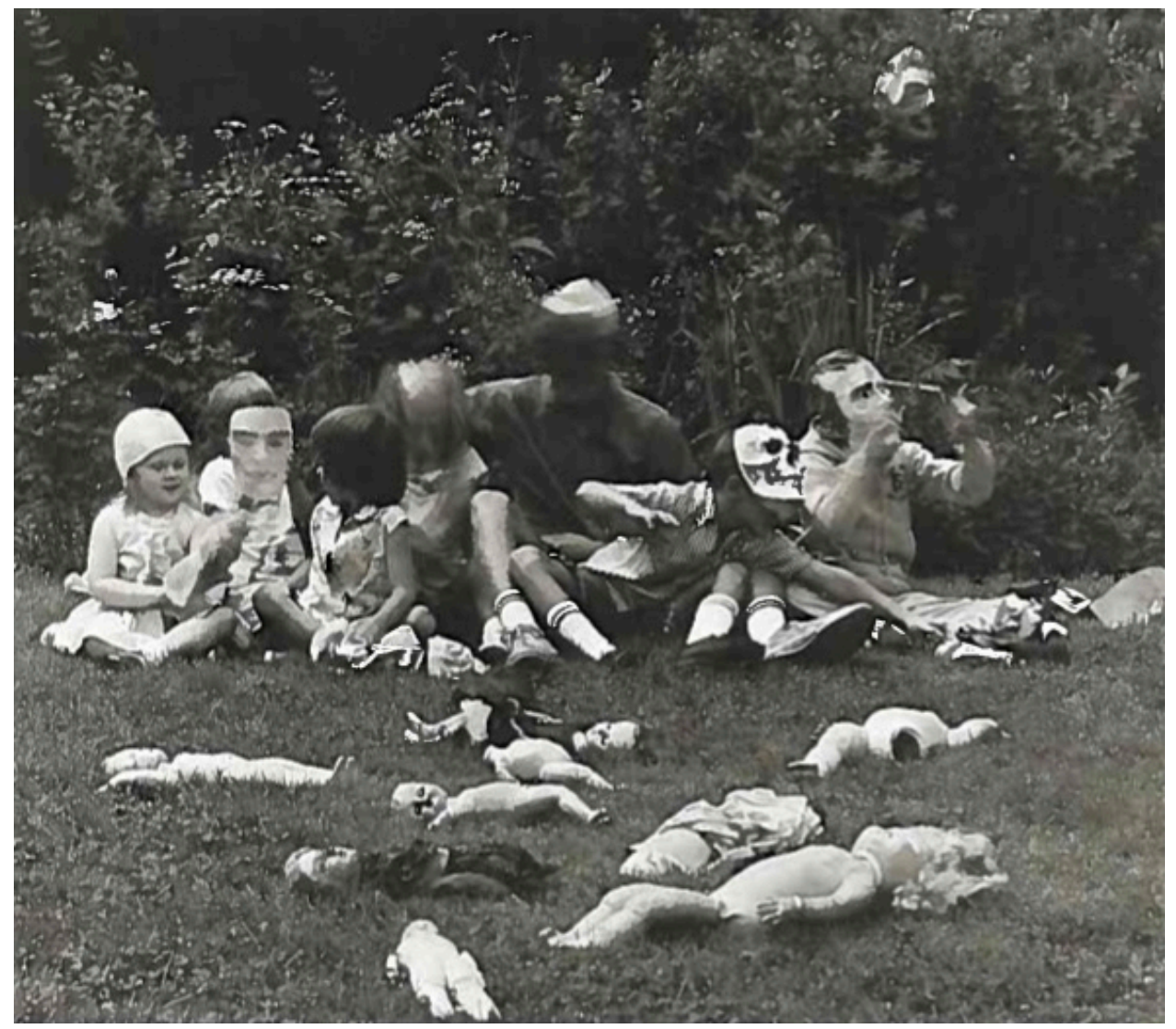

Figure 9. Ralph Eugene Meatyard, Untitled (Group of children with dolls and masks), 1963, gelatin silver print, 7 \% 16 x 8 1/4". Collection of Jonathan Greene. Copyright Estate of Ralph Eugene Meatyard.

Nathanial's shortcoming as a product of surmounting animistic thinking from childhood. Freud, "The Uncanny," 141. 
of the automaton, Olympia, in Hoffmann's short story. In Meatyard's photograph, the dolls serve as loci for parts of the girl's identity that she projects. Like the shadow from our previous example, the figures are the portions of the projected self personified - they are not fully whole. Thus, they remain in blur, masked, or unidentifiable.

Connecting Freud's observation with photography, Krauss analyzes how dolls can operate as tools for photographers seeking to render the characteristics of animistic thinking, especially when aiding the presumption that a doll can act as "the extreme opposite of oneself and yet the same as oneself, which is to say both alive and dead."72 Notably, Krauss posits the uncanny is represented in the images of Hans Bellmer in a project entitled Poupées that contains images of reconstructed doll limbs invoking castration anxiety (Figure 10). Bellmer's work is able to "produce the image of what one fears in order to protect oneself from what one fears" as a means of combatting traumatic episodes. ${ }^{73}$ Bellmer's photographs can be interpreted with reference to Freud's text, specifically the section describing young Nathanial's fear of having his eyes removed, which we know is spurred by the castration complex. Unlike the dolls in Bellmer's images, however, many of Meatyard's dolls are accompanied by human models, some of whom represent the psychological states of the children — as personifications of the

\footnotetext{
${ }^{72}$ Rosalind E. Krauss, "Uncanny," in Formless: A User's Guide, Rosalind E. Krauss and Yve-Alain Bois, eds. (Cambridge: The MIT Press, 1997), 194.

${ }^{73}$ Ibid. Bellmer's dolls are depicted in doubles: Other than the doll itself acting as a double for one's self, Bellmer reconstructs his dolls so that they are symmetrical and then layers multiple exposes over one another to achieve a further sense of the double. Krauss contends that by intensifying repetition, Bellmer's dolls hold "the inevitability of return." Further, the dolls Bellmer captures are reconstructed with bulbous, elongated parts (no heads), drawing formal comparisons to a penis. Through a sense of doubling built upon aspects of the doll as well as the print itself, the phallic symbol combats the fear of castration. Krauss, "Corpus Delicti," 86.
} 


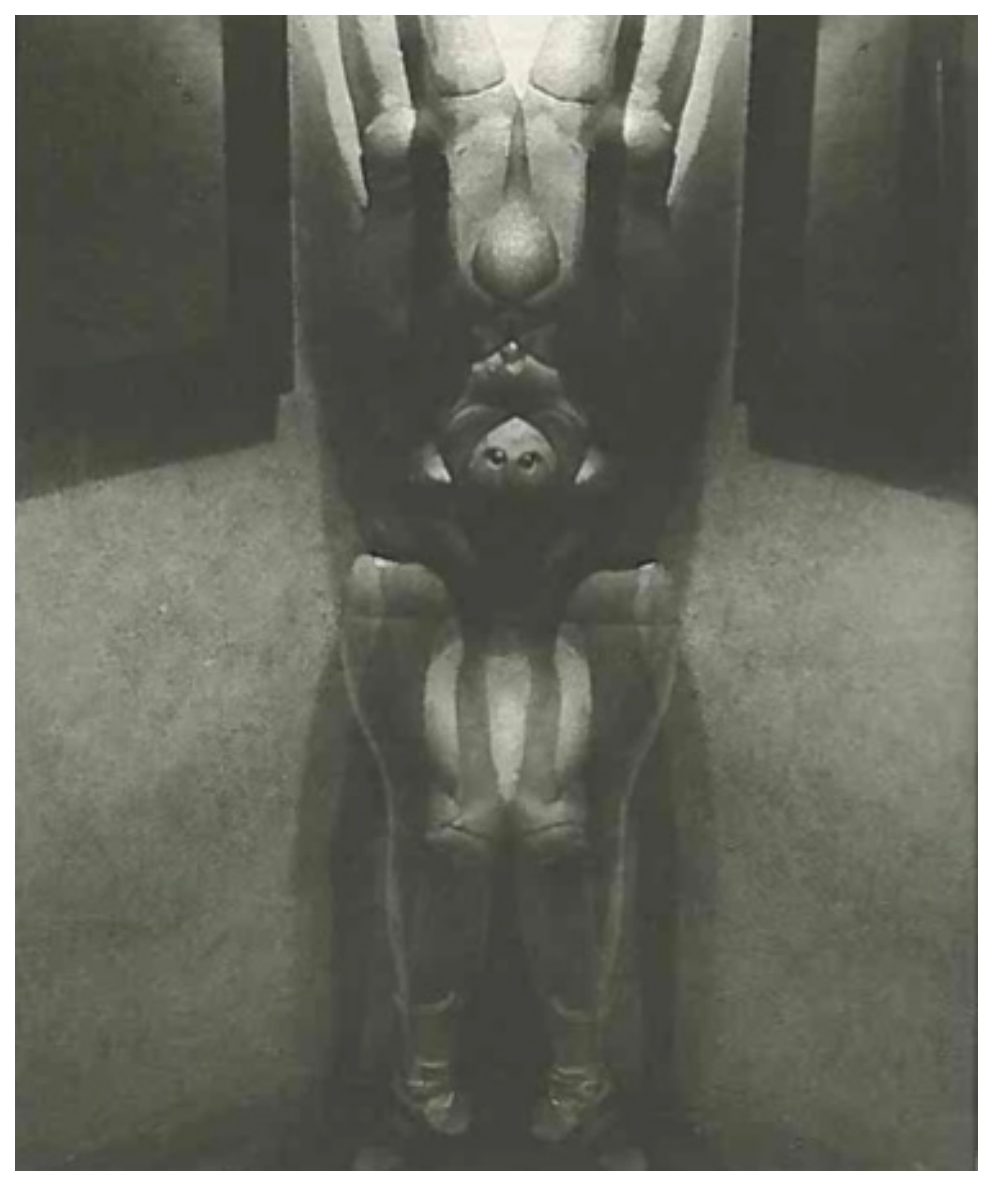

Figure 10. Hans Bellmer, L'Idole, 1937. Bihl Bellmer Collection. Courtesy Editions Filipacchi-Sonodip. 
projection of self, as seen in Untitled (Group of children with dolls and masks). In this fleeting moment, the young girl enters an environment that adults are incapable of knowing: to become an adult is to recognize that inanimate objects, such as dolls, will only ever be inanimate. With his camera and the strategic pairing of both dolls and people, Meatyard constructs scenes where the animate and inanimate conjugate.

Photographs like Untitled (Group of children with dolls and masks) can be interpreted with the aid of a psychoanalytic concept that Scottish psychiatrist R.D. Laing calls "the unembodied self" in The Divided Self $(1959) .{ }^{74}$ The unembodied self describes individuals who "find themselves to be, as they always have been, somewhat detached from their bodies. ${ }^{, 75}$ Laing states that the body — the object in the world that simply holds the unembodied self - functions as a kind of front, façade, or mask. Moreover, "the self then seeks by being unembodied to transcend the world and hence be safe." ${ }^{, 76}$ This is seemingly impossible for the unembodied self, an identity unable to penetrate the physical world due to the divide between it and the body that holds it. Laing applies his theory of the unembodied self in case studies of schizophrenics: an individual identifying

\footnotetext{
${ }^{74}$ The Divided Self is Laing's first major publication. By the time of his death in 1989, nearly three-quarter million copies had been sold in England alone.

${ }^{75}$ R.D. Laing, "The embodied and unembodied self," in the Divided Self (London: Penguin Books, 1990), 66. Laing's discussion of the unembodied self-which is the counterpart to the embodied self-succeeds a section on ontological security, which develops in an individual whose outward presentation and actions are guided by what they believe others expect from them, not by their true identity, essentially divorcing their body and mind. As a result, "external events no longer affect [them] in the same way as they do other," ultimately isolating their experiences from experiences shared and had by others. Their body, then, becomes yet another object in the world, entirely removed from their true self. See Laing, "Ontological insecurity," in The Divided Self, 39-61.

${ }^{76}$ Laing, "The inner self in the schizoid condition," in The Divided Self, 80.
} 
as the unembodied self is often outwardly passive, deadpan, and aloof. This is because his/her true sense of self does not associate with their body — the body and brain are therefore in a perpetual state of disconnect. Only on rare occasions does the unembodied self surface to the physical world. When this occurs, it is frequently brief and sporadic. This characterization helps expand the ways in which Meatyard's photographs can be analyzed. In addition to being a depiction of self-projection, the photograph of the blurred girl and masked figure in the shadowy interior can be understood as a moment when the unembodied self becomes visible, and the shadow functions as a means for transcendence. Perhaps this is why both figures appear blurred, because the body and true self are split, their convergence seemingly impossible.

In the case of the girl surrounded by unidentifiable companions, the masked and blurred figures represent the unembodied self. If we take the dolls as landing sites for those fragments of the young girl's identity that projects and the accompanying figures as personifications of those fragments, then it can be inferred that every subject not including her in Untitled (Group of children with dolls and masks) is the unembodied self made manifest. The body of the young girl is, therefore, as much of an empty shell as the dolls.

Laing contends that the unembodied self resists relations with other people, only associating "itself to itself and to the objects which itself posits." ${ }^{, 77}$ In other words, the unembodied self fails to connect with the experiences shared by others in the physical

\footnotetext{
${ }^{77}$ In his book, Laing describes a patient whose interactions with his wife were, for the patient, actually interactions with the image of his wife; it happened to be that, in the patient's mind, both his wife and the image he held of her were synchronized. Laing, "The inner self in the schizoid condition," 86.
} 
world. Instead, the unembodied self only ever interacts with the representations of the world for which it has made for itself. For a child, this may mean that they associate only with their imagination or the representations of things sharing physical space with the body in which the unembodied self resides. This is apparent in Meatyard's photograph of the young girl, wherein the methods of self-projection are ones exerted by the unembodied self. For the unembodied self in this example does not relate directly to the dolls but rather to the personalities of the dolls (represented by the other figures in the image), which are in reality nonexistent as they are the personalities of the girl.

The unembodied self relates to a body in ways different than the "embodied self., ${ }^{, 78}$ The unembodied self, in its search for transcendence, survives through its relations to objects of the imagination, thus completely separating it from the body that contains it and from other things in the world. This freedom compels the unembodied self "to be anybody in phantasy, and nobody in reality...This self can no longer either experience or give expression to its own desires in a way that is socially acceptable.",79 Meatyard's ghostly photographs, while maintaining their position as instances of animistic thinking, are moments when the unembodied self attempts to fully escape the body that holds it in an effort of corporeal transcendence. However, the unembodied self's inability to connect with objects in the physical world prevents it from becoming anything more than a transparent haze — it is "nobody in reality." This sentiment echoes

\footnotetext{
${ }^{78}$ Laing describes the embodied self: "Most people feel they began when their bodies began and that they will end when their bodies die." In other words, the embodied self established a direct connection with the body it is contained it. We can then assume that the survival of the unembodied self is less dependent than the embodied self on the body that holds it, which helps to understand the unembodied self's desire for transcendence. See Laing, "The embodied and unembodied self," 66.

${ }^{79}$ Laing, "Psychotic developments," in The Divided Self, 142.
} 
Meatyard's statements on the use of masks, especially in The Family Album of Lucybelle Crater.

Masks are a means for entering new realities. Indeed, when wearing masks, many of Meatyard's subjects enter a fantastical world by virtue of their connection to the physical spaces they occupy. In a pair of photographs from 1962, the bust of a teenage boy interjects into a corroding wooden interior from the frame's bottom edge (Figures 11 and 12). In one image, an opaque white mask settles on a shelf above the boy; to its right hangs a broken mirror that balances a reflective triangular shard on its top. In the mirror, the texture of a blurred object resembles that of the wall's rotting wood, although its shape is like that of another's torso and head. A doorframe creeps its way into the photograph from the right edge.

In the corresponding photograph, the boy has taken the opaque mask from the shelf and holds it to his face. But that is not the only difference Meatyard has incorporated into the composition: the glass shard has rotated ninety degrees, the boy has moved slightly to the right within the frame, the angle of the camera has dropped so that all props appear higher than in the first image, a new rectangular shadow has materialized above the mirror, and the blurred shape in the mirror's reflection has vanished. This duo of images accomplishes a goal shared by Meatyard's photographs of blurred figuresthat the body can "be depicted as a form of energy that is not entirely separable from the physical environment." ${ }^{80}$ This is certainly true, but perhaps a more accurate reading of this particular pair advocates that the culmination of the changes in the background

\footnotetext{
${ }^{80}$ Eugenia Parry Janis, Max Kozloff, and Adam D. Weinberg, Vanishing Presence, exh. cat. (New York: Rizzoli in conjunction with the Walker Art Center, 1989), 82.
} 


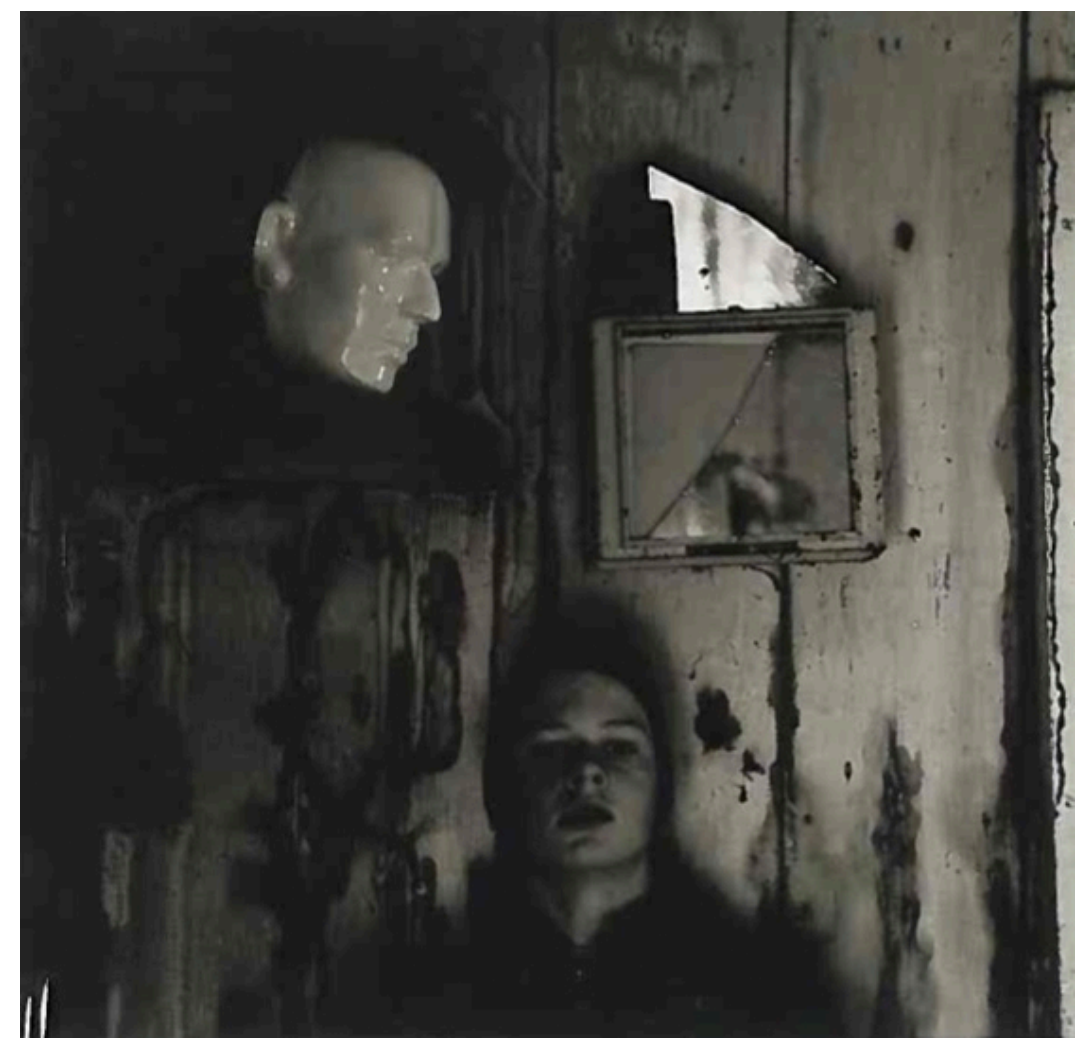

Figure 11. Ralph Eugene Meatyard, Untitled (Boy below white mask and broken mirror), 1962, gelatin silver print, $7 \frac{7}{16} \times 7 \frac{5}{8}$ ". Copyright Estate of Ralph Eugene Meatyard. 


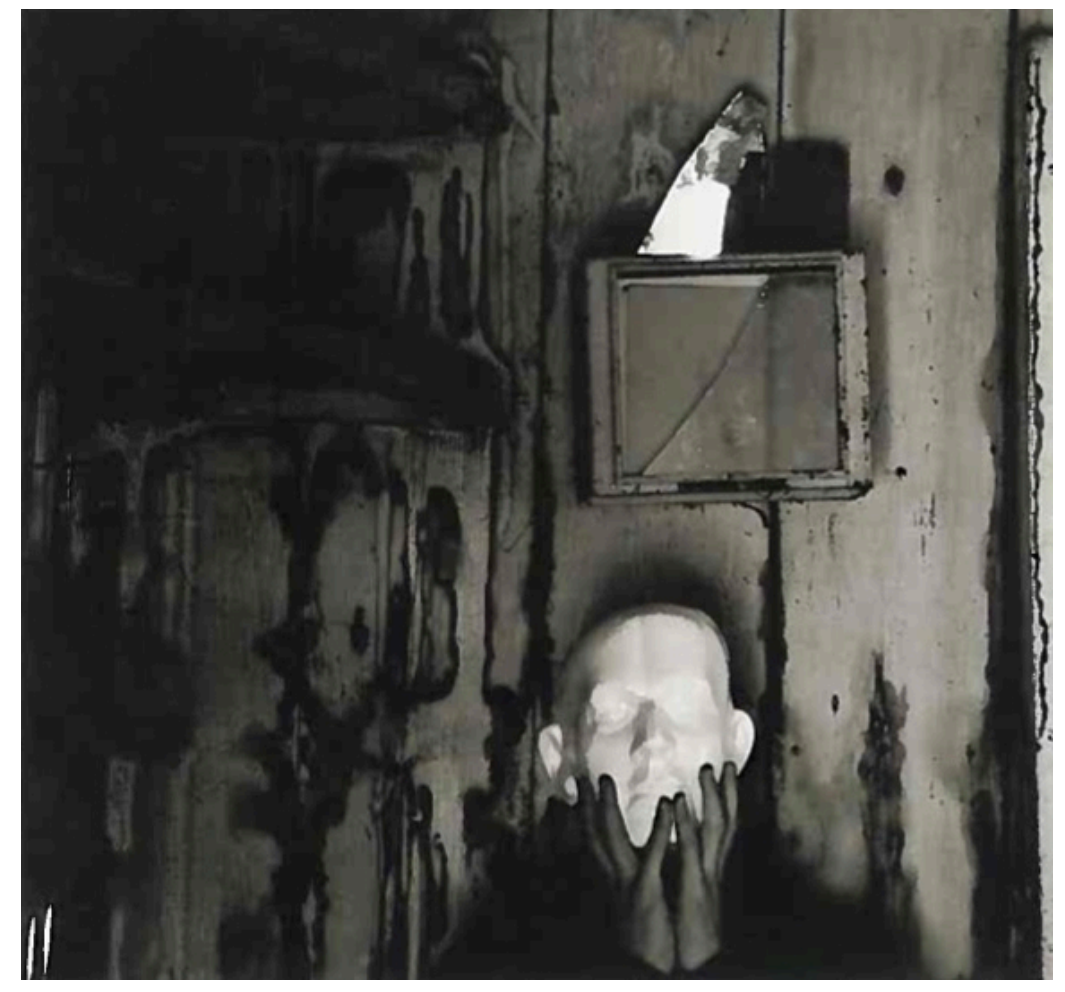

Figure 12. Ralph Eugene Meatyard, Untitled (Boy wearing white mask below broken mirror), 1962, gelatin silver print, $7^{7} / 16 \times 7 \frac{3}{8}$ ". Copyright Estate of Ralph Eugene Meatyard. 
express a shift into a new reality, a shift signaled by the figure donning the mask. In other words, the mask is a marker of corporeal change. In Meatyard's own words, a mask, when worn, serves to "non-personalize a person." ${ }^{\text {81 }}$ The teenage boy, when wearing the mask, becomes anyone, including us, and the mask becomes a means for inviting us into a different world. This pair of photographs, then, represents two different states: one where we, along with the figure, have surmounted the possibility for the mask to serve as a vehicle for the rise of magical forces. Here, we recognize the mask as an inanimate object on a shelf. In another state, when the mask is worn, the figure inhabits a space that is no longer completely the same- it has become unfamiliar. In this sense, these photographs exemplify the capability for the uncanny to simultaneously operate as heimlich and unheimlich that Freud described in 1919. The entire scene- the composition, the viewing perspective, the props, and the position of the figure-initially seems unchanged, yet a more thorough investigation of its contents will establish two different depictions of the same objects. Viewing both at the same time, each image strengthens the other's familiarity, but their differences—-which are kept hidden by similar placements—isolate them as unique photographs. Like the young girl among masked figures and dolls, this pair of photographs does not represent the qualities of the uncanny, but is uncanny—by assuming the mask, magical forces thought to have been surmounted have invaded reality and become manifest.

So far I have analyzed selections from Meatyard's oeuvre that present instances of self-projection, animistic thinking, and the mergence of the uncanny's etymological origins. There are photographs by Meatyard that embody the aspect of the uncanny that

${ }^{81}$ Meatyard, lecture to the Midwest SPE. 
deals with the castration complex, such as Untitled (Arched doorway with ghost) (1966) (Figure 13). This photograph features a barren interior of what we can presume to be a home. An arch, visually split by a crack in its apex, encapsulates a doorway linking two empty rooms. In the left of the frame two transparent feet are seemingly frozen in midwalk. Allowing our eyes to ascend from the ankles onto the rest of the figure, we come to notice that the rest of the body disappears - only the wall behind our would-be subject is visible. Here, Meatyard has captured what appears to be supernatural activity. An image like this certainly alludes to the kind of animistic thinking Freud describes. Yet it also elicits another facet of the uncanny that derives from the castration complex. The anxiety that may arouse in a viewer looking upon this photograph is comparable to-if not the same as - the anxiety Freud believes is provoked by the fear of castration.

Bellmer, in alignment with Freud, approached the primordial fear of castration head on by using double exposures to present phallic reconstructions of dolls. Meatyard, who was indeed interested in psychoanalysis and probing the psyche of a viewer, was likely making his work without ever reading "The Uncanny." ${ }^{\text {"2 }}$ But Freud's argues that castration anxiety can be invoked by the removal of any part of the body. Meatyard's figure in this photograph, whose feet have been separated from the invisible body, prompts the fear of castration, thus serving as a fetish. Moreover, the fear of castration in Meatyard's photographs of ghostly figures persists with respect to the fear of death.

Freud establishes that the fear of death lingers in us even after we have surmounted other

${ }^{82}$ Siegel, "The Universalizing Mask," 124. Meatyard "said famously very little about his own photographs." Neither in the unpublished primary sources nor in my conversations with Meatyard's son, Christopher, is it ever made clear that Meatyard read "The Uncanny." 


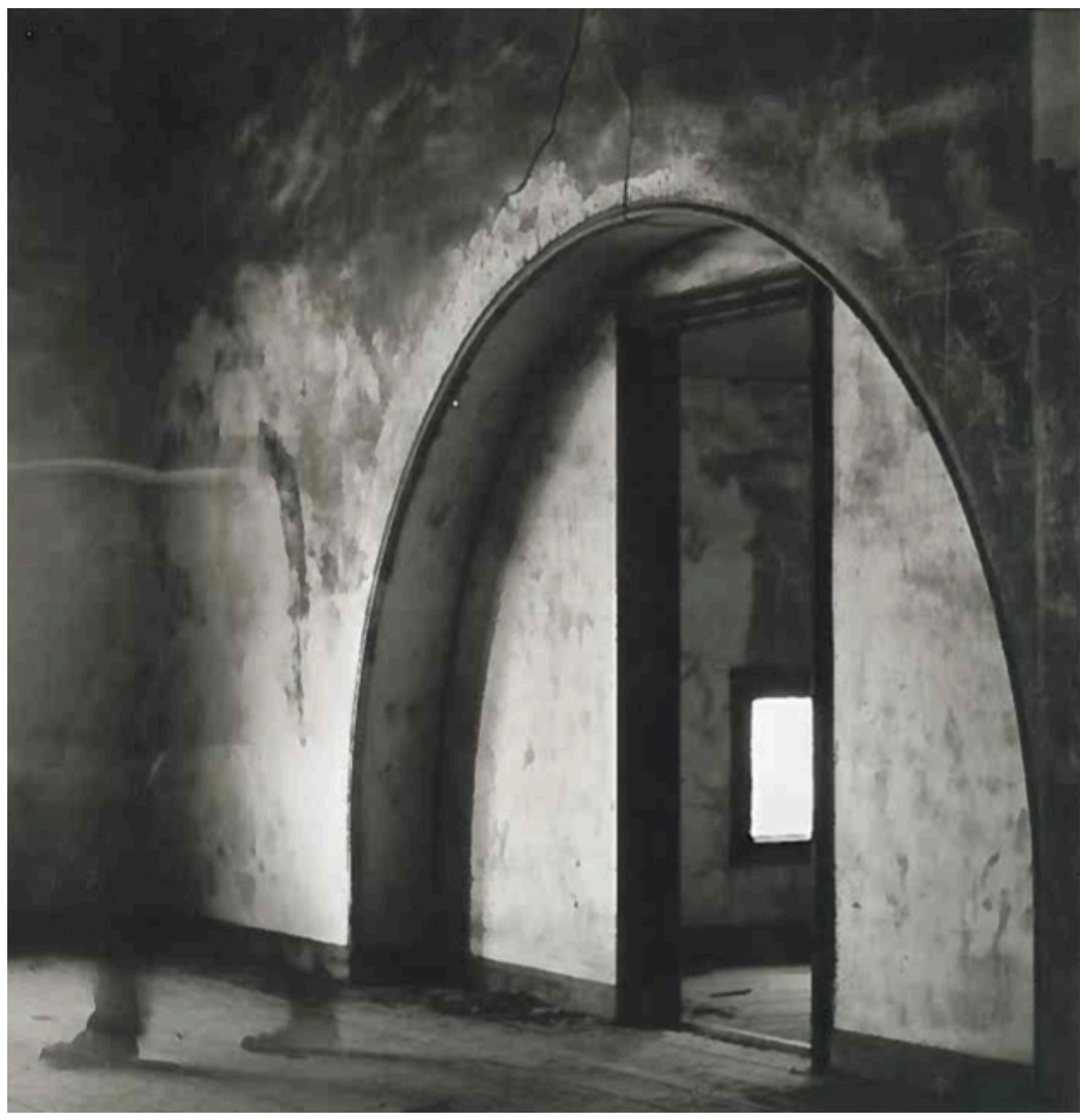

Figure 13. Ralph Eugene Meatyard, Untitled (Arched doorway with ghost), 1966, gelatin silver print, $7 \frac{3}{8}$ x 7 1/4". Copyright Estate of Ralph Eugene Meatyard. 
forms of animistic thinking, and that what is repressed is the possibility of the dead becoming alive again. ${ }^{83}$ Untitled (Arched doorway with ghost), a depiction of what appears to be a ghost, is thus a return of the repressed. Freud speculates that our fear of death is cemented in the fear of being buried alive, which he states is perhaps "the crown of the uncanny." 84 This fear, Freud believes, is an alternate form of the "fantasy of living in the womb" ${ }^{\sharp 5}$ that produces an infatuation for the mother later threatened by the fear of castration at the hand of the father figure. It can be reasonably assessed, then, that the anxiety felt by the castration complex can be duplicated by the fear of death. Labeling the photograph of the archway as a frightening one does not occur by the invocation of death itself, but by placing the fear of being trapped alive in a grave in the mind of a viewer, marked by the return of the dead - the ghost Meatyard has rendered using a prolonged exposure. Meatyard may not explicitly conjure the castration complex in a manner similar to Bellmer, but he is able to simulate a similar sense of fright, one that is directly related to the fear of castration. By doing so, Meatyard's photographs of blurred figures instigate the uncanny of the real in two of its variants: animism and the castration complex.

It is no coincidence that Meatyard's most poignant instances of the uncanny include the presence of children; or, when they do not, the subjects are often blurred or obscured to remove any obvious indication of an established sense of adulthood, as in

\footnotetext{
${ }^{83}$ Freud, "The Uncanny," 148-9.

${ }^{84}$ Freud, “The Uncanny," 150.

${ }^{85}$ Freud admits that a grave and a womb carry two different modes of feeling - one is inescapable and the other is comforting. What the parallel between the grave and womb represents is the "proximity to the castration complex" that the uncanny possesses. Ibid.
} 
Untitled (Arched doorway with ghost). Using children as his models allows Meatyard's photographs to function as scenes for the uncanny to unfold. Like Bellmer's Poupées project, which belongs distinctly to the Bretonian camp of European Surrealist movement of the first half of the twentieth century, Meatyard's photographs offer a dream world where the return of the repressed causes the principles of reality to become unstable. It is for this reason that Meatyard can be considered an extension of those Surrealists who were inspired by Freudian psychoanalysis.

In the preface to his book, Compulsive Beauty (1993), Hal Foster submits that the uncanny is the theoretical concept most suited to serve as a tool for comprehending Surrealism. ${ }^{86}$ The connection between Meatyard's photographs and Freud's "The Uncanny" suggests that Meatyard's practice can be framed as one in line with those of major Surrealist members, albeit one that developed nearly half a century later. Meatyard was not shy about speaking of his photographs as Surrealist works, going as far as deeming his images "sur-Real—the more real than real." ${ }^{87}$ Meatyard believed photography was capable of achieving the effects of Surrealism in ways unlike other mediums due to a photograph's contingency on a real-world event. ${ }^{88}$ It is as if Meatyard's aspirations - to create scenes that were more real than real—echoes the impression of the uncanny, which is to merge reality and the imaginary, the animate and inanimate. But

\footnotetext{
${ }^{86}$ Foster insists that the "historicity" of the uncanny allows it to serve as the ultimate tool for dissecting the works of Surrealists-Freud's essay was a contemporary of the European Surrealist movement. Hal Foster, "Preface," in Compulsive Beauty (Cambridge: The MIT Press, 1993), xvii.

${ }^{87}$ Meatyard, interview by Nathalie Andrews, 1970.

${ }^{88}$ Ibid.
} 
Foster suggests that the uncanny possesses yet another utility: "a usurpation of the referent by the sign or of physical reality by psychic reality," with an effect of "anxiety." 89 Indeed, Meatyard was capable of doing just this, notably in the image of the young girl and ensemble of dolls where the referent (the dolls) is transcended by the physical manifestation of what they indicate - the girl's inner self. This is just one example, however. For the devices used by the Surrealists, and more specifically Surrealist photographers, to disrupt reality were numerous.

Krauss notes that Surrealism strived to break the distinction between what is real and what is imaginary, a quality developed from André Breton's concept of “convulsive beauty," which is an "experience...of something that shakes the subject's self-possession, bringing exultation through a kind of shock." 90 The feelings generated by convulsive beauty, Krauss claims, is comparable to those prompted by the uncanny. Krauss claims a shock, especially a kind of shock that incorporates the inevitability of death, is the uncanny because it spurs the return of primordial modes of thinking held during stages of development when the animate and inanimate merge. A blurred dress activates without the complete trace of a wearer in Man Ray's Explosante-fixe (1934) (Figure 14). Only a figure's arms are visible (and even these appear anatomically inaccurate), shocking viewers by depicting life without a body and a sense of movement without motion. Its implications to death are projected by a sense of lifelessness - it is both an experience of convulsive beauty and the uncanny. Certain photographs of Meatyard's, such as Untitled

${ }^{89}$ Foster, "Beyond the Pleasure Principle," in Compulsive Beauty, 7.

${ }^{90}$ Krauss, "Corpus Delicti," 85. Breton is regarded as one of the founders of the Surrealism movement, if not the leader. His manifesto on 1924 provided the groundwork for many Surrealist initiatives. 


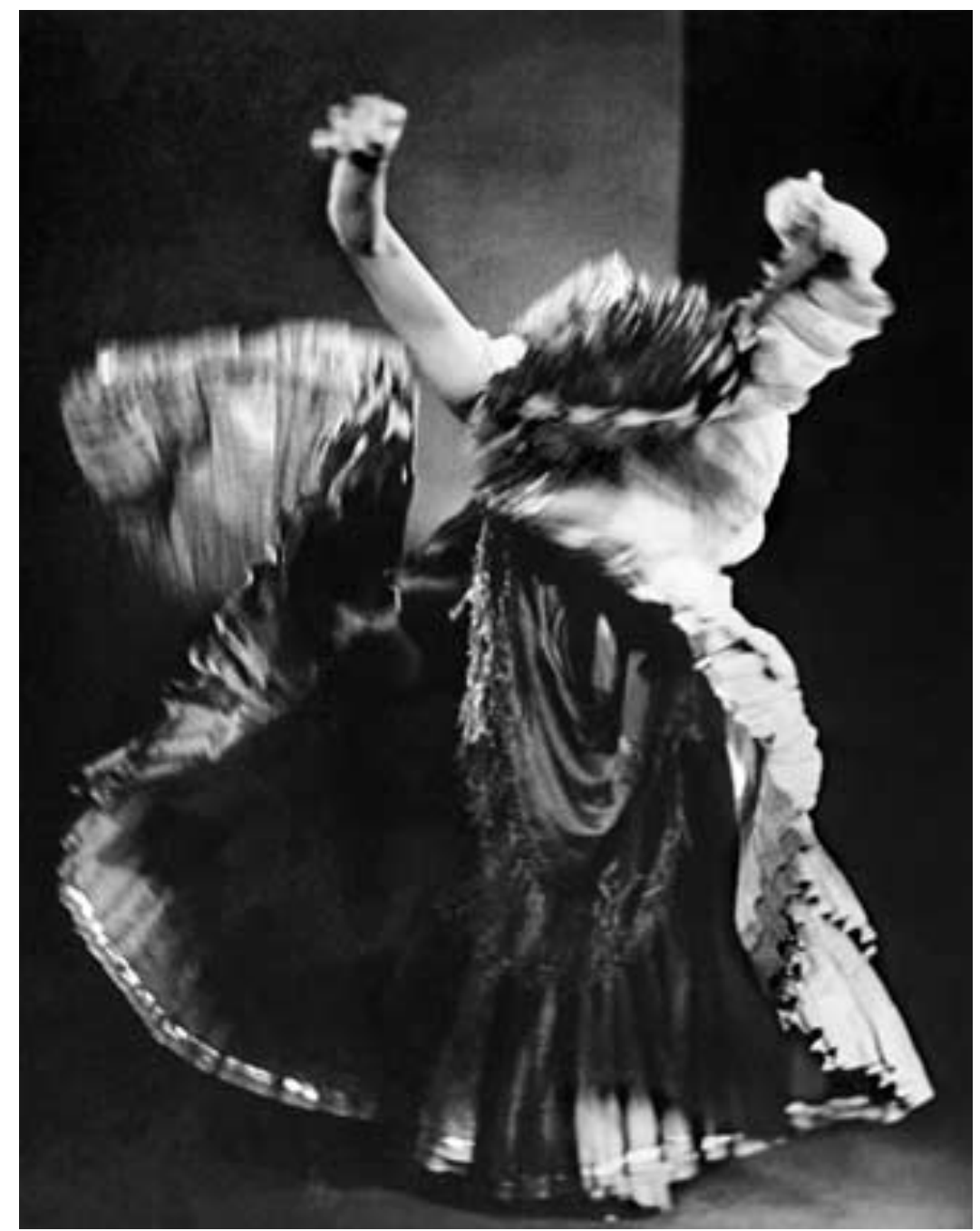

Figure 14. Man Ray, Explosante-fixe, 1934. Private Collection, Paris. 
(Two ghosts with a fireplace) (1969) (Figure 15), operate in the same manner, drawing upon deathly themes by capturing the activity of ghostly figures. Like Man Ray's image, the presence of Meatyard's figures are denoted more by clothes than by bodies, offering an encounter with the supernatural that is somewhat imperceptible. These photographs, which can instigate a shock for viewers by way of convulsive beauty and the uncanny, align with basic precepts of Bretonian Surrealism.

Tapping into the unconscious is also a driving force for Breton, a trait that he termed "the marvelous" to mean a moment when reality is obstructed through a "disorientation of "memory"” and/or a "disruption of "identity"."91 Breton provides two examples of "the marvelous"- the "romantic ruins" and "modern mannequins" 92 that pertain to Meatyard's photographs. There are instances where Meatyard inserts dolls or masks into ruined spaces, but perhaps no photograph contains both examples of "the marvelous" as provocatively as Untitled (Boy holding mannequin hand) (1961) (Figure 16), wherein a child's outstretched hand holds the severed forearm of a mannequin, the end of which nearly meets the edge of the frame, initially tricking our eyes into believing it extends to the rest of a body outside the composition. The child stands alone in front of a rotted wall half-covered in remnants of wallpaper-clearly this is an abandon space.

\footnotetext{
${ }^{91}$ Breton's meaning of "the marvelous" is one specific to Surrealism. Foster lists other forms the term has taken in history: a more antiquated version of the marvelous alludes to simply "a rupture in the natural order...not necessarily divine in origin:" Louis Aragon, a contemporary of Breton whose use of the term is in many ways similar to Breton, moves "the marvelous" into somewhat of a political territory, where it denotes a revolutionary action to upend the bourgeoisie. Contrastingly, Breton's use of the term "is more personal than political." Foster, "Compulsive Beauty," in Compulsive Beauty, 19-20.

${ }^{92}$ Foster, "Compulsive Beauty," 21.
} 


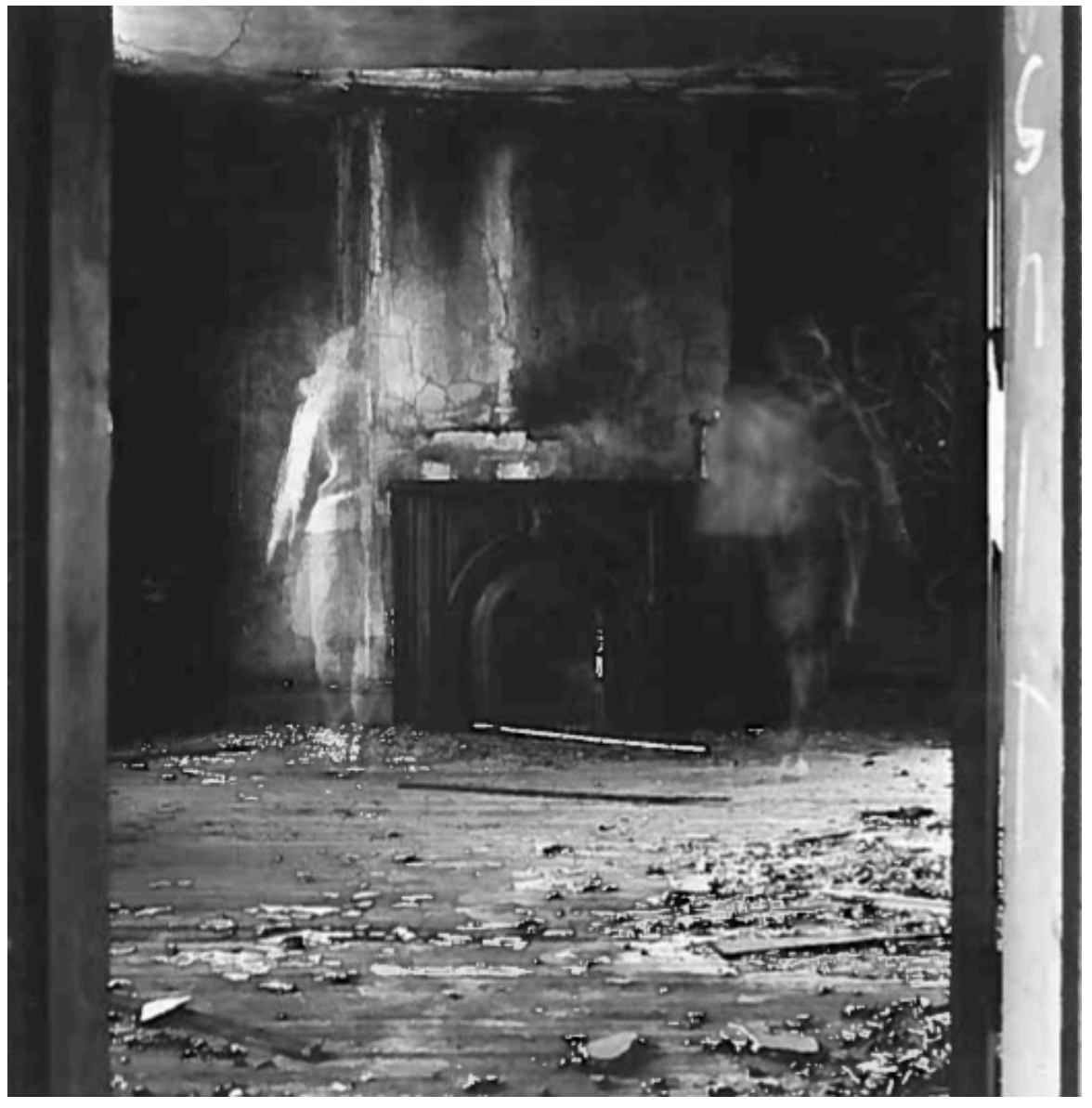

Figure 15. Ralph Eugene Meatyard, Untitled (Two ghosts with fireplace), 1969, gelatin silver print, $6 \frac{11 / 4 \times}{1} 6$ ”. Copyright Estate of Ralph Eugene Meatyard. 


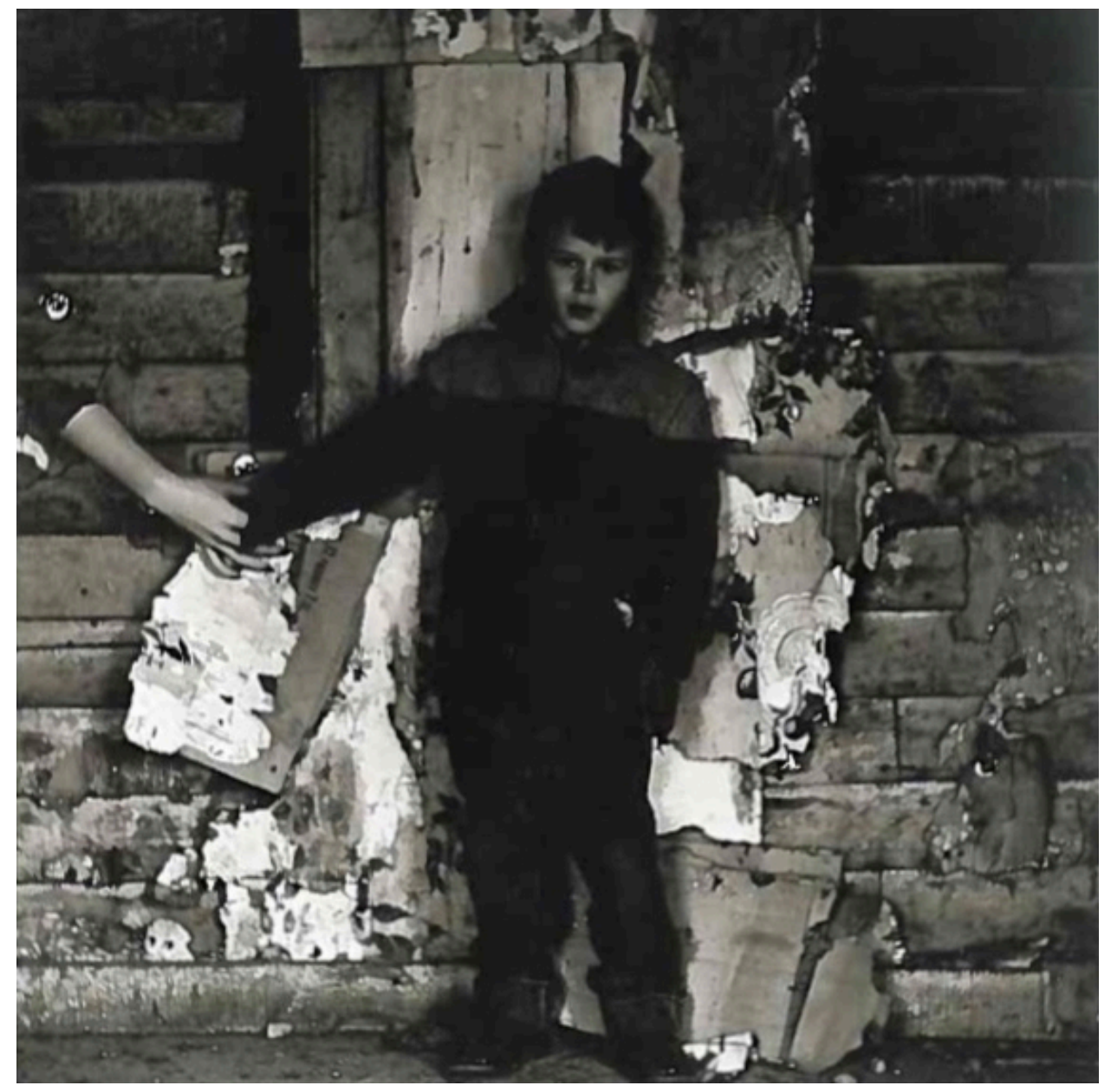

Figure 16. Ralph Eugene Meatyard, Untitled (Boy holding mannequin hand), 1961, gelatin silver print, $7 \frac{1}{2} \times 1 \frac{1}{2}$ ". Copyright Estate of Ralph Eugene Meatyard. 
This photograph operates as a Surrealist work not because the plastic arm fools us into believing something is there that is in actuality not there at all, but because it contains visual allusions to Breton's Manifesto and concurrent examples of "the marvelous."

Breton's text inspired many Surrealists, but certain figures of the movement found inspiration from other sources as well — namely, Freudian psychoanalysis. Many Surrealists were invested in depicting self-projection as Freud describes in his analysis of the double, or Doppelgänger, in "The Uncanny." Freud notes that an individual is able to transfer their sense of self to another either in full or in segments, using "mirror-images, shadows, guardian spirits, the doctrine of the soul and the fear of death" to do so. ${ }^{93}$ Freud omits that these self-projection techniques are mutually exclusive from others: Meatyard, when presenting the blurred girl alongside the masked figure in our previous example, employs shadow and spirits to portray the double. Similarly, the Surrealist Maurice Tabard's Hand and Woman (Main et femme) (1929) (Figure 17) contains references to more than one of Freud's listed means for self-projection: Tabard uses mirror-images, shadows, and spirits. Krauss argues the hooded man, who is positioned behind a woman hiding her face with the mirror, can rightly be interpreted as a reflection of her, one that is haunting and shaded..$^{94}$ Therefore, Meatyard's incorporation of shadows and masks, the meaning they exude, as well as his decision to rely on both at once are all gestures in line with the repertoire of Bretonian Surrealism.

There are, of course, overt dissimilarities between Meatyard's photographs and Surrealist photographs. In Meatyard's images that provoke the uncanny, children appear

\footnotetext{
${ }^{93}$ Freud, "The Uncanny," 142.

${ }^{94}$ Krauss, "Corpus Delicti," 82-4.
} 


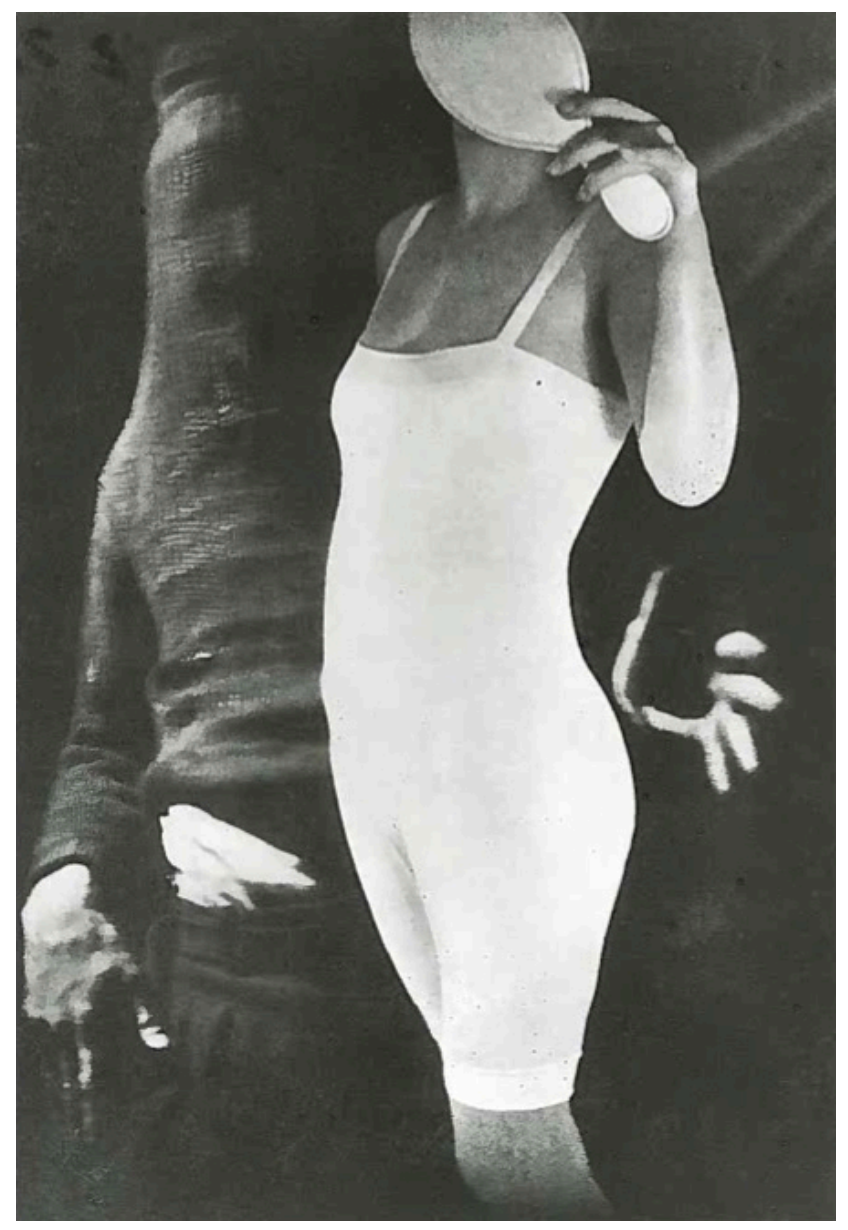

Figure 17. Maurice Tabard, Hand and Woman (Main et femme), 1929. Collection of Robert Shapazian, Fresno, California. 
more often than adults, and when adults do appear-like in the photographs with the fireplace or archway - they are typically obscured. On the other hand, Bellmer strictly incorporated doll parts in his photographs, and artists such as Tabard and Man Ray utilized adults as their models. This implies that Meatyard believed that the unconscious is best represented strictly through the depiction of children (before animism is repressed), while Surrealists, as exemplified by the artists mentioned here, were more likely to render their subject matter through the presentation of adults. Moreover, some Surrealists, as will be discussed in the next chapter, sought to exhibit the physical world as a coded reality. In other words, photographers like Bellmer, for example, sought to disrupt the ways in which viewers perceive the objects and people occupying the same space as they. Meatyard's photographs do not necessarily share this same pursuit. Rather, Meatyard seems to be most concerned with capturing the moments when fantasy invades reality.

The constitution of Meatyard's photographs as objects with Surrealist motives relies on the assembly of explicit visual references to concepts such as the marvelous and convulsive beauty found in images of family, friends, and abandon spaces. Further, since Foster and Krauss contend that Surrealism is highly engaged with psychoanalysis, Meatyard's photographs would invariably contain allusions to Freud and the uncannyindeed, they do. Likewise, Meatyard made photographs that can be interpreted with other psychoanalytic theories, such as Laing's notion of the unembodied self. Let this section conclude with a return to Laing. Particularly, he expands his discussion of the unembodied self to offer what is at stake for someone who identifies as such as well as the consequences of possessing a high level of detachment to the physical world. 
An individual who perceives a split between their body and mind may experience a form of psychoticism wherein the body, being completely detached from the self, not only interacts more closely with others, but also is entirely in "the actual possession of others." ${ }^{95}$ This, Laing argues, can lead to a "fear of the loss of the "self," a type of anxiety fueled by a sense of helplessness comparable to the fear of castration. ${ }^{96}$ For an individual carrying the fear of castration, Laing states that "appearing to be castrated" functions as a mode of defense for warding off unwanted feelings. ${ }^{97}$ Both of these fears are evident in Untitled (Male nude in bathroom) (1970) (Figure 18), where a full nude stands next to an open toilet inside a bathroom. We can determine that their sex is male by their body type and exposed penis, but the combination of their hair and the mask they wear makes their gender identity less fluid — with clothes on, this figure could presumably be female. Our viewpoint is positioned outside the bathroom in a hallway, as marked by the presence of a door and doorframe. The paint on the wall next to the toilet is coming undone, but otherwise this room is indicative of a house currently in use, a characteristic not held by many of Meatyard's preferred backdrops.

This photograph elucidates Laing's concept of the fear of the loss of self as well as his proposed method of countering the fear of castration. The fear of the loss of self is instigated when the body is felt to be an object owned by others through a series of outward acts of adherence and expectation. If not for the stark nudity of the figure, their identity would remain ambiguous. Outside of the private space of the bathroom, their

\footnotetext{
${ }^{95}$ Laing, "Psychotic developments," 144.

${ }^{96}$ Laing, "Psychotic developments," 149.

${ }^{97}$ The most useful way of appearing to be castrated is by pretending not to be, Laing says. Ibid.
} 


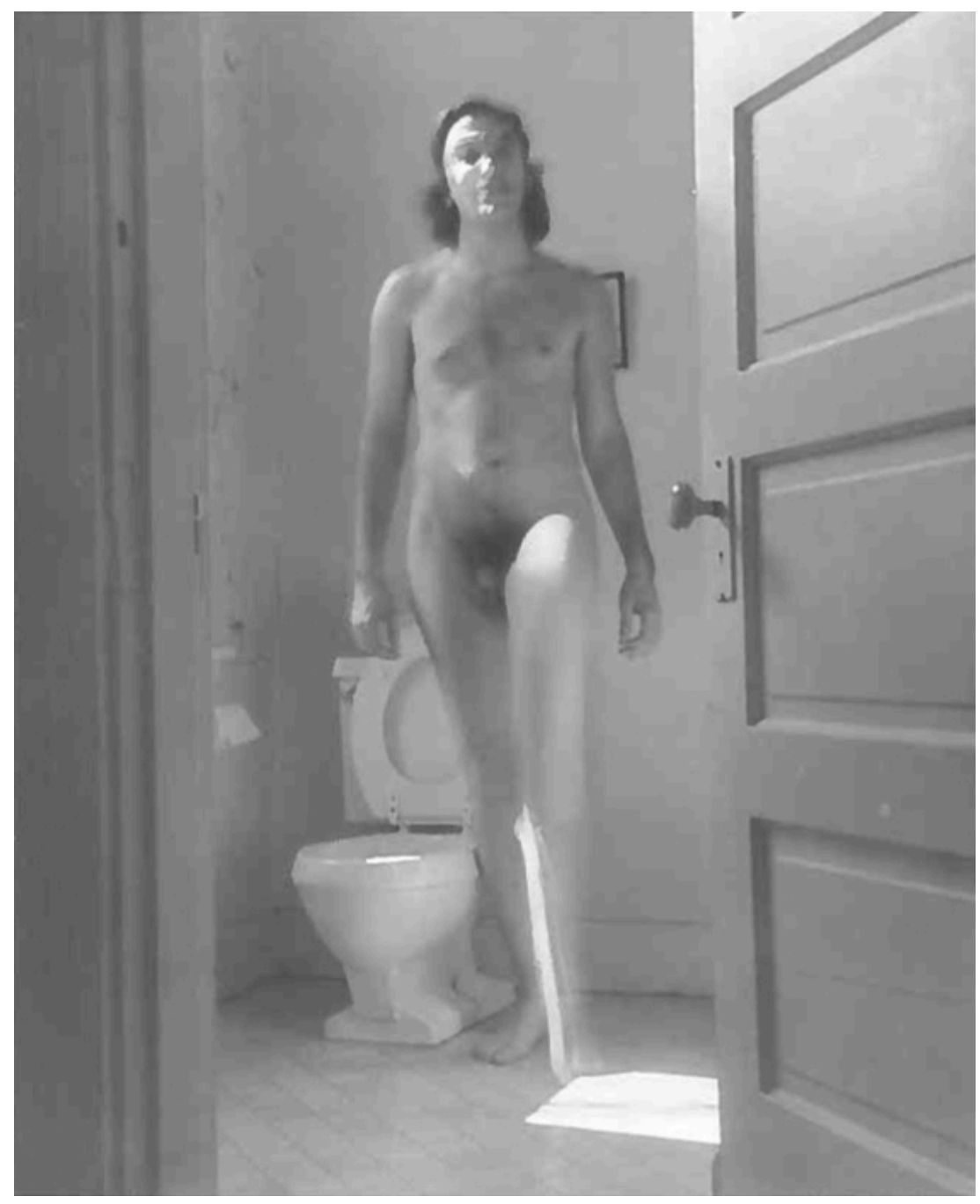

Figure 18. Ralph Eugene Meatyard, Untitled (Male nude in bathroom), 1970, gelatin silver print, $11 \frac{1}{16}$ x $9 \frac{1}{1} 16$ ". Copyright Estate of Ralph Eugene Meatyard. 
body offers a site for others to prescribe meaning, for the leg of the figure steps into the light shone through the window - the light from the outside world — and becomes blurred and indeterminate. When directly illuminated with sunlight, the leg (as well as the rest of the body) would disappear entirely, completing the losing one's sense of self. This photograph seems to capture the shell that holds the unembodied self, a shell more in the service of others than of the mind it bears.

The anxiety emitted by the fear of the loss of self is similar to that of the fear of castration, which Laing says can be repelled by pretending to already be castrated. This is portrayed in Meatyard's photograph as well. ${ }^{98}$ By wearing a mask, it remains uncertain that a male is behind the mask-indeed, the figure could be a woman. This, of course, would produce the illusion that they are always already castrated; so long as they are wearing clothing that would support this façade. This reading would be one of the uncanny, for we know that Freud's concept derives from "The Sandman" and its allusions to the castration complex. ${ }^{99}$ So the fear of the loss of self-much like Krauss' discussion of the fear of death—can be linked to fears of the uncanny. It can be concluded, then, that Meatyard's photographs of dolls, shadows, as well as masked and transparent figures, provoke the uncanny by rendering properties of the unembodied self, drawing comparisons to the strategies employed by Bretonian Surrealists. But it is Meatyard's use of children that ultimately invokes the uncanny and simultaneously distinguishes him from the Surrealists discussed here, who employed adults as models in

\footnotetext{
${ }^{98}$ It should be cleared that Laing speaks of the loss of self as a fear held exclusively by the unembodied self, whereas the fear of castration is a primordial fear. In psychoanalytic terms, the loss of self is a psychotic fear and the fear of castration is a neurotic fear. Here, Meatyard's photograph can be framed as either at once, not both simultaneously.

${ }^{99}$ Freud, “The Uncanny,” 140.
} 
their photographs. It is as if Meatyard, in parallel to Freud, believed that childhood is a phase when ghosts, spirits, and shadows are befriended, and adulthood is partially marked by the impossibility of these apparitions to enter daily life. In depicting particular aspects of Freud's concept of the uncanny in his photographs, Meatyard provides adult viewers with brief returns to a childlike state. 


\section{REFLECTIVE AND FRAGMENTED: MEATYARD AND THE INSTABILITY OF IDENTITY}

There are certain incongruities in characterizing Meatyard as a late Surrealist. For one, the Surrealists - particularly, Bretonian Surrealists-were working in Europe during the early decades of the 1900s. Meatyard, by contrast, began photographing in 1950, only making images until his death in 1972. In this sense, Meatyard is an epilogue of sorts for the trajectory of Surrealism, not necessarily a pure extension. But his creative endeavors affirm that the exploration of identity and subject formation did not end with the Surrealism movement, nor is the depiction of identity formation limited to Surrealist representational strategies. Meatyard was one of many artists in America probing photography's connection to identity during the twentieth century after Surrealism had concluded. His education as a photographer enabled him to create images that examine the psychological nature of family; Meatyard's work maintains congruencies with photographs by other Americans who were also invested in identity as subject matter. Surrealism may have provided groundwork for depicting the nature of identity, but some artists, including Meatyard, sought to expand on what the movement had established.

As discussed in chapter two, Surrealists like Hans Bellmer created photographs that alluded to "The Uncanny." Recall that Bellmer's Poupées incite the castration complex with the presentation of reconstructed dolls, especially through the use of double exposures. At the same time, Bellmer's photographs, such as Doll (La Poupée) (1936/49) 
(Figure 19) implicate aspects of Bretonian Surrealism—specifically the concept of the double. Rosalind Krauss explains that the double is a formal strategy that assists in recording reality as a set of encounters with material that operate as visual codes determining our behavior, activity, and internal conditions. In other words, the Surrealists understood the physical world as a linguistic system that is able to "signify" reality rather than function as the object of signification. ${ }^{100}$ Doubling acts as the "signifier of signification," that is to say, the double is a way of signaling meaning as such through the presentation of difference. Unlike other methods of rendering reality as coded, the double could exist in a single unitary image, thereby strengthening its connection to the world from which a photograph is taken. ${ }^{101}$ Doll (La Poupée) contains two identical legs of a doll (each a mirror image) placed side-by-side in front of a tree whose two limbs extend from the trunk at nearly the same angle out of the frame, thus functioning as an additional double. Here, the tree - a natural object in the physical world — provides a connection to reality for the artificially constructed doll legs, which operate as indicators of meaning by being unnatural. The combination of the tree and doll legs can be devised as a metaphor for photography itself: a photograph is a fabrication dependent on a narrow selection from reality, which aims to impose meaning on the physical world.

\footnotetext{
${ }^{100}$ Rosalind Krauss, "Photography in the Service of Surrealism," in L'amour Fou, 28-31.

${ }^{101}$ Surrealists initially used photo-collage to produce a "language effect" by presenting multiple images at once with sections of blank paper left visible between them. This technique interrupts the sequentially of time and space to produce signification, but relies on multiple images to do so. The Surrealists searched for other modes of producing the effects of photo-collage, albeit with a single image. The double, they discovered, was the means for doing so. Ibid.
} 


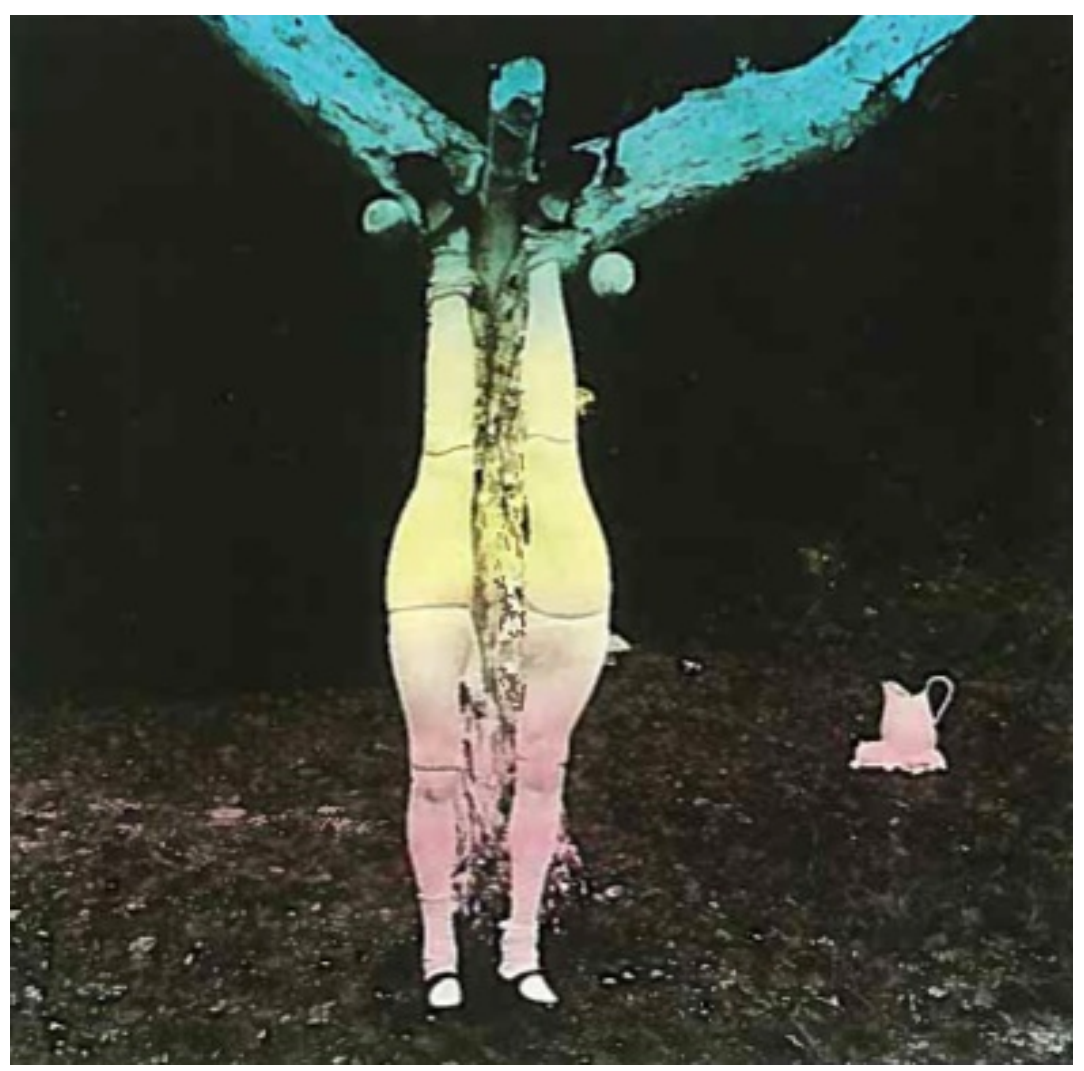

Figure 19. Hans Bellmer, Doll (La Poupée), 1936/1949. Musée National d'Art Moderne, Paris. 
For Krauss, photography's connection to the physical world and the presence of the double imply that a photograph is a fragment of reality "constituted as a sign."102 Particularly, Surrealist photography assumes that reality is representation and aims to render it as such. The double visually strengthens the presence of a coded reality. For Meatyard, masks and blurring techniques serve as variants of the double. Masks themselves are inherently doubles — a face worn over a face - and their inclusion in Meatyard's images, especially when worn by multiple people at once, draws a viewer's attention to differences in masks, bodies, and location. Romance (N.) from Ambrose Bierce \#3 (1962) (Figure 20) presents four masked figures seated on wooden bleachers that are marked in ascending value by row number (most of the rows contain their assigned number more than once, a kind of doubling itself). The masks deny viewers the ability to determine specifics about the figures' identities. Instead, the differences between bodies, posture, and pose serve as indicators of internal states. For example, the figure on the left, whose chins rests on their hand, could be in a moment of deep thought, but their mask is caught in anguish — the left eyeball is oozing out of its socket. Likewise, the figure lowest in the frame, with their legs spread wide and shoulders slouched, appears to be in a state of exhaustion. Yet the mask they wear depicts bulging eyes and a mouth agape. This mask, in opposition to the wearer's body language, is attentive and focused. The emotions of the masks in this image likely divert from the actual facial expressions of the seated figures. Here, masks are not only static barriers that generate a critical distance between subject and viewer, but they are also formal agents that highlight difference.

${ }^{102}$ Krauss, "Photography in the Service of Surrealism," 31. 


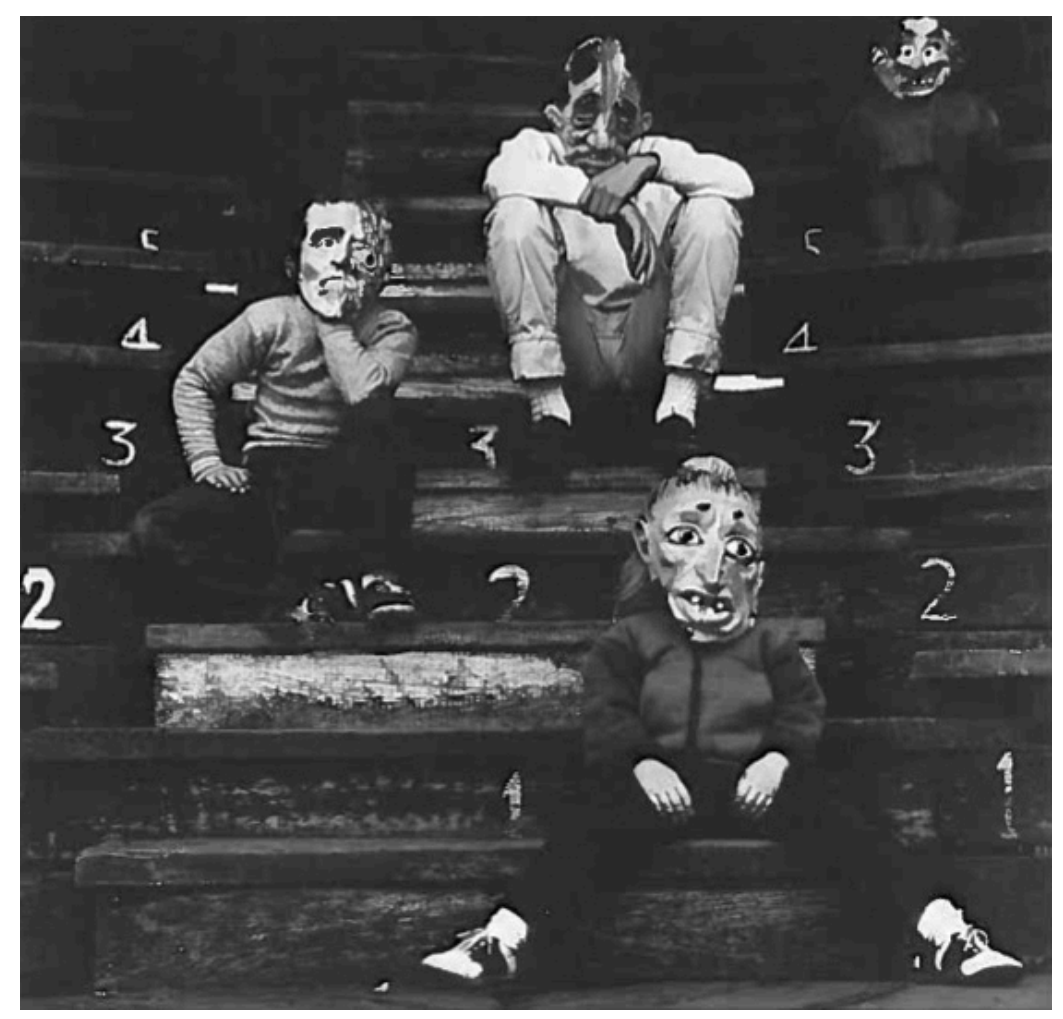

Figure 20. Ralph Eugene Meatyard, Romance (N.) from Ambrose Bierce \#3 (Masked children on numbered steps), 1962, gelatin silver print, $71 / 16 \times 7 \frac{3}{8}$ ". Copyright Estate of Ralph Eugene Meatyard. 
Doubling again prevails in an image of a young boy sitting on discarded newspaper in a disheveled room (Figure 21). The boy's face is blurred. Two different overlapping facial expressions can be determined: one where he looks towards the camera with intrigue, and another that catches him looking downward seemingly beat. The blur accentuates the ways in which the perception of childhood depends on visual indicators that protrude from a child's body. What's more, a pair of legs hang from the photograph's top edge, revealing an unidentifiable figure from the knees down. The legs initially seem identical, but a thorough inspection makes clear their differences: one foot rests higher than the other; one sock is pulled up the right leg while the other on the left leg is folded on itself; and one leg is diagonally slanted whereas the other is nearly vertical. The legs—-like Bellmer's tree—are the seated subject's connection to reality, for they are opaque and visually grounded, unlike the young boy whose face is not altogether coherent. So there are two doubles at play in this photograph: the legs serve as a link to the physical world for the boy, yet the differences in the two legs render the boy's connection to reality unstable, suggesting that adolescence can be erratic and intermittent.

Doubling is a vehicle in Surrealist photography as well as Meatyard's work. Meatyard, however, used doubling to address the instability of identity, whereas a photographer such as Bellmer employed doubling to address the constitution of reality as a whole. The use of the double as a representational tool, as Meatyard demonstrates, exceeds the parameters of Surrealism and informs the practices of other twentieth century photographers. Notably, Duane Michals is an artist who began photographing as early as 1958 and continues to do so in the twenty-first century. Like Meatyard, Michals' figurative photographs, often charged with homoerotic overtones, not only depict those 


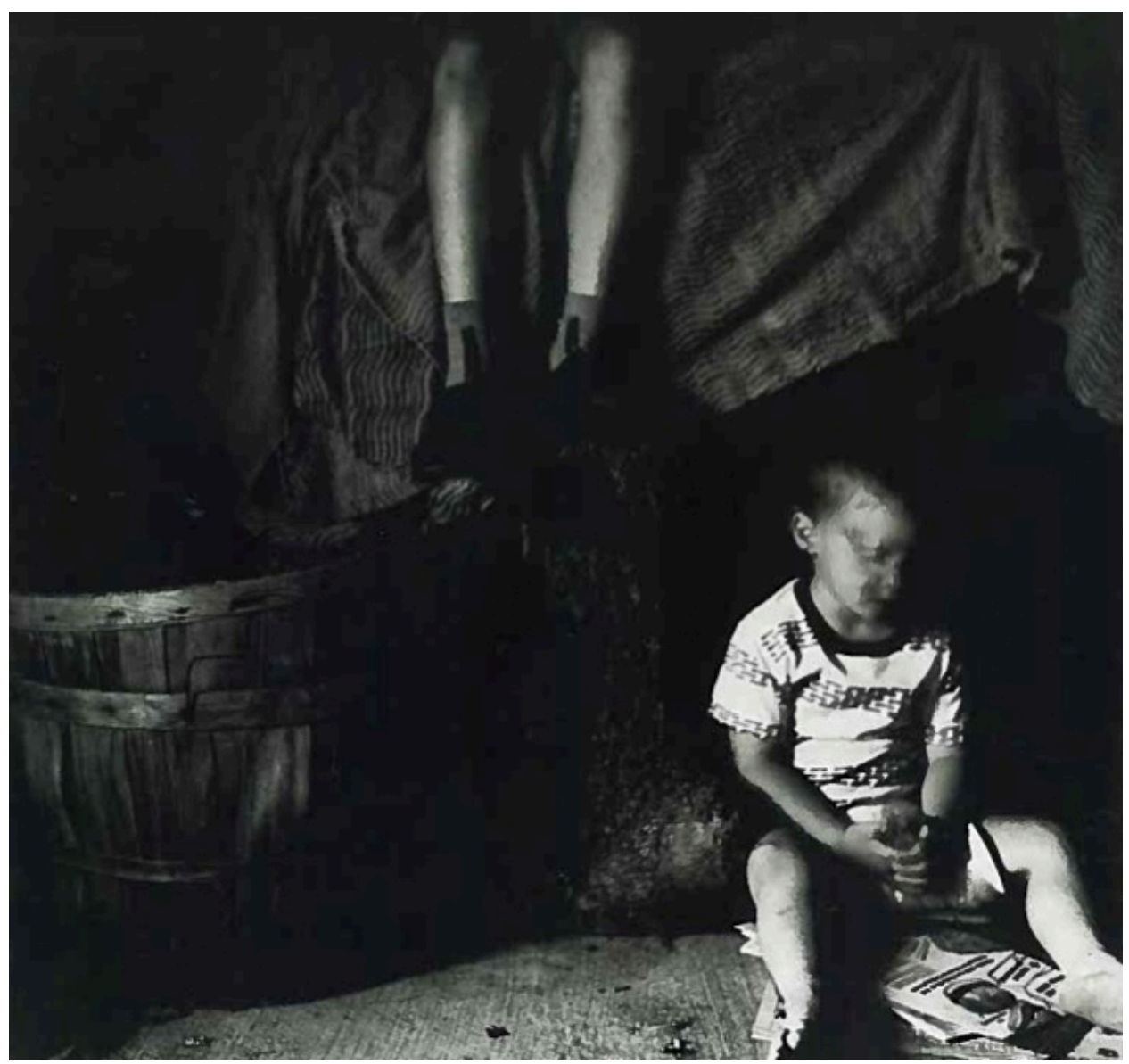

Figure 21. Ralph Eugene Meatyard, (title unknown), c. 1960, gelatin silver print. Copyright Estate of Ralph Eugene Meatyard. 
closest to him but also incorporate "notions of time, the imagination and the spirit... and an acceptance of mortality." ${ }^{103}$ Meatyard's photographs seldom carry overt themes of sexuality, but nonetheless his and Michals' images employ the double to address the instability of identity either in regard to childhood or sexual orientation, respectively. Michals' Now Becoming Then (1978) (Figure 22) incorporates the double by way of a single negative printed as a mirror image onto one sheet of paper. Two figures seem to be walking in opposite directions, split by a single vertical line that divides the frame. One figure's fingers hover a few inches from the line while the fingers of the other figure cross over it. Both are blurred in movement, but the directions they walk are indecipherable: "they are frozen, yet in motion; they are simultaneously appearing and disappearing; they are contradictory mirror images." 104 The doubling in Now Becoming Then is a marker of difference and contradiction as well as an indicator of temporal instability; Michals suggests as much in text written on the print itself, "When I say, 'This is now,' it immediately becomes then. It appears to us as a moment, but the moment itself is an illusion...It is a construction, an invention of the mind." This attention to difference functions similarly to the difference in body types and posture in Romance (N.) from Ambrose Bierce \#3. The physical states of the subjects in Meatyard's photograph imply that childhood is varied, unsettled, and, more importantly, difficult to classify. Moreover, both photographers deny their subjects singular identity (Meatyard with masks, Michals with mirror imaging), suggesting that individuality is indeterminate.

\footnotetext{
${ }^{103}$ Marco Livingston, “"The Sensual Duane Michals:' Photographer of Things Unseen,” in The Essential Duane Michals (London: Thames and Hudson, 1997), 10.

${ }^{104}$ Janis, Kozloff, and Weinberg, Vanishing Presence, 89.
} 


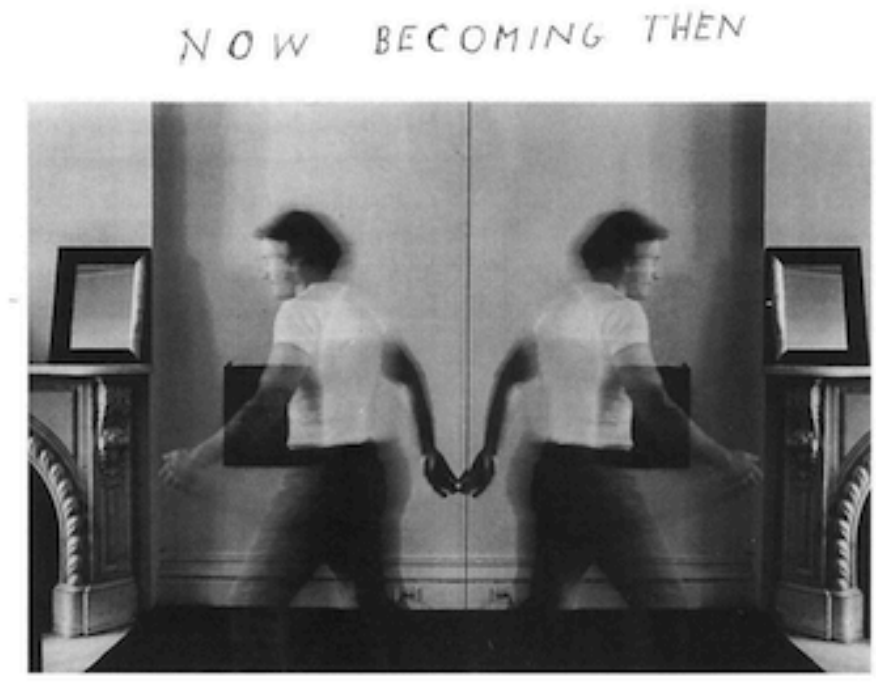

When I say this is now; it simediately becmes then. There is swo now. lt is and it ien't. To ne it appears ac a moneat, but that moneat is en illueion made up of a series of aloat. to bes and has heens. Their continuity suggesteren enent. Dut is fact it is an invertion, $a$ construction of the suind. The fasiclianity of the momeat mates it wivisibe. Oer liver are real dreams that have iven juat one moment, all at wae, now.

Figure 22. Duane Michals, Now Becoming Then, 1978, gelatin silver print, 8 x 10”. Courtesy Sidney Janis Gallery, New York. 
Michals employs the double again in A Story About a Story (1989) (Figure 23). By using mirrors, Michals captures his subject, a young male dressed in black holding his chin, in two ways: one in which the subject faces the camera and one in which viewers are able to see the backside of the subject's head. These two angles alternate in an unending loop that recedes out of the frame. The subject at once looks towards the camera and at himself. In this image, the double draws attention to difference in a similar sense to Meatyard's photograph of the boy sitting on newspaper: we recognize changes in the two versions of the same figure that insinuate an emotional imbalance. In A Story About a Story, the figure simultaneously focuses on himself and the world around him. In both Meatyard's and Michals' examples, doubling emphasizes that subject formation is fleeting and indefinite. Likewise, the photographs they have created represent the evolution of certain Surrealist tactics.

Both photographers explore the notion of identity by experimenting with the camera's capabilities: Meatyard with blurring techniques and Michals with inserting a mirror into the frame. Jacques Lacan, the mid-twentieth century psychoanalysist who critically analyzed Freud's theories using a Structuralist perspective, argues that a person's relationship to themself, and to the world of others, is constructed during the early phases of life by their encounter with and cognizance of their own image, what he calls the "mirror stage." Indeed, the mirror is a device that reflects oneself back at them, prompting a "transformation that takes place in the subject when he assumes an 


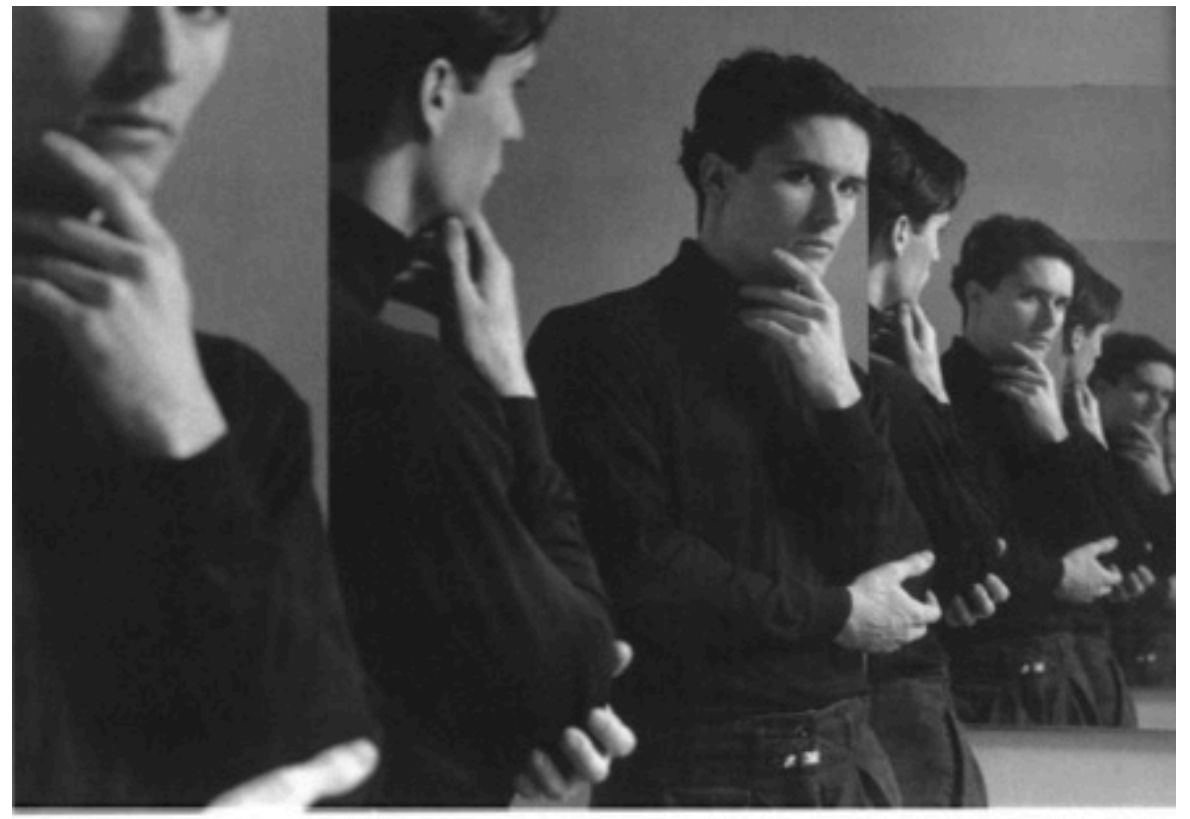

A STORY ABOUT A STORY

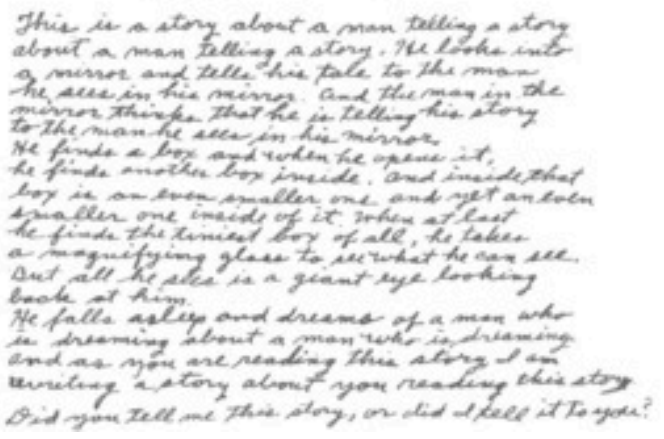

Figure 23. Duane Michals, A Story About a Story, 1989, gelatin silver print. Copyright Duane Michals, 1990. 
image. ${ }^{105}$ Lacan contends that one's perception of reality is built upon the experiences had during the mirror stage. As a result, we are always in negotiation with the ontological state of our bodies and what we know about ourselves from seeing our reflections. The mirror stage, however, is not entirely dependent on a literal encounter with a mirror-it is an event that occurs from the age of six to eighteen months in a person's life. ${ }^{106}$ What should be taken at face value in regard to Lacan's theory is that the mirror stage is a "psychic or ontological operation through which a human being is made by means of identification with his fellow-being." ${ }^{107}$ The "fellow-being," in this case, is that image of one's own self constructed in an infantile mind. Here, the mirror is largely a metaphor, but it is nonetheless a useful device for thinking about identity formation as well as the photographs of Meatyard and Michals.

Michals' Story About a Story echoes Lacan's concept in a never-ending loop in which it becomes difficult to distinguish the subject, who is planted in the physical world, from their reflection. The man holding his chin sees himself in a way he never could without the use of a mirror, therefore providing him with an image of those physical characteristics of his body that help determine his own sense of self. If he moves, the

${ }^{105}$ Lacan uses the term imago to describe the image of ourselves we see in a mirror. Briefly, the imago is a kind of shadow that follows us in our daily lives via reflective surfaces. Sometimes we look upon the imago in full, at other times we only get a glimpse of it in our peripheries. Nevertheless, it is always present. Jacques Lacan, "The Mirror Stage as Formative of the Function of I as Revealed in Psychoanalytic Experience," in Écrits: A Selection, trans. Alan Sheridan (New York: W.W. Norton and Company, 1977), 2.

${ }^{106}$ Lacan, "The Mirror Stage as Formative of the Function of I as Revealed in Psychoanalytic Experience," 1-2.

${ }^{107}$ Elisabeth Roudinesco, "The Mirror Stage: An Obliterated Archive," in The Cambridge Companion to Lacan, ed. Jean-Michel Rabaté (Cambridge: Cambridge University Press, 2003), 29. 
image of himself shifts and what he thought he knew of his body is disrupted. Equally, Now Becoming Then suggests that a mirror image hardly insinuates sameness and instead creates a series of differences that, when pieced together, form a full sense of identity for an individual, which may in fact be very different from the person who exists in the physical world. In Now Becoming Then, the vertical line functions as a threshold dividing the separate figures that is ultimately crossed by the hand of the figure on the right. Lacan argues "the mirror-image would seem to be the threshold of the visible world." ${ }^{108}$ This passage helps to frame the dividing line in Now Becoming Then as a representation of reflectivity. In this reading, Michals insinuates that a reflection is capable of penetrating reality to mold identity.

Similarly, Meatyard's photographs insist that the formation of identity is dependent on the perception of self-image. Masks, as well as his claims on the function of masks in his photographs mentioned in previous chapters, represent the ways in which photographs are tools for constructing and maintaining identity. For the static mask is a surrogate for the face donning the same smile or expression each time it is photographed, thereby letting viewers easily determine whom they look upon in a family photograph. Since Meatyard believed that masks strip wearers of their individuality, it can be inferred that masks operate as mirrors for viewers (remember that Lucybelle Crater is everybody). It is apparent Meatyard understood that photography is popularly regarded as a means for stabilizing identity, yet the breaks and disruptions he incorporated into his images reflect his position that a photograph—like Lacan's mirror stage—only provides subjects and viewers (who are often the same) with images of themselves.

${ }^{108}$ Lacan, "The Mirror Stage as Formative of the Function of I as Revealed in Psychoanalytic Experience," 3. 
Meatyard's dedication to experimental forms of photography was partially propelled by his distaste for documentary photography. He distinguished his work from documentary by capturing events he deliberately staged; the gesture is a constant in many of his bodies of work and series. ${ }^{109}$ Staging photographs was a form of subversion intensified by Meatyard's inclusion in the Lexington Camera Club and learning under club leader Van Deren Coke. Coke, a native Lexingtonian who had travelled across the country seeking mentorship from American photographers including Ansel Adams and Edward Weston, insisted on a photographic process that began by selecting a background before inserting objects or models, thereby building scenes to be photographed rather than shooting fragments from the real world. ${ }^{110}$ Staging compositions in front of chosen backgrounds is a practice that permeates Meatyard's images. He regularly used certain settings - an abandoned barn or the former estate of Cassius Clay—as backdrops. Meatyard and Coke strongly commended each other's work and regularly described their interactions: In 1968, Meatyard wrote about how they often worked jointly, either one "leading the other."111 Meatyard, however, eventually surpassed Coke as the leader of the Lexington Camera Club and perhaps as a photographer altogether during the mid1950s. ${ }^{112}$ Still, there are striking parallels between the Meatyard's and Coke's

\footnotetext{
${ }^{109}$ For example, Meatyard produced a series of abstract photographs that capture beams of light filtered through blocks of frozen ice that Meatyard made by freezing water in glass bowls.

${ }^{110}$ Ralph Eugene Meatyard, "Remembering F.v.d.C.," Kentucky Review (Autumn 1968), 49-51.

${ }^{111}$ Meatyard, "Remembering F.v.d.C.," 49.

${ }^{112}$ See Brian Sholis, “Assembly Required,” 10-1.
} 
photographs, so much so that their techniques may have mutually benefitted from each other. During Meatyard's lifetime, curators and critics took note of how the personal relationship between the two photographers translated into the images they made, as they were featured in exhibitions together in Lexington and beyond. This included a twoperson exhibition during 1956-7 at New York's A Photographer's Gallery that paired Coke's photographs of nature with Meatyard's abstracted works. This exhibition garnered a review in the New York Times that highlighted the differences in their photographic styles. ${ }^{113}$ Yet if the figurative photographs by each artist are juxtaposed, it is clear that there is a large degree of propinquity in regard to their subject matter. Like Meatyard, Coke was a photographer who made works that render identity as ambiguous and enigmatic. But Coke did not incorporate the double to the extent that Meatyard (or Michals) did. Instead, Coke and Meatyard draw comparisons in the use of props and ability to depict their subjects as transparent.

Of the many props Meatyard inserted into his compositions, dolls seem to be some of his more preferred items, as he would situate them alongside humans, animal carcasses, or antique domestic objects (Figure 24). In this vein, Meatyard recognized and intended to maintain a doll's connection to the home and its status as an index of childhood, and thereby marker of ephemerality. Coke, who lived in multiple locations during his life, ${ }^{114}$ also made images evoking themes of time and death: he sought dead

${ }^{113}$ Jacob Deschin, “Two-Man Exhibition,” New York Times, January 6, 1957.

${ }^{114}$ Coke was born in Lexington, KY, earned an MFA in Indiana, was a college professor in Florida, headed the department of photography at the San Francisco Museum of Modern Art, and was the founding director of the University of New Mexico Art Museum. He died in 2004 in Santa Fe. 


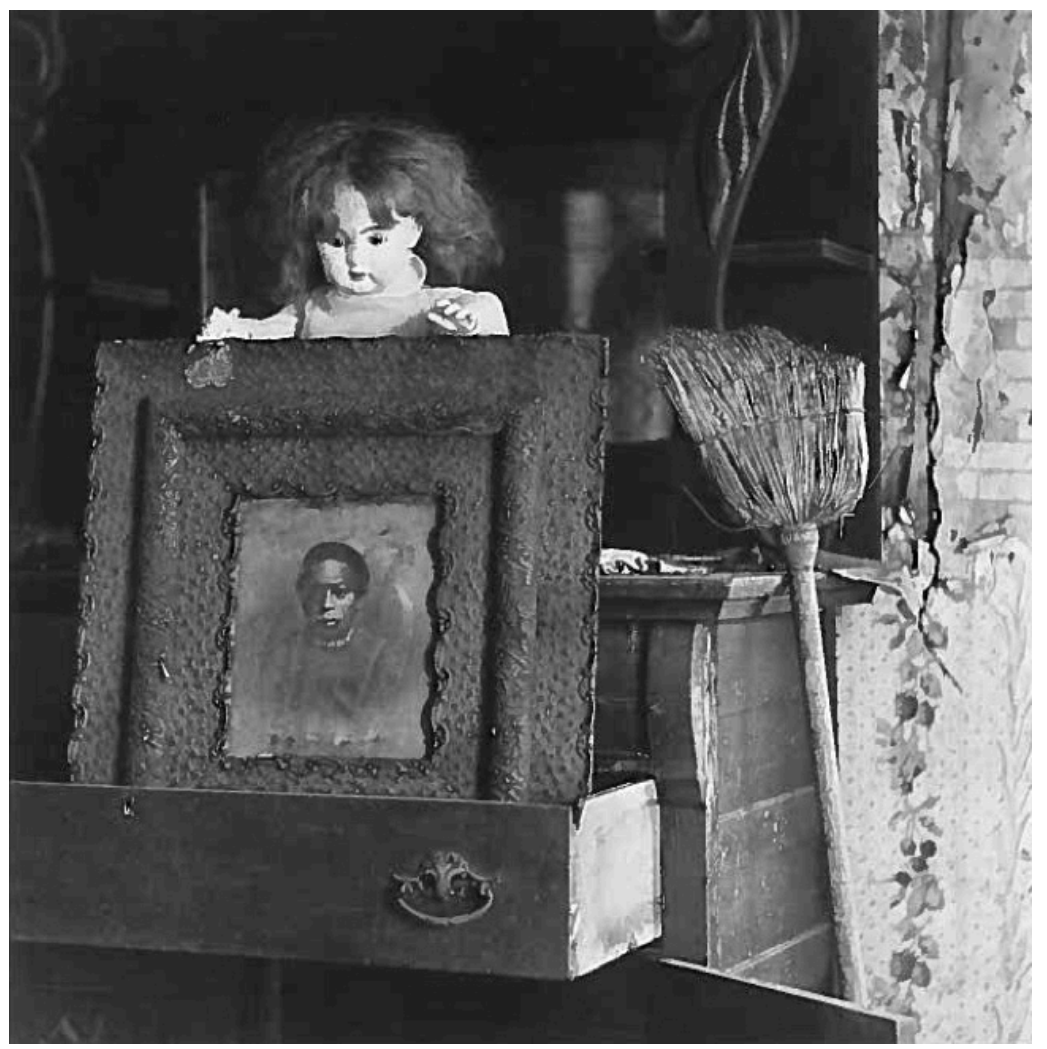

Figure 24. Ralph Eugene Meatyard, Untitled (Still life: doll atop photo), 1961, gelatin silver print, 7 1/4 x 7 1/8”. Copyright Estate of Ralph Eugene Meatyard. 
animals, antiques, and dolls as subjects. ${ }^{115}$ The Witnesses (1959/1966) (Figure 25)

contains a young girl cupping a small rodent in her hands; she is positioned under seventeen dolls each dangling from a thread as if they had been violently hung by the neck. A predominant wash of grey tones dominates the frame and visually divides the girl and the dolls, an effect Coke likely achieved by either brushing development fluids onto the print in the darkroom or by dodging and burning techniques. To the girl's left are two other dolls standing side-by-side placed between silhouettes of horned figuresrepresentations of the devil. The dolls are an eclectic group: medieval knights and monarchs, Western outlaws, Napoleonic soldiers, and twentieth century nuns and monks, all meeting the same fate.

The Witnesses can be interpreted in a similar manner as Meatyard's image of the young girl and masked figures in which she engages in an act of self-projection. The subject in Coke's photograph, a girl some years older than the one in Meatyard's, focuses on what she holds and not on her environment, just as the young girl in Untitled (Group of children with dolls and masks) concentrates on an indistinguishable item. Instead of being accompanied by a lively group of masks, however, Coke's figure resides in solace; the dolls that may have entertained her previously are now, quite literally, lifeless. Meatyard's photograph represents the developmental stage when fantasy can become reality while The Witnesses captures the preceding stage when animistic thinking is surmounted.

\footnotetext{
${ }^{115}$ See Gerald Nordland, "Introduction," in Van Deren Coke: Photographs, 1956-1973, Van Deren Coke and Gerald Nordland, exh. cat. (Albuquerque: University of New Mexico Press and Van Deren Coke, 1973).
} 


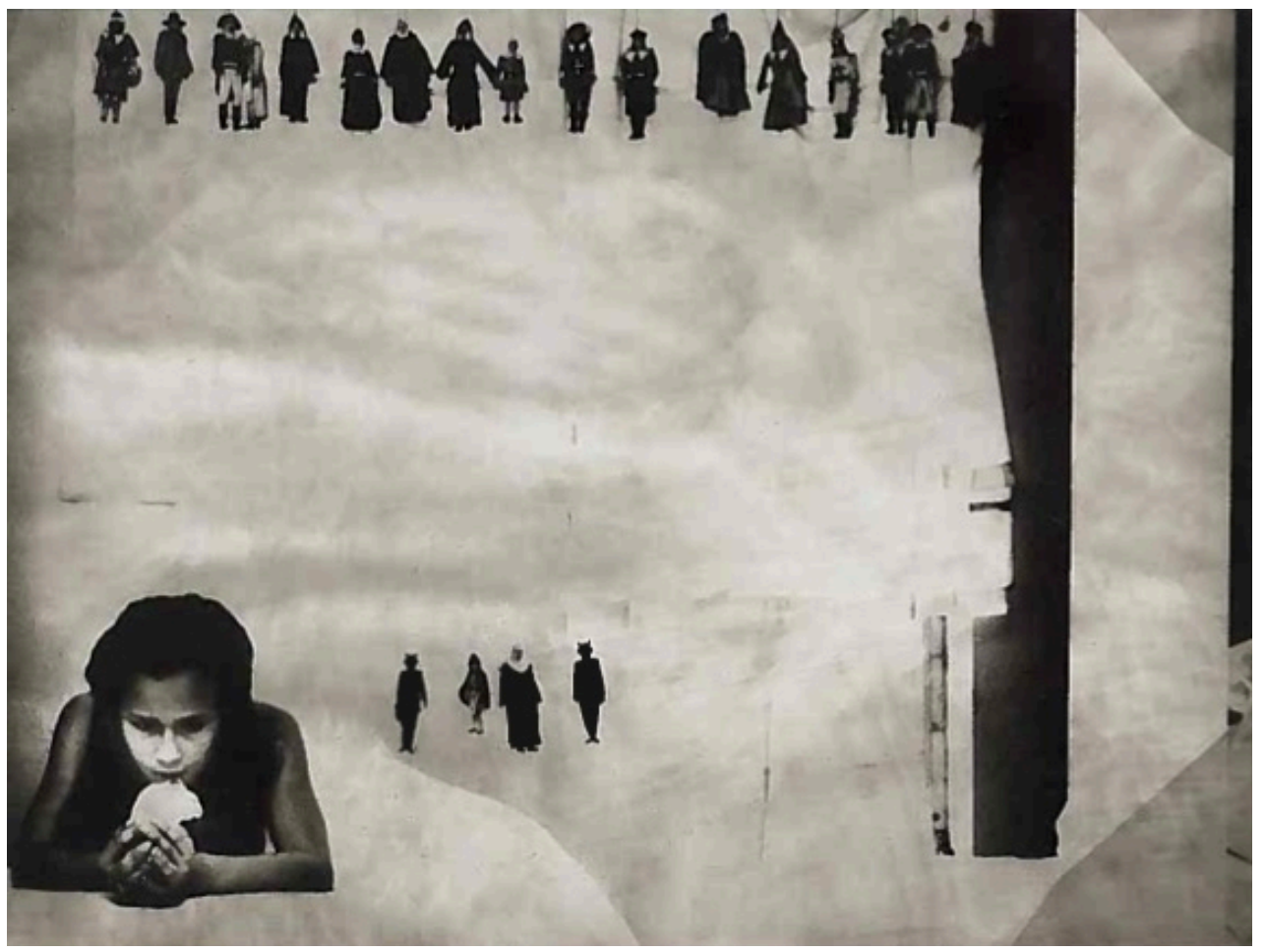

Figure 25. Van Deren Coke, The Witnesses, 1959/1966. Courtesy Arizona State University Art Museum. 
It is the dolls in both photographs that allow us to view the images in this sequential mode, and it is the dolls by which we can gain a sense of how Meatyard's and Coke's perspectives of childhood, identity, and death overlap. In Untitled (Group of children with dolls and masks), the dolls are agents for understanding the self. Here, the dolls are not only the girl's toys, but they are also aids for her self-image. Yet the figures they generate - the ones that may provoke the uncanny for adults — are ghoulish, unidentifiable, and partially metaphysical. It is as if Meatyard is offering a view of childhood that is not innocent nor pure but rather devious and abrasive. Coke's The Witnesses plausibly echoes this outlook, for the girl shows no concern for the dolls hanging above her: we can assume that she hung each one-by-one-a tedious process, indeed. She has surmounted animism through violence and looks upon the rodent as her next victim, knowing that killing it would surely rob it of the very thing the dolls lacklife. The dolls in Untitled and The Witnesses are markers of the progression of subject formation, and both photographs explore those stages of life when the perception of self fluctuates between associating with one's own body and inanimate objects.

Coke's intrigue of death and temporality is exemplified in Recollections of Malvern Hill (1970) (Figure 26), a multiple exposure photograph depicting no less than three figures — one of which is accompanied by a large dog — all sitting in chairs on a seemingly congruent grassy plot. Practically everything in the image is transparent, and a sense of incoherence prevails throughout the scene as Coke utilizes nearby walls and architecture to accentuate geometric patterns within the featured landscapes. Memory and loneliness are departure points here: the entire composition stresses ephemerality, and the 


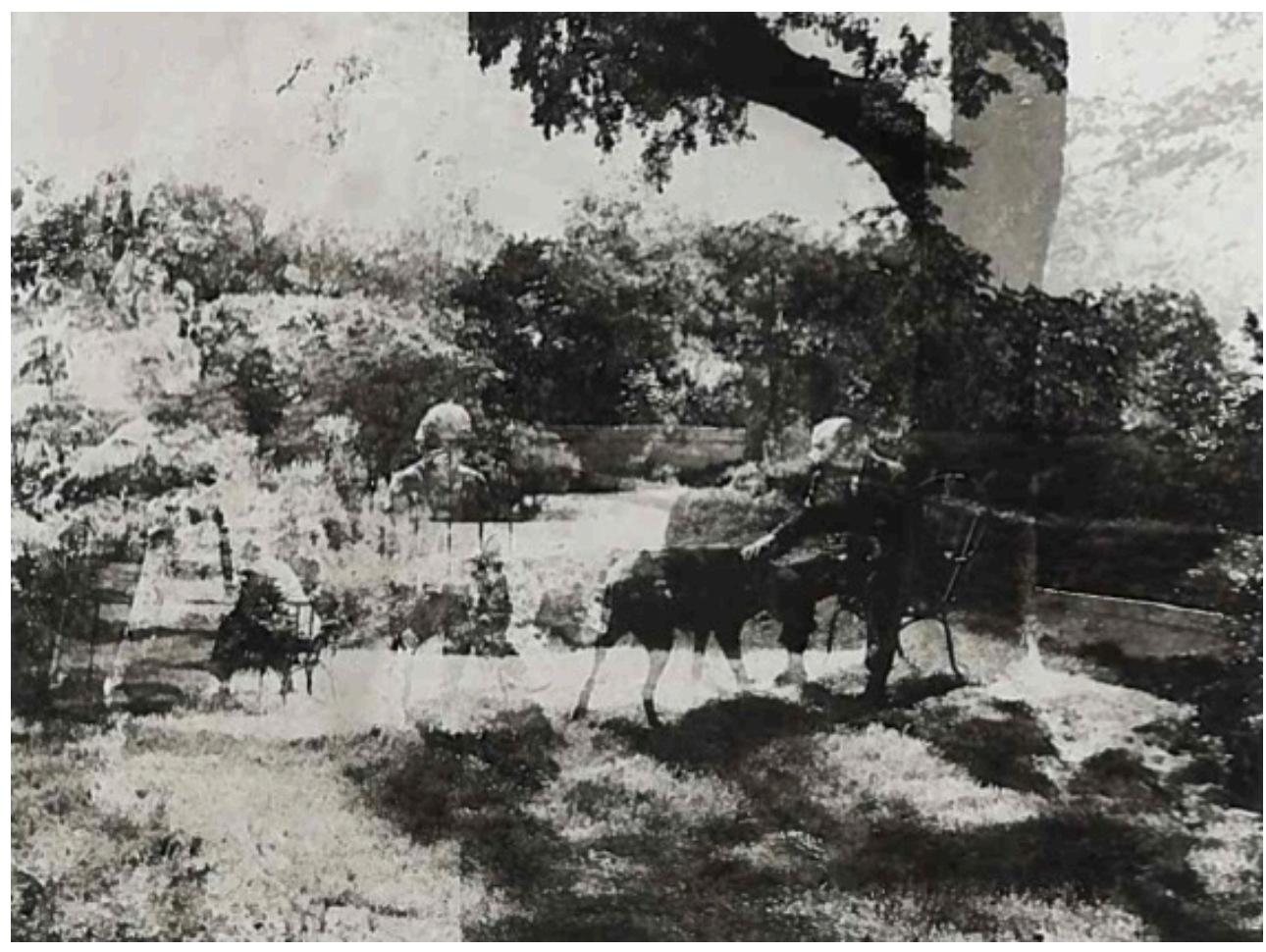

Figure 26. Van Deren Coke, Recollections of Malvern Hill, 1970. 
varying degrees of the figures' transparency separate them into distinct, individual realms.

There are certain parallels to Meatyard's photographs at play in Recollections of Malvern Hill. Coke achieves a ghostliness of his subjects to address death, physicality, and the possibility of life continuing after one's body fails in a manner similar to how Meatyard approaches these topics in his photograph of the two transparent figures and the fireplace between them. Coke, however, uses a multiple exposure in Recollections of Malvern Hill, whereas Meatyard prolonged the camera's exposure time to depict his figures as ghosts. In any case, both techniques broach, as Henry Holmes Smith argued in describing Coke's photographs, the bluntness of death and the startling experience death can induce in seemingly pensive scenes. ${ }^{116}$ In addition, the contents of Coke's photographs mirror those of Meatyard's photographs that evoke the uncanny: the architecture, enclosed green-space, lawn-chairs, and dog imply that these figures are situated around a home. These components of the photograph and ghostly effects allow this example of Coke's to be categorized as the uncanny, as a depiction of the kind of repressed belief in the return of the dead. Recollections of Malvern Hill represents modes of thinking held by children whose identities are constructed by way of association with magical forces, such as the ghosts Coke depicts.

In making photographs, Coke was informed by dominant photographic techniques that persisted during the first half of the twentieth century. Before the age of twenty, Coke traveled to the West Coast to meet and study under Edward Weston, who then sent

\footnotetext{
${ }^{116}$ Henry Holmes Smith, "Van Deren Coke," in Van Deren Coke: Photographs, 19561973. Originally published in Photography 16:11 (November 1961).
} 
him to learn under Ansel Adams. ${ }^{117}$ Coke's familiarity with art photography would be beneficial for those who received his guidance in Lexington, including Meatyard. Coke taught Meatyard and others Adam's famed Zone System and presented them with prints by Weston. ${ }^{118}$ The relationship that Coke and Meatyard shared would lead the two photographers to joint ventures in their education as image-makers.

In 1956, Coke and Meatyard attended a three-week long photography workshop at Indiana University, where they took part in sessions learning under photographers such as Aaron Siskind and Minor White. ${ }^{119}$ There, White introduced Meatyard to Zen philosophy and literature, the teachings of which would inspire Meatyard's practice thereafter. At the workshop White emphasized ways in which photography's inherent properties contribute to a viewer's reading of a single photograph, and he led group critiques that often concluded with references to the formal aspects of the works presented. ${ }^{120}$ Meatyard's participation in this workshop enhanced his familiarity with the photographic process as

${ }^{117}$ Van Deren Coke became enamored by photography shortly after he graduated from boarding school in Virginia. Afterward, he joined the Lexington Camera Club and met Benjamin Hart, the club's mentor. Hart showed the club prints by Weston and others. These prints clearly had a profound effect on the young Coke, who then decided to travel westward. By 1944, Coke had met Alfred Stieglitz and Paul Strand as well. Grace Schaub, "Van Deren Coke," Photographer's Forum 14:3 (1992), 50-2.

${ }^{118}$ Sholis, “Assembly Required,” 7.

119 The workshop, organized by Henry Holmes Smith, held sessions on analytic methods of viewing photographs; experimental shooting techniques; and communal critiques; Sholis, "Assembly Required," 10.

${ }^{120}$ White allowed critiques to evolve into abstract discussions but would bring conversations to focus on a photograph's formal components. Henry Holmes Smith, "The Education of Picture Minded Photographers," Aperture 5:1 (1957): 24-8. 
well as how Zen can be incorporated into it-Meatyard's interest in Zen culminated in a body of work entitled "Zen Twigs.",121

White was introduced to Zen in 1953 shortly after to moving to Rochester, and his dedication to Zen was overt and apparent to those who knew him. ${ }^{122}$ However, there was a time when White was photographing without the guidance of Zen, before he moved on from "using the camera as a tool for self-discovery."123 Throughout existing literature on Meatyard, authors frequently mention Zen when discussing his time spent learning under White. Undeniably, the role of Zen in Meatyard's life is a significant one. But here I seek to draw a fresh comparison between figurative photographs by Meatyard and White made before the latter became acquainted with Zen.

As has been argued, blurring in Meatyard's photographs can serve as an indicator of the splitting of the self, either as a result of self-projection, the return of the deceased, or as an attempt to defend oneself from castration. Indeed, the blur signals a disruption of identity. White's Movement Studies Number 56 (1949) (Figure 27) employs blurring in a similar fashion. Here, we look downward on a staircase attached to the stark white wall of a building. The landing area it leads to connects to a perpendicular set of stairs moving

${ }^{121}$ Ibid. Meatyard's interest in Zen was maintained after the workshop at Indiana University partially due to his friendship with Thomas Merton, a well-known literary and religious figure of the mid twentieth century. Merton, who was friend of Zen scholar D.T. Suzuki, turned to Zen to help better his understanding of Christianity. Meatyard, interview with Nathalie Andrews, 1970.

122 To attain a sense of how White's interest in Zen permeated his teaching styles, relationships with others, and domestic habits, see Arnold Gassan et al., "Minor White as a Teacher," Aperture no. 95, Minor White: A Living Remembrance (Summer 1984).

${ }^{123}$ Paul Martineau, “'My Heart Laid Bare:' Photography, Transformation, and Transcendence," in Minor White: Manifestations of the Spirit, exh. cat. (Los Angeles: J. Paul Getty Museum, Los Angeles, 2014), 8. 


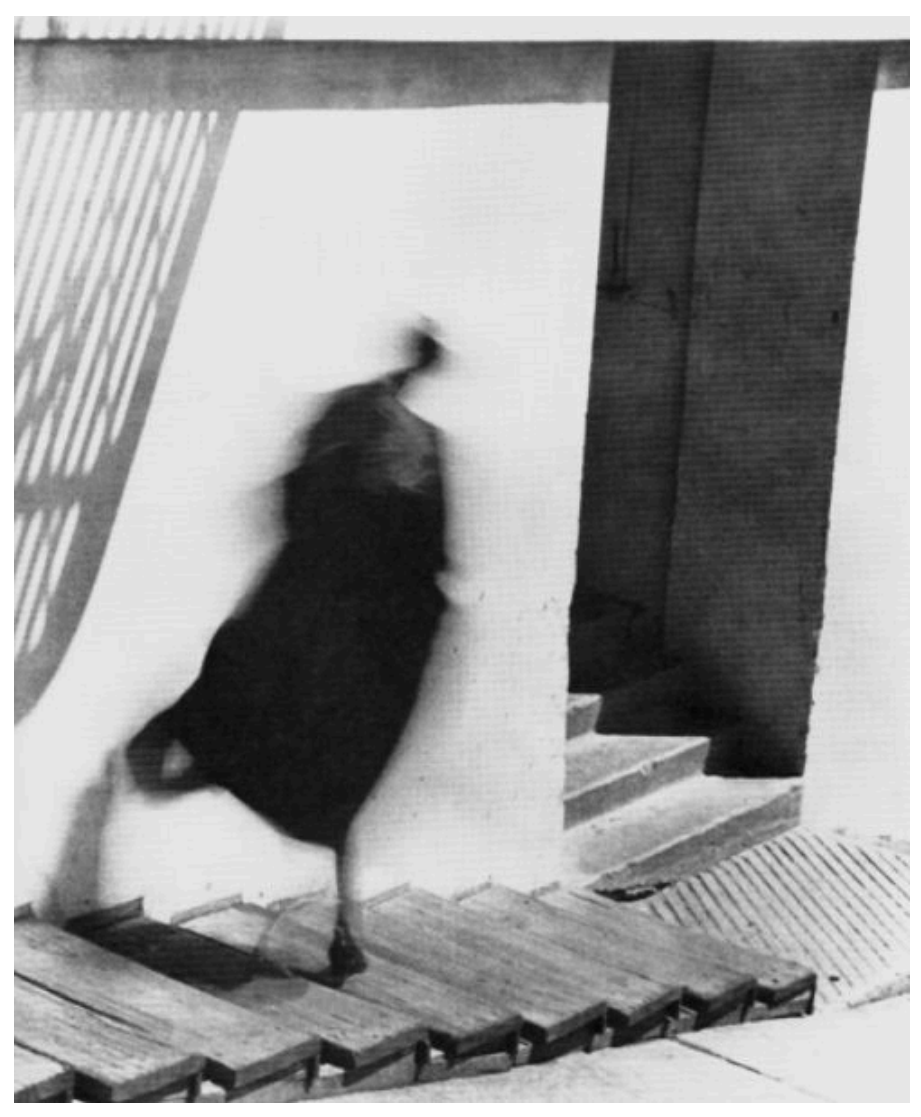

Figure 27. Minor White, Movement Studies Number 56, 1946. Courtesy The Minor White Archive, Princeton University Art Museum. Copyright Trustees of Princeton University. 
into a shadowed doorway that divides the wall into two sections. The primary focus of the image is a figure descending the visible staircase - they are completely in blur. Because the subject is wearing a large dark cloak or coat, we are denied specific details of his/her face, body type, gender, or age. Only a foot covered by a heeled shoe appears in focus. There are certain formal components at play here, too: diagonal lines populate areas of the photograph; heavy contrast separates interior spaces from exterior ones; and repetition helps to unify the composition.

Deborah Klochko argues that Movement Studies Number 56 is an example of the expressionistic "camera-as-brush concept" and only in passing does she consider the possibility that "the person is caught in the act of becoming someone else." ${ }^{\text {"124 }}$ Klochko stops short of what is also true about this photograph: the blur and formal qualities of Movement Studies Number 56 prompt an interpretation concerning identity that many of Meatyard's photographs elicit, such as Untitled (Male nude in bathroom). In Untitled (Male nude in bathroom), the light intruding the bathroom hits the figure's blurred leg, suggesting that the identity the figure assumes in public — and in the presence of othersdoes not coincide with their true sense of self. In White's image, the blurred figure makes his/her way to the staircase leading into the building, escaping the public space in which he/she currently resides. The doorway in White's photograph operates similarly to the window in Meatyard's - both are bridges between the public and the private, between the space where others claim ownership to another's identity and the space where the

${ }^{124}$ Klochko refers to the blur immediately after she likens the figure to the "pin-headed people of Henry Moore." The quote I have cited directly follows this sentence. Deborah Klochko, "A Visual Vocabulary: The Pedagogy of Minor White," in The Moment of Seeing: Minor White at the California School of Fine Arts, Stephanie Comer and Deborah Klochko, eds. (San Francisco: Chronicle Books, 2006), 93-4. 
unembodied self thrives. Each photographer accomplishes the separation of spaces with formal qualities of photography: Meatyard with light and White with depth. Blurring and formal components are tools for Meatyard and White in this comparison, but stronger overlaps of subject matter and technical approaches of the two photographers can be made. Specifically, when juxtaposing Meatyard's The Family Album of Lucybelle Crater and White's The Temptation of St. Anthony is Mirrors (1947-8) sequence.

The Temptations of St. Anthony is Mirrors consists of 32 individual portraits of Tom Murphy, a student who White mentored during his tenure at the California School of Fine Arts in San Francisco. In the majority of the images from the sequence Murphy is nude, often severed by White's strategic cropping techniques. Murphy's face is in full view in only eleven photographs; there is heavy concentration on his feet, hands, and genitalia throughout the sequence. Religious and classical iconography persist throughout, noticeably with the halo effect White achieves in one of the few close-ups of Murphy's head (Figure 28) as well as an allusion to the dead body of Christ (Figure 29), insinuating classical sculpture. ${ }^{125}$ Elemental undertones pervade the sequence, specifically with the inclusion of rocks and pieces of wood as props. In some photographs, rocks appear near Murphy's feet or he lays atop a rocky surface, clothed; in others, he stands on a wooden floor or is accompanied by a large piece of driftwood that, in some images, is wedged between his limbs (Figure 30). White bound the photographs in The Temptations of St. Anthony is Mirrors into a small book format, of which only two copies were made: one for White and the other for Murphy. Due to its overt motif of

\footnotetext{
${ }^{125}$ In addition to the history of classical art, Martineau notes that The Temptation of St. Anthony is Mirrors draws formal and stylistic comparisons to Stieglitz's modernist photographs of his wife, Georgia O'Keefe. Martineau, "My Heart Laid Bare," 8.
} 


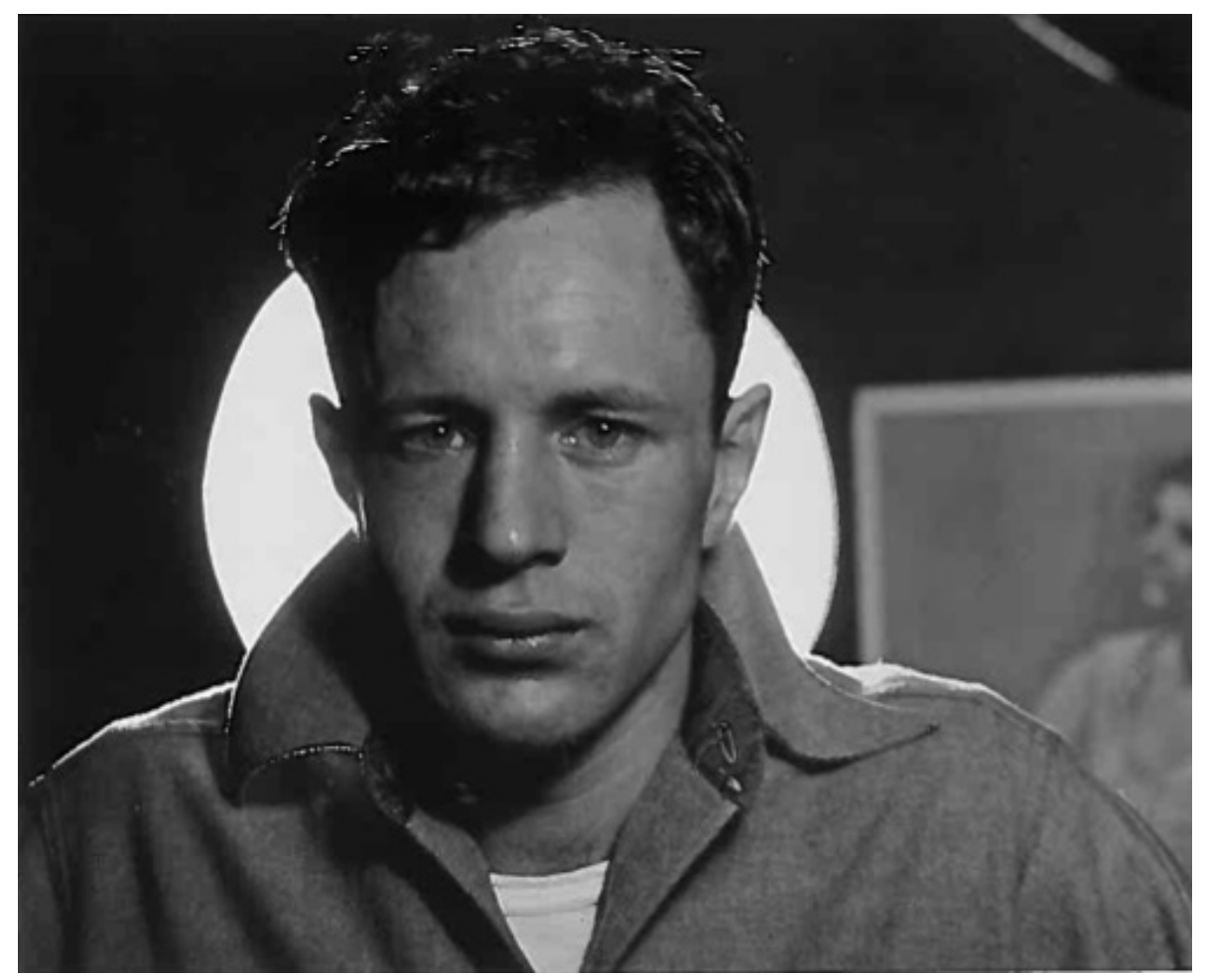

Figure 28. Minor White, Tom Murphy, San Francisco, from The Temptation of St. Anthony is Mirrors, 1948, gelatin silver print, $3 \frac{1}{2} 2$ x $4 \frac{5}{16}$ ". Courtesy the Minor White Archive, Princeton University. Copyright Trustees of Princeton University. 


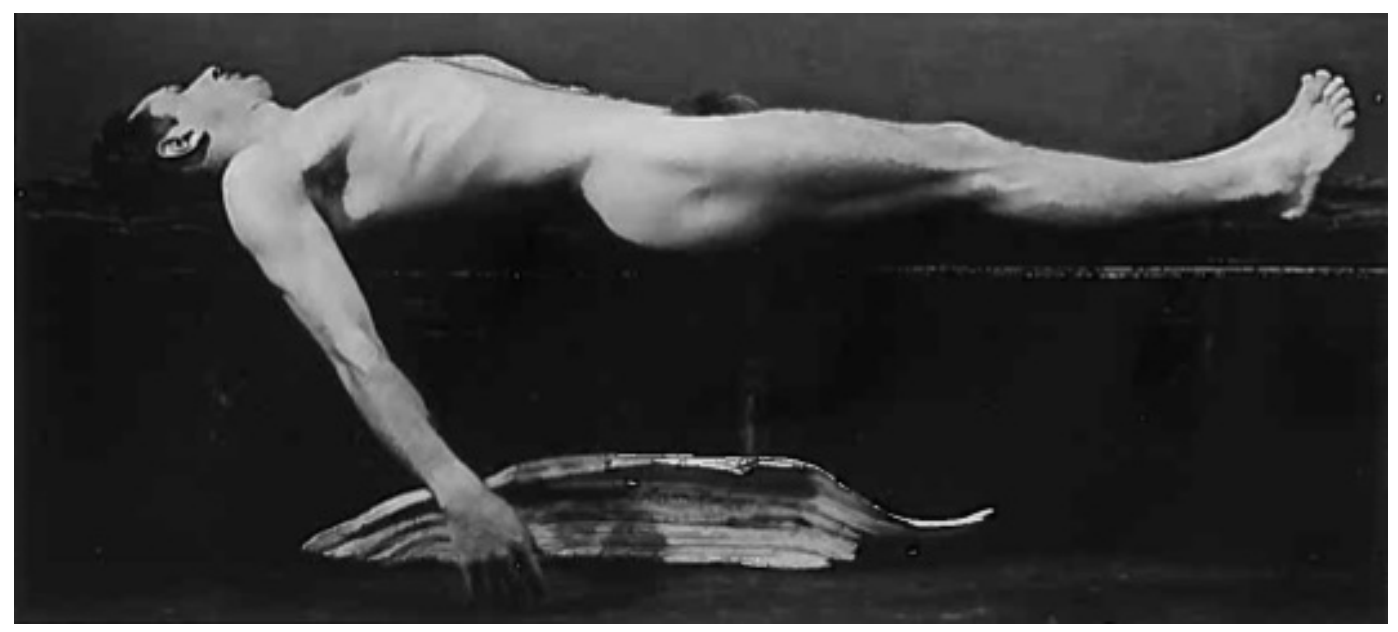

Figure 29. Minor White, Tom Murphy, San Francisco, from The Temptation of St. Anthony is Mirrors, 1947, gelatin silver print, $2 \frac{1}{16}$ x $4 \frac{5}{8}$ ". Courtesy the Minor White Archive, Princeton University. Copyright Trustees of Princeton University. 


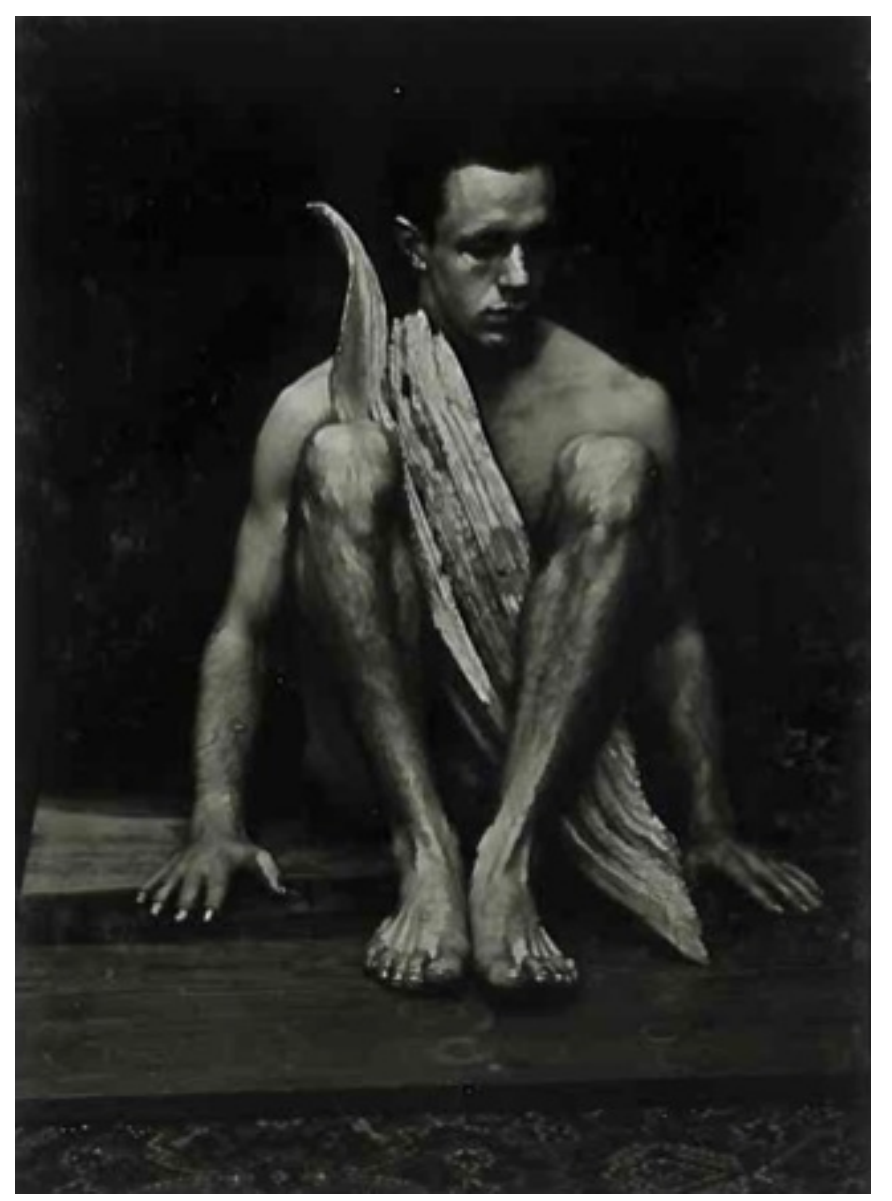

Figure 30. Minor White, Tom Murphy, San Francisco, from The Temptation of St. Anthony is Mirrors, 1947, gelatin silver print, $4 \% \frac{9}{16}$ x $3 \frac{5}{16}$ ". Courtesy the Minor White Archive, Princeton University. Copyright Trustees of Princeton University. 
homoeroticism, White never displayed the sequence in public. The first time the full sequence was published and exhibited was in 2015 in an exhibition at the J. Paul Getty Museum in Los Angeles and an accompanying catalogue. ${ }^{126}$

White frequently produced photographs that operate in a manner similar to Stieglitz's "equivalents," in that they are abstract images that invoke the inner-state of the photographer or the viewer via "designed-contained-meaning." 127 The notion of equivalence, for White, could be articulated through the exploration of mirroring, hence the title of the St. Anthony sequence. ${ }^{128}$ The Temptation of St. Anthony is Mirrors stands as an occasion for White to convey his identity as a homosexual male living during 1940s, a time when the public display of male frontal nudity was an illegal act—indeed, this sequence is an equivalent of White's own sense of self. ${ }^{129}$ But viewers should also read the photographs of Murphy as potential equivalents for themselves, as White's sequences intend to "guide the viewer to discoveries about themselves and the images they were meant to perceive in a larger context." ${ }^{\prime 130}$ The Temptation of St. Anthony is Mirrors is a representation of White's identity, but it also affords the viewer an opportunity to consider photography as a vehicle for the reflection of their identity. The Temptation of St. Anthony is Mirrors is similar to that of Meatyard's Lucybelle Crater

${ }^{126}$ Ibid.

${ }^{127}$ Andrew E. Hershberger, "The Time Between Photographs in Minor White's Sequences," in The Time Between: The Sequences of Minor White, Deborah Klochko and Andrew E. Hershberger, exh. cat. (San Francisco: Modernbook Editions and the Museum of Photographic Arts in San Diego, 2015), 7.

${ }^{128}$ Ibid.

${ }^{129}$ Martineau, "My Heart Laid Bare," 8.

${ }^{130}$ Deborah Klochko, “An Affinity of Exhibitions," in The Time Between, 24. 
project in that both bodies of work address identity through the presentation of each photographer's close companions in private spaces. Of course, White is exploring sexuality and Meatyard investigates the concept of family. Yet both projects embody photographic strategies of depicting identity that rely on subject fragmentation and concealment.

The Lucybelle Crater project disguises figures with masks, but Meatyard applies other forms of concealment, too. For example, the two figures standing on a front porch in LBC and Eastern Man's Friend, LBC (c. 1969-72) (Figure 31) are obscured by shadows from nearby trees as well as the shadow of (presumably) Meatyard himself. Moreover, a viewer's vision of Lucybelle Crater is mostly interrupted by the accompanying figure. All three people (Lucybelle Crater, her companion, and the photographer's shadow) form a congruent line, but none of their identities are apparent. In one photograph from the St. Anthony sequence, Murphy is seen kneeling in a nude silhouette (Figure 32). His arms cross over his body and his right hand clasps his left elbow. Murphy's full body appears in the image except for his neck and head. White has cropped his subject, transforming Murphy into an anonymous man. In a separate image, Murphy is clothed and reclining on a rocky terrain, but his left leg is outside the frame (Figure 33). White has once again maimed Murphy, refusing a full formation of his subject. In both the Lucybelle Crater project and St. Anthony sequence, identity is never completely established - it is always incomplete. Meatyard and White use masks or compositional alignment and cropping, respectively, to insist that a photograph is incapable of capturing the totality of a person's identity. The types of identity differ for both photographers, but the ways in which they approach addressing family and 


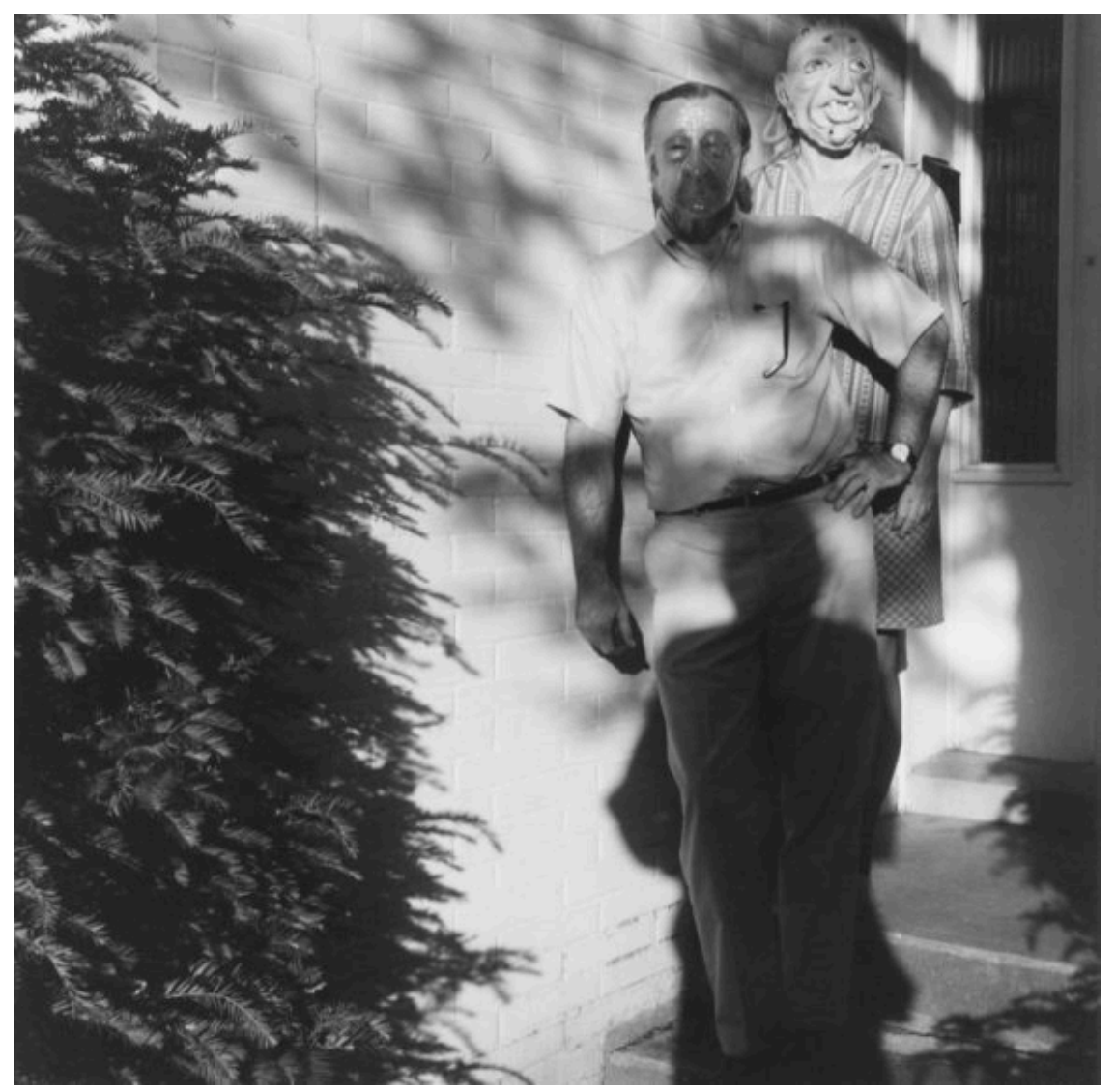

Figure 31. Ralph Eugene Meatyard, LBC and Eastern Man's Friend, LBC, c. 1969-72, gelatin silver print, $73 / 8 \times 7 \% 16$ ". Copyright Estate of Ralph Eugene Meatyard. 


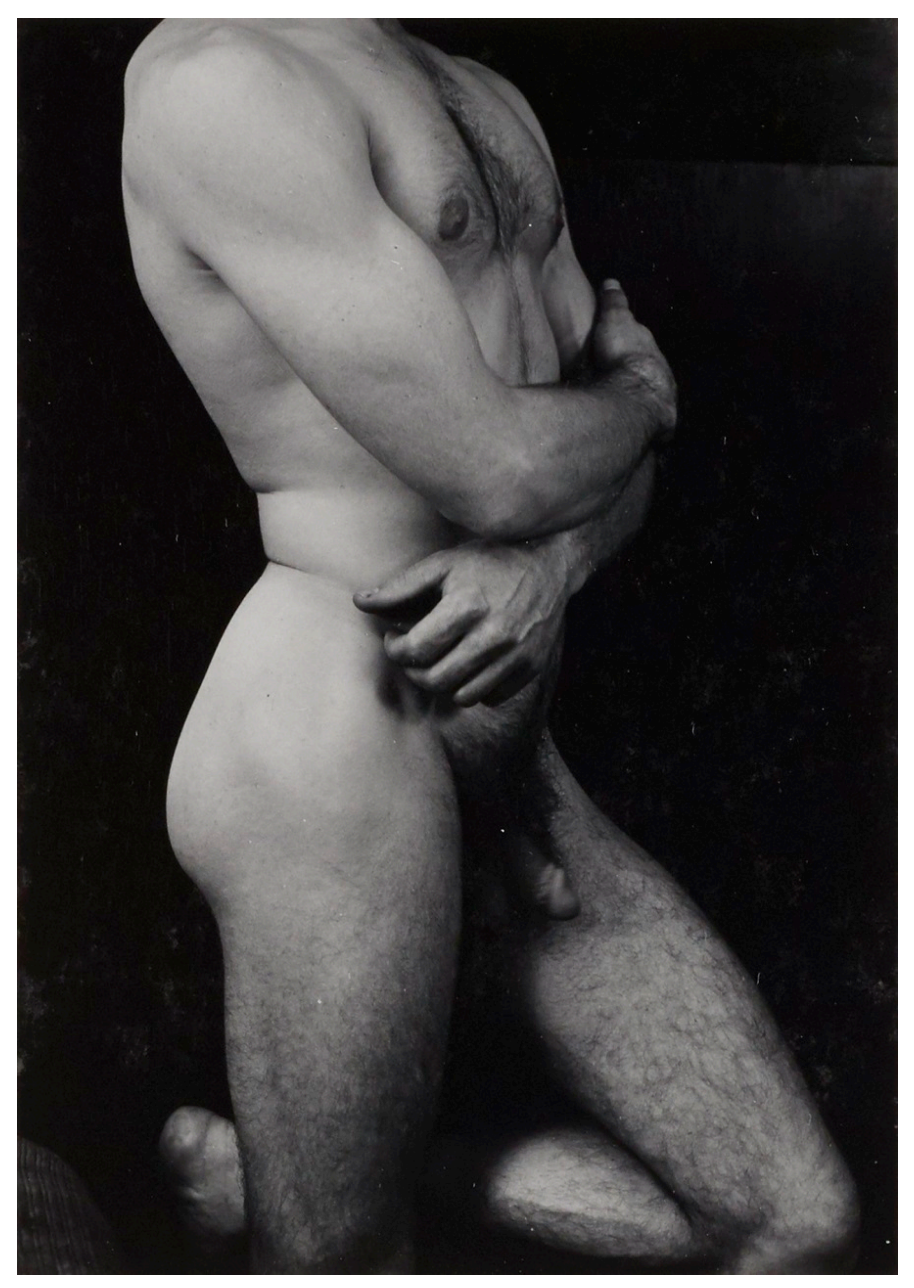

Figure 32. Minor White, Tom Murphy, San Francisco, from The Temptation of St. Anthony is Mirrors, 1947, gelatin silver print, 4 1/2 x $3 \frac{1}{8}$ ". Courtesy the Minor White Archive, Princeton University. Copyright Trustees of Princeton University. 


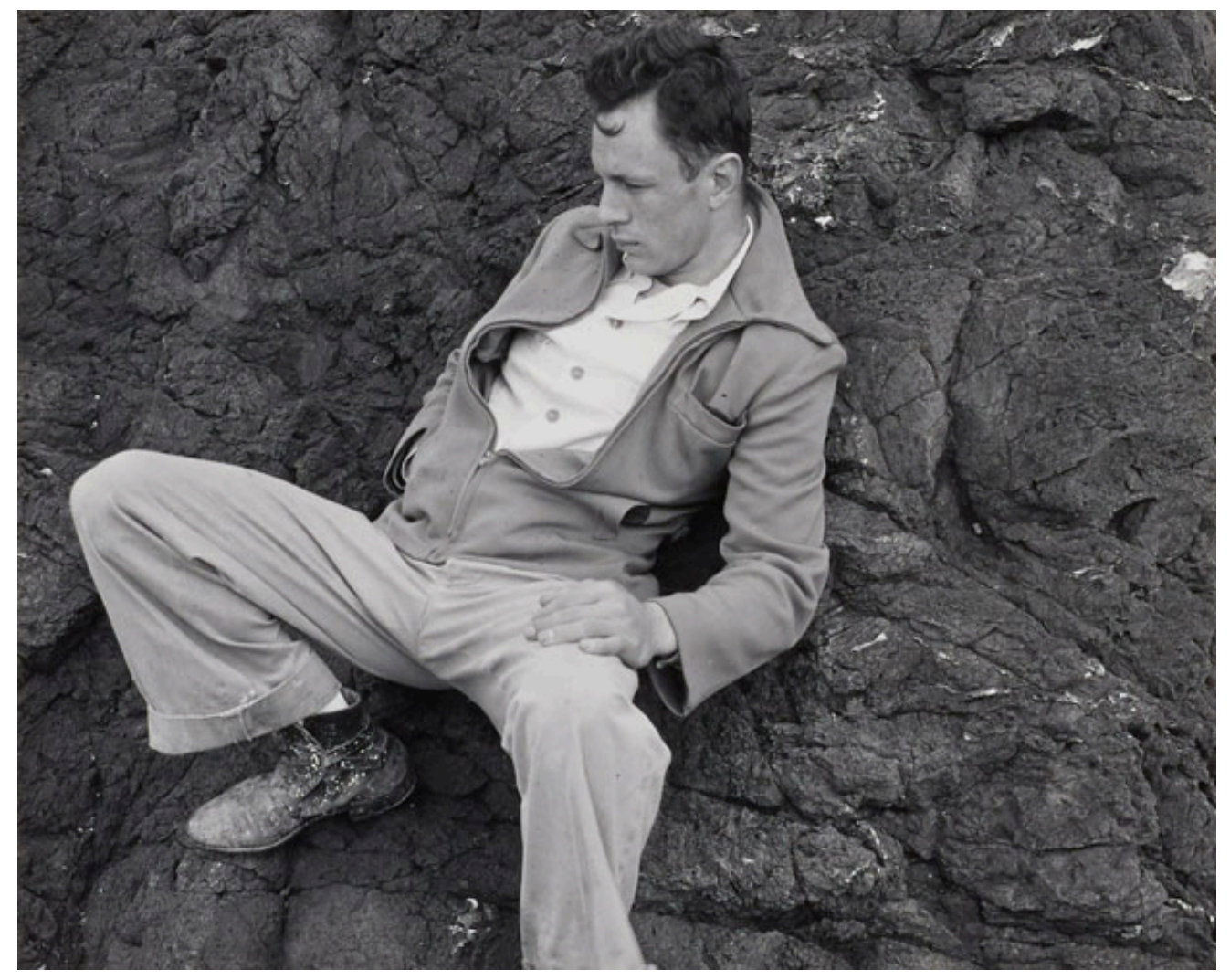

Figure 33. Minor White, Tom Murphy, San Francisco, from The Temptation of St.

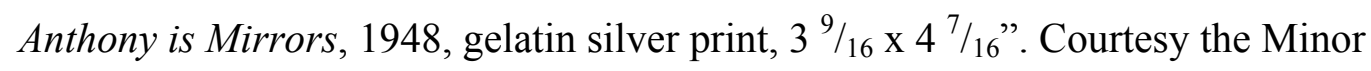
White Archive, Princeton University. Copyright Trustees of Princeton University. 
homosexuality are alike. Meatyard and White depict their subjects in states of uncertainty and division.

The comparison provided here, much like the comparison between Meatyard and Michals, is grounded in Lacan's mirror stage. White's sequence, as a reflection of both himself and potentially of viewers, holds definite implications to Lacan. By rendering Murphy as fragmented and incomplete, White insinuates that his own identity—indeed, the identity he carries in public - is lacking. The completeness of the photograph-asmirror is illusory: either the edges of the frame or some wooden shard interrupts Murphy's body. If The Temptation of St. Anthony is Mirrors collectively represents White's identity as a homosexual man, it can be assumed that the photographer understood the disjointedness between his internal state and the image of himself constructed by others, his own reflection, or photography. At the same time, the $S t$. Anthony sequence is reflective of everyone. When developing the theory of the mirror stage, Lacan leaned on the concept of identity as it is laid out in philosophy and not psychology: that is, the subject of the mirror stage is not the individual, but "man himself, inasmuch as he is the foundation of his own thoughts and actions." ${ }^{\text {131 }}$ There is a certain universality to White's photographs of Murphy, one in which each viewer is the incomplete subject. The same could be said for The Family Album of Lucybelle Crater. Some viewers are likely to be familiar with the conventions Meatyard employs when capturing Lucybelle Crater and her friends, and the masks his subjects wear further a reading of practiced ubiquity by removing individuality. Meatyard's constructed family album, like Lacan's mirror stage, provides viewers with an image of family and,

${ }^{131}$ Roudinesco, "The Mirror Stage: An Obliterated Archive," 27. 
subsequently, themselves. Identity is formed by adherence to the image, regardless of how real world events of behaviors may deviate from that image. The "function of the mirror stage...is to establish a relation between the organism and its reality."132 Photographs by Meatyard, Michals, and White illustrate, in distinct ways, how the camera is the mirror, the photograph the reflection, and the viewer the subject. Each of these three components affects the utilization and behavior of the others-for example, past photographs influence how viewers will use a camera in the future. Consequently, the photographic process of subject formation is perpetually ungrounded. But where does the photographer fit in this analogy? As the controller of the camera and creator of the photograph, the photographer would presumably be somewhere between the mirror and reflection. Perhaps the photographer is like a shadow that goes unnoticed until the moment when he/she disrupts the image we create for ourselves in a fashion similar to Meatyard's interfering shadow in LBC and Eastern Man's Friend, LBC. If Meatyard, as a photographer, is the shadow in the process of subject formation, then it can be inferred that he is the site for the kind of self-projection Freud discusses in "The Uncanny." Meatyard himself becomes the device that aids the development of identity. But this belief is ultimately surmounted, replaced by the assumption that one is solely responsible for manufacturing his/her own image. When this occurs, Meatyard fades in to the background, no longer able to conjure our purest aspects of self.

${ }^{132}$ Lacan, "The Mirror Stage as Formative of the Function of the I as Revealed in Psychoanalytic Experience," 4. 


\section{CONCLUSION}

Meatyard notably said very little when showing his photographs to friends. The American writer Guy Davenport recalled meeting Meatyard through a mutual friend, the poet Jonathon Williams, in the mid-1960s: Williams had driven Davenport and others to visit the home of the Meatyards, where the group looked at some of Meatyard's most recent work. ${ }^{133}$ Davenport remembers how Meatyard - then and during the nine years in which the two men knew each other-would remain quiet as others gazed upon images of the Meatyard family and abstractions of nature, never insisting that any of them possessed a fixed meaning. ${ }^{134}$ Davenport's observances were affirmed by my conversations with Christopher Meatyard, who spoke of his father's interest in

connecting with viewers' psyches through photography. ${ }^{135}$ Perhaps this is why Meatyard was silent in the presence of viewers, for here was the opportunity to witness the immediacy of his work in the reactions of Davenport, Williams, and others.

There is at least one trio of photographs by Meatyard whose reception went unseen by the photographer. After Meatyard died in 1972 from a cancer he had caught

${ }^{133}$ See Guy Davenport, "Reminiscence," in Ralph Eugene Meatyard (an Aperture Monograph), ed. by James Baker Hall (Millerton, NY: Aperture, 1974).

${ }^{134}$ Davenport realized after Meatyard had died that the photographer enjoyed having him gauge his images over the course of the near decade they knew each other. Apparently, Meatyard relayed to his wife that Davenport "[knew] what to say." Davenport, "Reminiscence," 127-8.

${ }^{135}$ Personal communication with Christopher Meatyard, November 15, 2016. 
two years prior, his fellow Lexington Camera Club member, Robert C. May, discovered and developed a roll of film that Meatyard had — unbeknownst to anyone else - left in his camera. ${ }^{136}$ Among the negatives was a sequence of self-portraits depicting Meatyard on a hill overrun with weeds and tall grass (Figures 34-6). In the three images, Meatyard, initially facing the camera, rises from a reclined position to turn and walk toward a barren tree that occupies the top left quadrant of each photograph. Meatyard looks down and away from viewers in only the last photograph. These images were exhibited shortly after May developed them, and it was here that the poet Wendell Berry, who knew Meatyard since 1966, viewed them for the first time; to Berry, the photographs were Meatyard's “elegy and farewell."137 After Meatyard had passed, his family, Davenport, May, and a few others trekked to the Red River Gorge in central Kentucky. On a mountain's peak, Meatyard's oldest son emptied his father's cremated remains into the landscape, followed by a wave of flowers sent by Meatyard's daughter. ${ }^{138}$

His final self-portraits suggest that, by the time of his death, Meatyard had sufficiently discerned photography's inextricable tie to death. As a process that eternalizes what would otherwise be ephemeral moments, photography foregoes temporality in the process of marking the exact instant of death for whatever event may unfold before the camera. For this reason, Barthes declares photographers are "agents of

\footnotetext{
${ }^{136}$ Wendell Berry, "Remembering Gene Meatyard, in Ralph Eugene Meatyard: An American Visionary, 86.

${ }^{137}$ Ibid.

${ }^{138}$ This was the second funeral to be held for Meatyard - the first being traditionally Protestant in nature. At the Red River Gorge, Christopher Meatyard read a poem dedicated to his father, the group drank wine Meatyard had made himself, and they ate an abundant picnic dinner. Davenport, "Reminiscence," 131.
} 


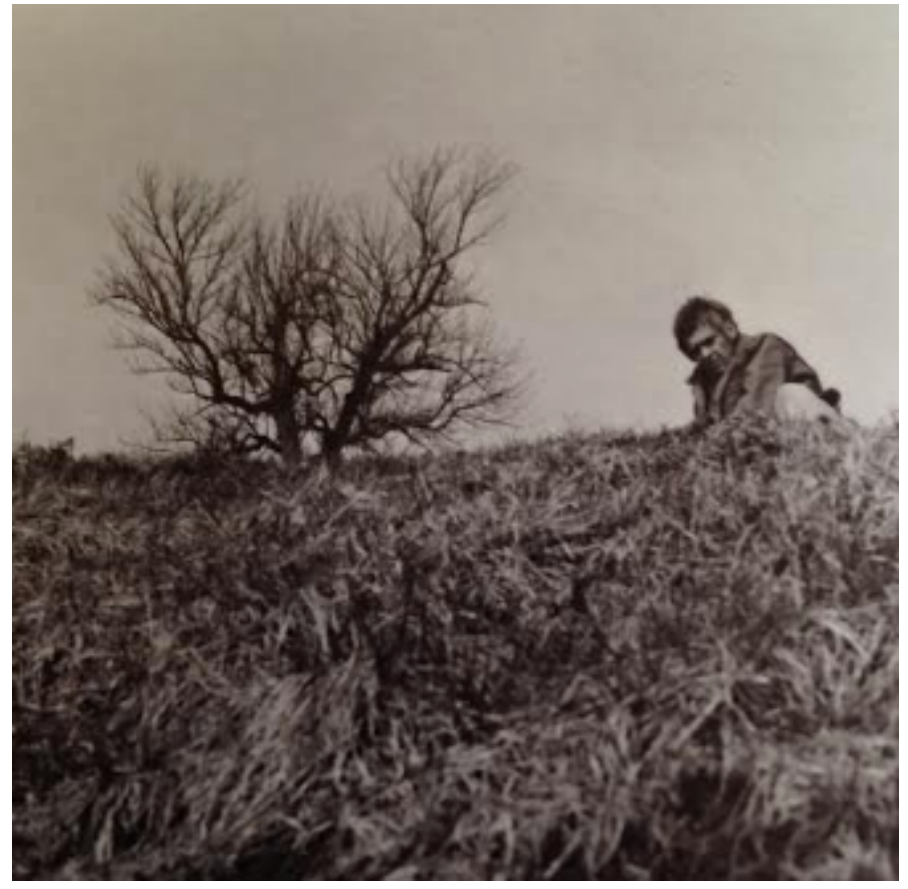

Figure 34. Ralph Eugene Meatyard, Untitled (Series of three self-portraits with artist walking over hill) (image one), 1972, $63 / 4 \times 67 / 8$ ". Copyright Estate of Ralph Eugene Meatyard. 


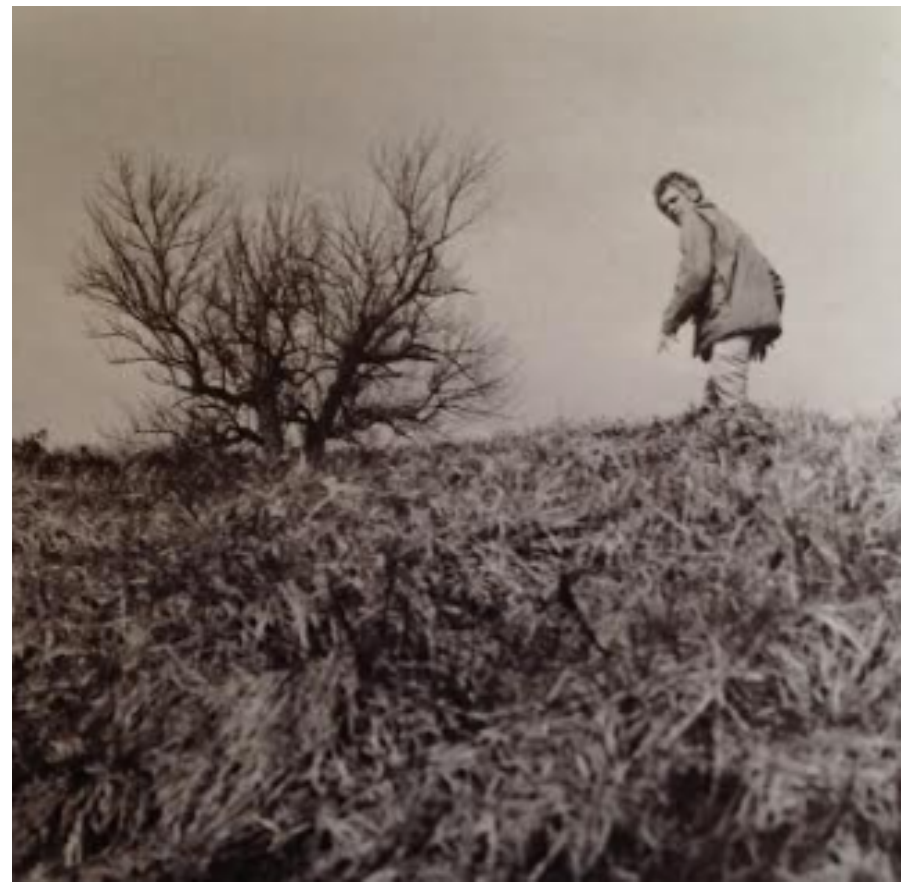

Figure 35. Ralph Eugene Meatyard, Untitled (Series of three self-portraits with artist walking over hill) (image two), 1972, $63 / 4 \times 67 / 8$ ". Copyright Estate of Ralph Eugene Meatyard. 


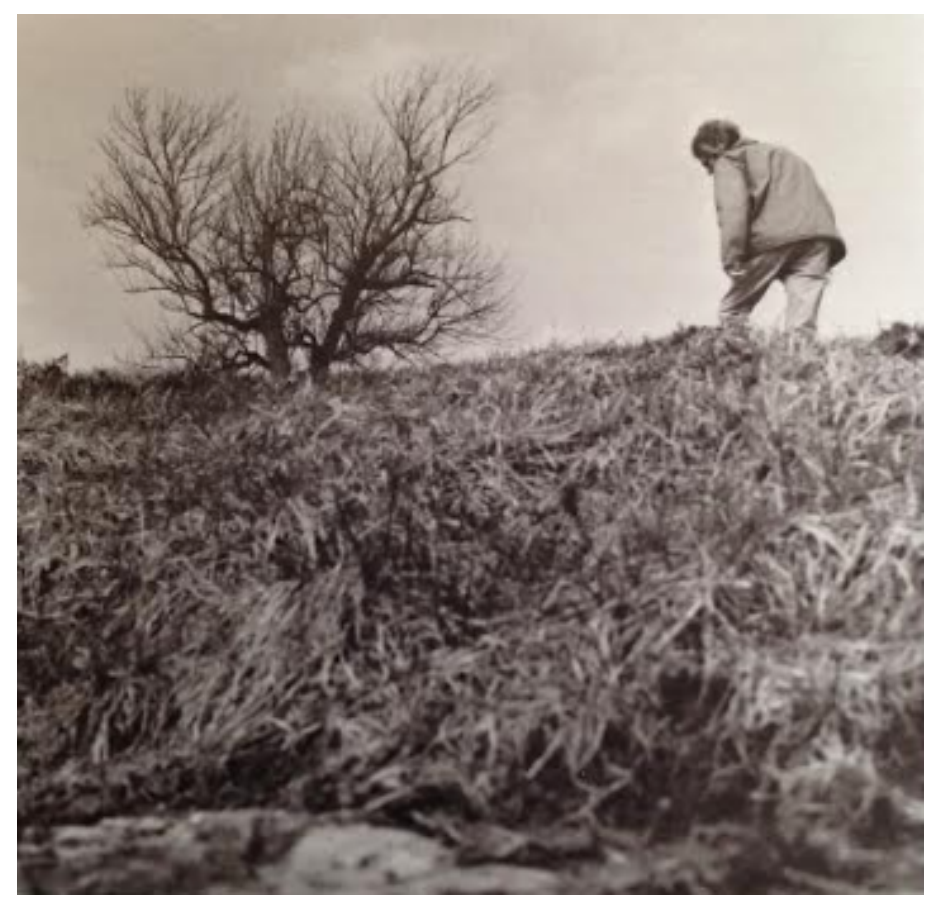

Figure 36. Ralph Eugene Meatyard, Untitled (Series of three self-portraits with artist walking over hill) (image three), 1972, $63 / 4 \times 67 / 8$ ". Copyright Estate of Ralph Eugene Meatyard. 
Death." ${ }^{139}$ Meatyard likely understood that family photography is not primarily a means for preservation, but is rather a practice in recording death. Every photograph of siblings or relatives is, according to Barthes, unable to overcome the inevitably of death for its subjects. ${ }^{140}$ Meatyard's photographs of his children, wife, and friends subvert the genre of family photography through pose, setting, and composition as well as through the overt acknowledgment of death — those ghouls, spirits, and ghosts he so often depicted.

Freud's conception of the uncanny also carries implications of death. For animism or the omnipotence of thought to return as repressed material in adults, such ways of thinking had to become obsolete. Indeed, Freud even refers to these as "superannuated modes of thought." ${ }^{\prime 14}$ A reading of Meatyard's photographs as elicitations of the uncanny presumes that certain aspects of childhood had to be, in a sense, eradicated. Meatyard might not have necessarily believed that family photography destroys family, per se, but it would conclude that he recognized group photographs are incapable of holding inherent meaning - family photographs do not automatically maintain the concept of family. Family photography, to Meatyard, could be anything, including depictions of masked children playing in abandon sheds. By deviating from convention, Meatyard developed his own language of family photography.

The masks in Meatyard's images are worth noting once more. They are not indicators of death nor do they alone represent the return of repressed material—rather they are one thread of a larger tapestry. The masks do, however, rid Meatyard's subjects

\footnotetext{
${ }^{139}$ Barthes, Camera Lucida, 92.

140 "Whether or not the subject is already dead, every photograph is this catastrophe." Barthes, Camera Lucida, 96.

${ }^{141}$ Freud, “The Uncanny," 157.
} 
of their individuality and allow viewers to identify with the figures they see. After all, masked figures are at once no one and everyone. The masks are mirrors and, according to Barthes, the photograph is always already death. By this token, viewers of Meatyard's photographs are met with the very real nature of their eventual expiration. So Meatyard is therefore the maker of death in twofold: by simply being a photographer and by depicting the return of repressed of material. This may be why his works are so difficult to categorize. What is certain is the products Meatyard created are illustrative of a man who explored with indefatigable curiosity the myth that a photograph is an analogue of reality. 


\section{REFERENCES}

Adams, Ansel et al. Minor White: A Living Remembrance. New York: Aperture, 1984.

Barthes, Roland. Camera Lucida. New York: Farrar, Straus, and Giroux, 1981.

. Image-Music-Text. New York: Farrar, Straus, and Giroux, 1977.

Batchen, Geoffrey. Burning with Desire: The Conception of Photography. London and Cambridge, MA: The MIT Press, 1997.

Barrow, Thomas F., Shelley Armitage, and William E. Tydeman. Reading Into Photography: Selected Essays, 1959-1980. Albuquerque: University of New Mexico Press, 1982.

Bloom, John. Photography at Bay: Interviews, Essays, and Reviews by John Bloom. Albuquerque: University of New Mexico Press, 1993.

Bourdieu, Pierre. "On the Family as a Realized Category." Theory Culture Society 13:19 (1996): 19-26.

Bourdieu, Pierre et al. Photography: A Middle-brow Art. Standford, CA: Stanford University Press, 1990.

Bunnell, Peter with Maria B. Pellerano and Joseph B. Rauch. Minor White: The Eye That Shapes. Boston, Toronto, and London: The Art Museum, Princeton University in association with Bulfinch Press/Little, Brown and Company, 1989. Published in conjunction with the exhibition of the same name.

Coke, Van Deren. "Conversation with Van Deren Coke," interview by Henry Brimmer. Photo Metro 8:77 (1990): 5-10.

. Secular and Sacred. Albuquerque: University of New Mexico Press, 1992.

. “Creative Photography - 1956." Aperture 4:1 (1956): 4-29.

. “The Photographs of Ralph Eugene Meatyard.” Aperture 7:4 (1959): 158-168. 
Coke, Van Deren and Gerry Norldand. Van Deren Coke: Photographs 1956-1973. Albuquerque: University of New Mexico Press, 1973. Published in conjunction with the exhibition of the same name.

Coleman, A.D. "Mysteries on the Verge of Vernacular." Portfolio Magazine no.17 (Summer 1993): 17-24.

. "Ralph Eugene Meatyard: Everyday Mysteries." Photo Techniques 19:2 (Mar/Apr 1998): 20-24.

. Light Readings: A Photography Critic's Writings, 1968-1978. Albuquerque: University of New Mexico Press, 1998.

Comer, Stephanie and Deborah Klochko. The Moment of Seeing: Minor White at the California School of Fine Arts. San Francisco: Chronicle Books, 2006.

Deschin, Jacob. "Two-man Exhibition: Photographs of Teacher and Student Compared." New York Times, January 6, 1957.

Foster, Hal. Compulsive Beauty. Cambridge, MA: The MIT Press, 1993.

Frailey, Stephen. "Ralph Eugene Meatyard: International Center for Photography, New York." Artforum International 43:6 (Feb. 2005): 169.

Freud, Sigmund. The Uncanny. Translated by David McLintock. London: Penguin Books, 2003.

Gamon, Mark. “Giving Photographs.” The British Journal of Photography 123:34 (1976): 709-710.

Gassan, Arnold et al. "Minor White as a Teacher." Aperture no. 95, Minor White: A Living Remembrance (Summer 1984): 38-44.

Hall, James Baker, ed.. Ralph Eugene Meatyard (an Aperture Monograph). Millerton, NY: Aperture, 1974.

. Minor White: Rites and Passages (an Aperture Monograph). Millerton, NY: Aperture, 1978.

. "The Strange New World of Ralph Eugene Meatyard.” Popular Photography 65:1 (July 1969): 120,146.

Hawkes, Terence. Structuralism and Semiotics. Berkeley: University of California Press, 1977.

Hirsch, Julia. Family Photographs: Content, Meaning, and Effect. New York: Oxford University Press, 1981. 
Hirsch, Marianne, editor. The Familial Gaze. Hanover, NH: University Press of New England, 1999.

Hoffmann, E.T.A. Selected Writings of E.T.A. Hoffmann, translated and edited by Leonard J. Kent and Elizabeth C. Knight. Chicago and London: The University of Chicago Press, 1969.

Janis, Eugenia Parry, Max Kozloff, and Adam D. Weinberg. Vanishing Presence. Minneapolis: Walker Art Center in conjunction with Rizzoli, 1989. Published in conjunction with the exhibition of the same name.

Jasud, Lawrence. "Reading Minor White: The Sound of One Hand Clapping." History of Photography 16:2 (1992): 173-174.

Kozloff, Max. "Meatyard.” Artforum International 13:3 (Nov. 1974): 68-72.

. Duane Michals: Now Becoming Then. Altadena, CA: Twin Palms Publishers, 1990.

Krauss, Rosalind E. and Yve-Alain Bois. Formless: A User's Guides. New York: Zone Books, 1997.

Krauss, Rosalind and Jane Livingston. L'Amour Fou: Photography and Surrealism. Washington, D.C.: The Corcoran Gallery of Art in conjunction with Abbeville Press, 1985.

Lacan, Jacques. Écrits: A Selection. Translated by Alan Sheridan. New York: W.W. Norton and Company, 1977.

Laing, R.D. The Divided Self. London: Penguin Books, 1959.

Lévi-Strauss, Claude. Anthropology and Myth: Lectures 1951 - 1982. Translated by Roy Willis. Oxford: Basil Blackwell, 1987.

. Myth and Meaning. New York: Schocken Books, 1978.

Livingstone, Marco. The Essential Duane Michals. London: Duane Michals in conjunction with Thames and Hudson, Ltd, 1997.

Long, J.J, Andrea Noble, and Edward Welch, editors. Photography: Theoretical Snapshots. New York: Routledge, 2009.

Lyons, Nathan, ed. Photographers on Photography. Englewood, NJ: Prentice-Hall, Inc., 1966. 
Martineau, Paul. Minor White: Manifestations of the Spirit. Los Angeles, CA: Getty Publications in association with the J. Paul Getty Museum, 2014. Published in conjunction with the exhibition of the same name.

May, Robert C. “The Lexington Camera Club, 1936-1972.” Kentucky Review 9:2 (Summer 1989): 3-47.

Meatyard, Christopher. "Merton's 'Zen Camera' and Contemplative Photography." Kentucky Review 7:2 (Summer 1987): 122-144.

Meatyard, Ralph Eugene. Lecture to the Midwest Society for Photographic Education, Louisville Conference, March 1972. Unpublished talk devoted to the Lucybelle Crater project. Transcript in Meatyard archive.

. "Remembering F.v.d.C.” Kentucky Review (Autumn 1968): 49-51.

. "My Aims." Unpublished draft of lecture delivered to the Louisville Photographic Society, 1959, Meatyard archive.

. Interview by Nathalie Andrews, February 25, 1970, transcript, Oral History Center, University of Louisville Archives \& Records Center, Louisville, KY.

Meatyard, Ralph Eugene, with notes by Arnold Gassan and Wendell Berry. Ralph Eugene Meatyard. Lexington, KY: Gnomon Press, 1970.

Meatyard, Ralph Eugene, Barry Magid, Guy Davenport, and Christopher Meatyard. Father Louie: Photographs of Thomas Merton. New York: Timken Publishers, 1991.

Meatyard, Ralph Eugene, Eugenia Parry, and Elizabeth Siegel. Ralph Eugene Meatyard: Dolls and Masks. Santa Fe: Radius Books, Inc., 2011. Published in conjunction with the exhibition of the same name.

Meatyard, Ralph Eugene et al. The Family Album of Lucybelle Crater. Asheville, NC: Madelyn Meatyard in association with the Jargon Society, 1974.

Michals, Duane. Sleep and Dream. New York: Lustrum Press, 1984.

Mora, Gilles. The Last Photographic Heroes: American Photographers of the Sixties and Seventies. New York: Abrams, 2007.

Mortenson, Erik. "The Ghost of Humanism: Rethinking the Subjective Turn in Postwar American Photography." History of Photography 38:4 (November 2014): 418434.

Newhall, Beaumont. "New Talent.” Art in America 49:1 (1961): 56. 
Newhall, Nancy. From Adams to Stieglitz: Pioneers of Modern Photography. New York: Aperture Foundation, 1989.

Putzar, Edward. "Zen Camera or the Un-making of the Photographer." Aperture 17:2 (1973).

Rabaté, Jean-Michel et al. The Cambridge Companion to Lacan, edited by Jean-Michel Rabaté Cambridge: Cambridge University Press, 2003.

Reily, Stephen and Roger Lipsey. Meatyard/Merton Merton/Meatyard: Photographing Thomas Merton. Louisville, KY: Fons Vitae, 2013. Published in conjunction with the exhibition of the same name.

Schaub, Grace. “Van Deren Coke.” Photographer's Forum 14:3 (1992): 50-54.

Sholis, Brian and John Jeremiah Sullivan. Kentucky Renaissance: The Lexington Camera Club and Its Community, 1954-1974. New Haven: Yale University Press in association with the Cincinnati Art Museum, 2016. Published in conjunction with the exhibition of the same name.

Smith, Henry Holmes. "The Education of Picture Minded Photographers." Aperture 5,1 (1957): 24-28.

Spence, Jo and Patricia Holland, editors. Family Snaps: The Meaning of Domestic Photography. London: Virago, 1991.

Sontag, Susan. On Photography. New York: Picador, 1977.

Tagg, John. The Disciplinary Frame: Photographic Truths and the Capture of Meaning. Minneapolis: University of Minnesota Press, 2009.

Tannenbaum, Barbara, ed. Ralph Eugene Meatyard: An American Visionary. New York: Akron Art Museum and Rizzoli International Publications, Inc., 1991. Published in conjunction with the exhibition of the same name.

Todd, Joyce. "Town Meets Gown." Accent on the Creative and Performing Arts (October 1966): 12-13.

Toperzer, Tom R. and Van Deren Coke. Ralph Eugene Meatyard: A Retrospective. Normal, IL: Center for the Visual Arts Gallery, College of Fine Arts, Illinois State University, 1976. Published in conjunction with the exhibition of the same name.

White, Minor. The Time Between: The Sequences of Minor White. Edited by Deborah Klochko and Andrew E. Hershberger. San Francisco: Modernbook Editions, 2015. Published in conjunction with the exhibition of the same name. 
. Minor White: The Eye That Shapes. Princeton, NJ: The Trustees of Princeton University, 1989.

White, Minor and James Baker Hall. Minor White: Rites and Passages. New York: Aperture, Inc., 1978.

Young, Cynthia, ed. Ralph Eugene Meatyard. Göttingen, Germany and New York: Copublished by Steidl Publishers and the International Center of Photography, 2004. Published in conjunction with the exhibition of the same name. 


\title{
CURRICULUM VITAE
}

\author{
Hunter Kissel \\ 6703 OBryan Rd.•502-930-7174•hunter.kissel@gmail.com
}

\section{Education}

University of Louisville

Thesis: "Traces of the (Un)Familiar: Family, Identity, and the Return of the Repressed in the Photographs of Ralph Eugene Meatyard"

MPA $2017 \quad$ University of Louisville

BA 2014 Transylvania University, Lexington, KY

Specialization: Studio Art

Fall $2013 \quad$ Florence School of Fine Arts, Florence, Italy

\section{Professional Experience}

2016-Present Gallery Attendant, Cressman Center for Visual Arts, Louisville, KY

2016-Present

2015-2016

2015

2015

$2014-2015$

2014

2012
Arts Contributor, Under Main, Lexington, KY

Curatorial Research Assistant (Chris Reitz, Ph.D.), University of Louisville, Louisville, KY

Curatorial Fellow, Kentucky Museum of Art and Craft (KMAC), Louisville, KY

Curatorial Fellow, The Speed Art Museum, Louisville, KY

Graduate Assistant (Peter Morrin, Director Emeritus of the Speed Art Museum), University of Louisville, Louisville, KY

Executive and Exhibitions Intern, Lexington Art League, Lexington, $\mathrm{KY}$

Intern, Institute 193, Lexington, KY 


\section{Exhibitions}

2017

2016

2015

2014

2013

\section{Grants/Fellowships/Awards}

2015

2014

2013

2012
"Pursuing the Uncanny: Ralph Eugene Meatyard," MA thesis exhibition, Hite Art Institute at the University of Louisville, Louisville, KY, Curator

"Softly Verdant: New Work by Julia Sebastian," The Huff Gallery at Spalding University, Louisville, KY, Curator "Summer Breaks: Labor, Leisure, Lust," Hite Art Institute at the University of Louisville, Louisville, KY, Co-curator

"Highlights From the Permanent Collection," Kentucky Museum of Art and Craft (KMAC), Louisville, KY, Curator

"University Open," Downtown Arts Center, Lexington KY, Participating artist

"SIREN: A Beginning," Morlan Gallery, Lexington KY, Co-curator and participating artist

"On the SoFA: State of Fine Art," Anne Wright Gallery at Georgetown College, Georgetown, KY, Participating Artist
Graduate Student Travel Grant, Hite Art Institute, University of Louisville

Hite-KMAC Fellowship, University of Louisville and Kentucky Museum of Art and Craft

Hite-Speed Fellowship, University of Louisville and the Speed Art Museum

Cressman Scholarship Award, University of Louisville

Cressman Scholarship Award, University of Louisville Holleian Society Award for Creative Work Outside the Classroom, Transylvania University

Excellence in Media Award: Painting, Transylvania University Juried Art Exhibition, Transylvania University

Dean's Purchase Award, Transylvania University Juried Art Exhibition, Transylvania University 
2011-2014

President (2013-2014) and member of the Transylvania Student Art League, Transylvania University

\section{Publications}

\section{Catalogues, Reviews, Websites:}

“A Unique Pairing: Teri Dryden at B. Deemer." Under Main (http://www.under-main.com), June 2017.

"Kentucky Insurgence: The Lexington Camera Club at the Cincinnati Art Museum." Under Main

(http://www.under-main.com), December 2016.

"Plenty to Consider: Sparks and Marks at Arts Place Gallery." Under Main (http://www.under-main.com), August 2016.

“On Sanford Biggers' Laocoön.” The Hite Aegis Review. (www.hiteaegis.org), June 2016.

"Points of Reference: A Brief Analysis of the Lineage of Manet's Olympia." In Summer Breaks: Labor, Leisure, Lust. University of Louisville: Hite Art Institute, 2016.

"Ways of Validation: Lawrence Tarpey at the University of Kentucky Art Museum." Under Main (http://www.under-main.com), June 2016.

"Process as Subject, Materiality as Guide." Under Main (http://www.under-main.com), April 2016.

\section{Professional Affiliations and Outreach}

2017

Selection Committee, Outstanding Mentor Award, College of Arts and Sciences, University of Louisville, Louisville, KY

2016-Present Member, College Art Association (CAA)

2016-2017 Member, AEGIS: The Association of Graduate Students at the Hite Art Institute

2015-2017

Fine Arts representative for the Graduate Network of Arts and Sciences (GNAS), University of Louisville, Louisville, KY

\section{Languages}

German (Basic Reading Proficiency) 